Distribution Category: Atomic, Molecular, and Chemical Physics (UC-411)

\section{ARGONNE NATIONAL LABORATORY 9700 South Cass Avenue Argonne, Illinois 60439}

ANL/APS/TB-5
ANL/APS/TB -5

DE93 008832

\title{
Functional Description of APS Beamline Front Ends
}

\author{
by Tuncer Kuzay \\ Experimental Facilities Division \\ Advanced Photon Source
}

February 1993

work sponsored by

U.S. DEPARTMENT OF ENERGY

Office of Energy Research 


\title{
FUNCTIONAL DESCRIPTION OF THE APS BEAMLINE FRONT ENDS
}

\author{
Tunch M. Kuzay
}

\section{Introduction}

Traditional synchrotron sources were designed to produce bending magnet radiation and have proven to be an essential scientific tool. Currently, a new generation of synchrotron sources is being built that will be able to accommodate a large number of insertion device (ID) and high quality bending magnet (BM) sources. One example is the 7-GeV Advanced Photon Source (APS) now under construction at Argonne National Laboratory (ANL). The research and development effort at the APS is designed to fully develop the potential of this new generation of synchrotron sources [1].

Of the 40 straight sections in the APS storage ring, 34 will be available for IDs. The remaining six sections are reserved for the storage ring hardware and diagnostics. Although the ring incorporates $80 \mathrm{BMs}$, only 40 of them can be used to extract radiation. The accelerator hardware shadows five of these 40 bending magnets, so the maximum number of BM sources on the lattice is 35 .

Generaily, a photon beamline consists of four functional sections. The first section is the ID or the BM, which provides the radiation source. The second section, which is immediately outside the storage ring but inside a concrete shielding tunnel, is the front end (FE), which is designed to control, define, and/or confine the x-ray beam . In the case of the APS, the front ends are designed to confine the photon beam. The third section, just outside the concrete shielding tunnel and on the experimental floor, is the first optics enclosure (FOE), which contains optics to filter and monochromatize the photon beam. The fourth section of a beamline consists of beam transports, additional optics, and experiment stations to do the scientific investigations. This document describes only the front ends of the APS beamlines. An early conceptual study of the APS front end design is given in [2].

By 1996, the APS will complete 32 front ends, 16 ID sources composed largely of undulators and, to a lesser extent, wigglers and $16 \mathrm{BM}$ sources. A detailed physics study of the APS sources is provided in [3]. Table 1 provides useful beam characteristics data on two of the currently planned APS sources. 


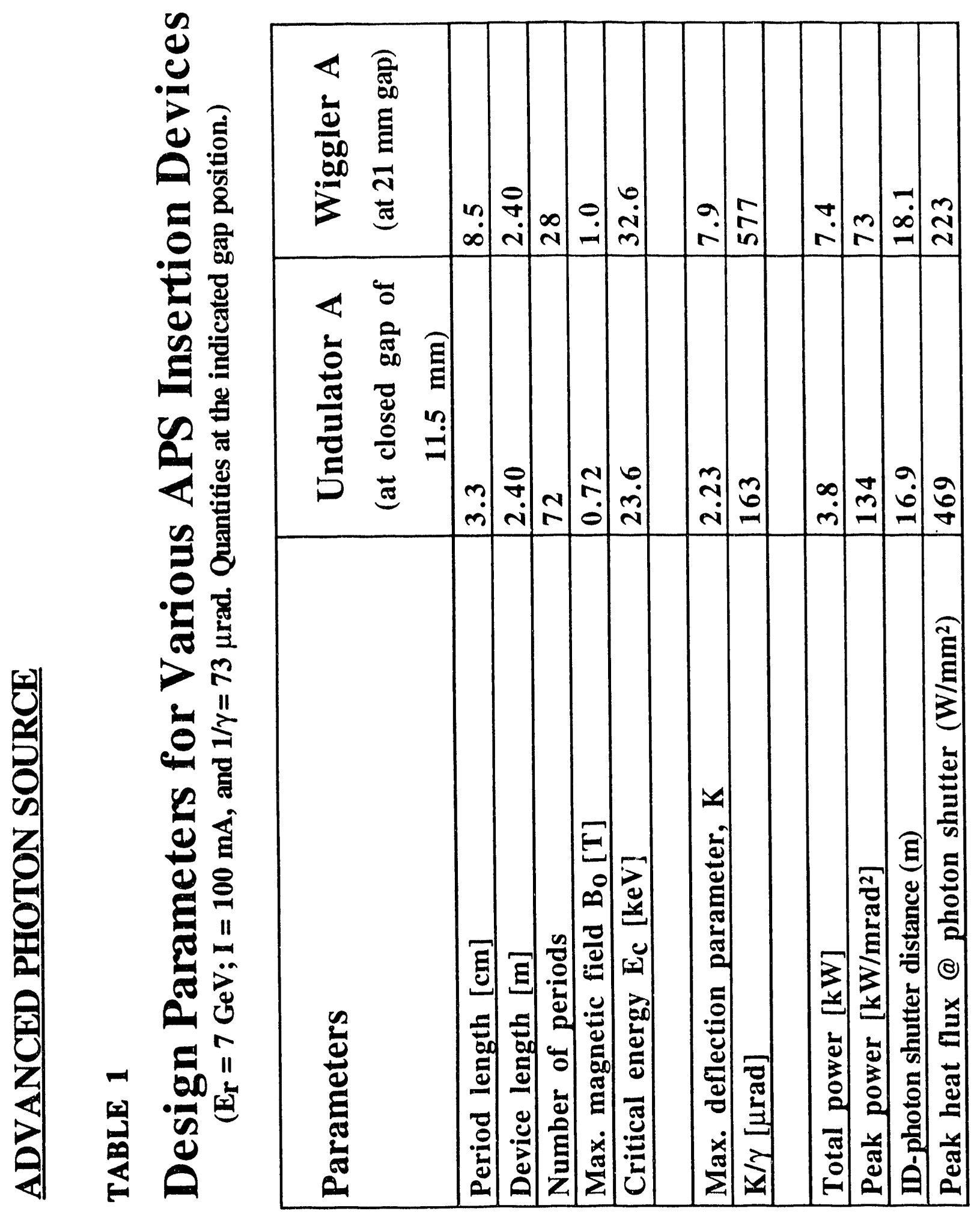




\section{The APS Front End Design and Safety Philosophy}

The APS front ends are standardized and modularized to achieve several purposes. As mentioned above, by 1996, 32 front ends will have been built. This is a large enough number to warrant standardization for the resulting reduction in cost. In addition, standardization results in reduced engineering and design effort, ease of manufacturing, quality control and quality assurance, ease in installation, and reliability in maintenance and operations. Because of the geometric properties of the radiation produced by either insertion devices or bending magnets, fundamental differences exist between the front ends for the ID beamlines and those for the BM beamlines. Thus, two kinds of APS front ends are being developed: one for the IDs (currently planned undulators and wigglers) and another for BMs. The ID front end components are designed for the most critical wiggler size and for the highest heat flux levels of the APS undulators to accommodate the variation in the radiation properties produced by wigglers and undulators. This approach results in a single design to suit all the APS ID front ends.

Needless to say, the standardized designs of the APS front ends also must satisfy the baseline requirements for any front end design. That is, the front ends are configured via a complex design, control, and interlock system:

(i) to ensure personnel safety with the required redundancy and logical control systems during commissioning and operating phases,

(ii) to maintain the ring vacuum integrity,

(iii) to provide proper collimation so that the beam cannot strike unprotected and elements that are not cooled within the vacuum envelope even under steering errors,

(iv) to provide shuttering and, hence, absorbance of the full power of the beam and/or bremsstrahlung during injection and/or in case of a vacuum failure,

(v) to provide required information on the angular and spatial position of the photon beam $\mathrm{n}$ a feedback fashion to the ring side in order to maintain a stable beam,

(vi) to operate within the phase-space parameters of the beam that the experimenters expect and for which they prepare their equipment. 
Regarding safety, the most probable accident in a front end is a vacuum breach at the traditional window location. On sensing such a breach, the front end is designed with vacuum instrumentation that can determine the rate of the propagation and decide whether it is a fast breach and the beam must be dumped, or whether it is slow enough to safely shut down the front end instead. Beam dump is fast and occurs typically within $10 \mu \mathrm{s}$. Because the fastest acting element on the front end to be affected by the dump is the fast valve with 7 to $9 \mathrm{~ms}$ actuation time, the valve remains safe. If the vacuum leak is deemed slow enough, then beam dump is not necessary. In this case, the front end is safely shut down until the next maintenance time. In the slow shut down process, one or both of the photon shutters (PS1 and PS2, respectively) are actuated to intercept the beam. This action takes about one second. In return, the interlock system triggered by PS1 actuates closing of the two safety shutters and the fast and the slow valves. Both the safety shutters and the slow valve close in one second. Because the PS1 is down, there is no danger from the beam to the slow or the fast valves. It has been suggested that because the respective ID "jaws" are also opened with this action, photon-induced gas loads from PS1 are reduced due to the diminished power from the ID.

During a ring fill when positron injection occurs, bremsstrahlung radiation can occur in the front end. To absorb the bremsstrahlung radiation, the tungsten safety shutters are closed. Because the safety shutters cannot stop the beam radiation, they are interlocked to PS1 and PS2 for thermal protection. Any neutron generation downstream of the beam pipe in the front end is absorbed by adequate boroted polyethylene treatment in and around the ratchet wall penetration.

The current APS front end designs meet the specifications listed in Table 2 for the first phase of the project. In the second phase, the front end designs are expected to meet operating specifications at $300 \mathrm{~mA}$ ring current with full size 4.8-m Undulators.

\section{Front End Aperture Sizing}

The standard design of the ID front ends is understandably much more complex than the BM front end design, and the ID front end design will be primarily detailed here. The ID front ends must satisfy the power requirements of the 3.3-cm-period Undulator A coupled with the horizontal beam size of the 8.5-cm-period Wiggler A (see Table 1). For a $100 \mathrm{~mA}$ ring current at 7-GeV positron beam energy, planned wsigglers (for a maximum $\mathrm{K}$ factor of 14) cover a photon energy range of 5 to $32.6 \mathrm{KeV}$. The source ID 
TABLE 2. Global Specifications for the APS Front Ends

- $7 \mathrm{GeV}$ Positron Beam Energy

- $100 \mathrm{~mA}$ Beam Current

- ID Radiation Fan $= \pm 1.5 \mathrm{mrad}$

- BM Radiation Fan $= \pm 3.0 \mathrm{mrad}$

- PBPM Sensitivity $< \pm 1 \mu \mathrm{m}$

- Beam Stability

- Spatial Size $\leq \pm 0.1 \sigma$

- Angular Size $\leq \pm 0.1 \sigma^{\prime}$ 
radiation fan width is taken to be $\pm 1.5 \mathrm{mrad}$ (for the $\mathrm{BM}$ front ends, the source fan width is $\pm 3.0 \mathrm{mrad}$ ). An optical path sketch resulting from the ray-tracing studies for the ID front end is shown in Fig. 1.

A ray-tracing study using the SHADOW code [4] is the starting point in the design for requisite aperturing needs and the component size determination of the front end elements. This results in an optical pass configuration for the front end. This is shown in Fig. 1 in a 3D depiction. In Figs. 2 and 3, the same information is shown in vertical and horizontal planes, respectively. In Tables 3 and 4, the aperture sizes are listed for all the components on the ID and the BM front ends. The straight sections on the Storage Ring can have either one or two undulator- and/or wiggler-type 2.4-m devices or a single 4.8-m ID. The vertical and horizontal beam confinements for the ID front ends are complicated because of the possibility of placing various length IDs on the straight section. The calculated maximum acceptance angles for the beam under missteering conditions are presented in Table 5. In these calculations, the origin of the wiggler beam divergence is assumed to be at the very beginning of the straight section, whereas for undulators, it is at the center of the ID.

The APS front ends are housed within the Storage Ring tunnel. The shielding tunnel walls are made of heavy concrete and fashioned as a "dog-leg" ratchet wall to provide the maximum aisle access to the front end inside the tunnel. The usable length of the front end area of the tunnel is about 7.5 meters for both the IDs and the BMs and is necessarily congested by the components, particularly in the ID case. For all front ends, the access to the tunnel is via a sliding door in the tunnel wall (ratchet wall door). The front end environment provides the following features:

- Air temperature: $\quad 23 \pm 1^{\circ} \mathrm{C}$

- Cooling DI water temperature: $\quad 23 \pm 1^{\circ} \mathrm{C}$

- Serviceable through a sliding ratchet wall door

- Structurally stable and vibration free

- Survey and alignment availability 


\section{ADVANCED PHOTON SOURCE}

\section{Table 3. Optical Path from Ray Tracing in thelD Front End}

\begin{tabular}{|c|c|c|c|c|}
\hline Component & $\begin{array}{l}\text { Loca } \\
0.0\end{array}$ & $\begin{array}{l}m \\
\text { of WA }\end{array}$ & $\begin{array}{l}\text { Physical } \\
\text { Aperture } \\
\mathrm{mm} \times \mathrm{mm}\end{array}$ & $\begin{array}{l}2.044 \times 0.29 \\
\text { Ray Traced } \\
\text { Beam Size } \\
\mathrm{mm} \times \mathrm{mm}\end{array}$ \\
\hline BPM 1 & & 18.755 & $70 \times 26$ & $38 \times 5.5$ \\
\hline Fixed Mask 1 & & & $\begin{array}{l}64 \times 26 \text { (in) } \\
52 \times 12 \text { (out) }\end{array}$ & $\begin{array}{l}40 \times 5.7 \\
41 \times 5.8\end{array}$ \\
\hline $\begin{array}{l}\text { Photon Shutter } \\
\text { Lead Collimator }\end{array}$ & & $\begin{array}{l}20.532 \\
21.292\end{array}$ & $\begin{array}{l}70 \times 16 \\
62 \times 20 \\
(68 \times 26)\end{array}$ & $\begin{array}{l}42 \times 6.0 \\
44 \times 6.2\end{array}$ \\
\hline $\begin{array}{l}\text { Fast Valve } \\
\text { BPM } 2 \\
\text { Fixed Mask } 2\end{array}$ & & $\begin{array}{l}21.946 \\
22.365 \\
22.745 \\
23.049\end{array}$ & $\begin{array}{l}70 \times 18 \\
70 \times 18 \\
70 \times 18 \text { (in) } \\
(62 \times 6) \text { (out) }\end{array}$ & $\begin{array}{l}45 \times 6.4 \\
45 \times 6.5 \\
47 \times 6.7\end{array}$ \\
\hline $\begin{array}{l}\text { Photon Shutter } \\
\text { Filters } \\
\text { Safety Shutter }\end{array}$ & & $\begin{array}{l}23.848 \\
24.675 \\
25.764\end{array}$ & $\begin{array}{l}70 \times 10 \\
72 \times 10 \\
72 \times 20\end{array}$ & $\begin{array}{l}49 \times 6.2 \\
(50 \times 6.5) \\
53 \times 6.8\end{array}$ \\
\hline Lead Collimator & & 26.837 & $\begin{array}{l}72 \times 20 \\
(78 \times 26)\end{array}$ & $55 \times 7.1$ \\
\hline Window & & 27.369 & $\begin{array}{l}72 \times 8.8(w) \\
72 \times 12(c)\end{array}$ & $\begin{array}{l}56 \times 7.3 \\
56 \times 7.3\end{array}$ \\
\hline
\end{tabular}




\section{ADVANCED PHOTON SOURCE}

\section{Table 4. Optical Path from Ray Tracing in the BM Front End}

$\begin{array}{ccll}\text { Component } & \text { Location } & \text { Physical } & 6.0 \times 0.292 \\ & \text { Aperture } & \text { Ray Traced } \\ & \mathrm{mm} & \mathrm{mm} \times \mathrm{mm} & \text { Beam Size } \\ & & \mathrm{mm} \times \mathrm{mm}\end{array}$

\begin{tabular}{|c|c|c|c|}
\hline Fixed Mask 1 & 9.20 & $\begin{array}{l}129 \times 30 \text { (in) } \\
60 \times 18 \text { (out) }\end{array}$ & $55.2 \times 2.69$ \\
\hline BPM 1 & 10.9 & $90 \times 24$ & $65.4 \times 3.18$ \\
\hline Fixed Mask 2 & 13.67 & $\begin{aligned} 110 \times 36 & \text { (in) } \\
84 \times 12 & \text { (out) }\end{aligned}$ & $82 \times 4.0$ \\
\hline Photon Shutter 1 & 13.93 & $130 \times 24$ & $84 \times 4.1$ \\
\hline Lead Collimator 1 & 14.47 & $\begin{array}{l}92 \times 20 \\
(98 \times 26)\end{array}$ & $87 \times 4.2$ \\
\hline Fast Valve & 15.3 & $110 \times 18$ & $92 \times 4.5$ \\
\hline Delay Line & 17.32 & $125 \times 30$ & $104 \times 5.1$ \\
\hline BPM 2 & 18.02 & $125 \times 18$ & $108 \times 5.3$ \\
\hline Fixed Mask 2 & 18.51 & $\begin{array}{l}125 \times 20 \text { (in) } \\
111 \times 5.2 \text { (out) }\end{array}$ & $111 \times 5.4$ \\
\hline Photon Shutter 2 & 18.77 & $130 \times 24$ & $113 \times 5.3$ \\
\hline Lead Colimator 2 & 19.31 & $\begin{array}{l}122 \times 20 \\
(128 \times 26)\end{array}$ & $116 \times 5.6$ \\
\hline Safety Shutter & 20.24 & $132 \times 20$ & $121 \times 5.9$ \\
\hline Lead Collimator 3 & 21.35 & $\begin{array}{l}139 \times 20 \\
(145 \times 26)\end{array}$ & $128 \times 6.2$ \\
\hline Window & 21.87 & $\begin{array}{l}145 \times 8.8(w) \\
145 \times 12(c)\end{array}$ & $\begin{array}{l}131 \times 6.6 \\
131 \times 6.6\end{array}$ \\
\hline
\end{tabular}




\section{ADVANCED PHOTON SOURCE}

Table 5. Beam Mis-steering Allowances in APS Front Ends

From the Center of

ID Straight Section
From the Beginning of ID Straight Section

\section{Vertical Beam}

Confinement

(mrad)

(mrad)

Max. Vertical Beam

Missteering Acceptance

1.53

1.34

FE Beam Dump Interlock

1.29

1.13

Max. Pass -through

0.29

0.26

\section{Horizontal Beam}

Confinement

(mrad)

(mrad)

Max. Horizontal Beam

Missteering Acceptance

3.76

3.40

FE Beam Dump Interlock

1.29

1.13

Wigglers

3.53

3.08

Undu.lators

1.29

1.13

Max. Pass -through

3.01

2.69 
- Radiation protection:

Requirements of APS-LS-141, "Radiological Design

Considerations: Review of the Radial Ratchet Wall Shielding," are satisfied

- All utility/control modules are placed outside the FE tunnel

Figure 4 is the elevation view of the conceptual design of the standard ID front end at the APS. In this conceptual design, the components on the ID front end are (in the order of their appearance in Fig. 4):

1. All metal ring isolation valve

2. Photon beam position monitor 1

3. Fixed mask 1

4. Photon shutter 1

5. Collimator

6. All metal slow valve

7. All metal fast valve

8. Photon beam position monitor 2

9. Fixed mask 2

10. Photon shutter 2

11. Filter assembly

12. Integral safety shutter/collimator

13. Ratchet wall penetration

14. Window

In Figs. 5a through 51, all the SHADOW ray-tracing plots are presented for the ID front end components.

The above designs are nearly but not entirelyly the same as those that were critiqued by an independent Design Review Board (DRB), and which were subsequently costed and approved at the Title I review conducted by the U.S. DOE Engineering Research Committee in FY1991.

The design challenge of the APS ID front ends lies in packaging all of the front end components in the tight space available. Both the maximum height and the maximum width of the components must be considered carefully to ensure the front end is serviceable during operation. Therefore, 
nothing should be mounted lower than at 2.2 meters elevation in the synchrotron tunnel, and a mere $515 \pm 15 \mathrm{~mm}$ width is available between the front end edge plane and the ratchet wall to slide the components in and out of the tunnel. The width of the component support table had to be closely controlled to a maximum of $485 \mathrm{~mm}$ to make room for such movement. In the front end design, it is preferred that the components stay with their respective table supports during such maintenance and servicing. This greatly facilitates subsequent front end alignment problems. The total power, peak heat flux and the beam width of the planned IDs combined with the limited space available result in tough engineering challenges in the front end component designs. From Table 1, it is seen that the normal incidence heat fluxes from the planned IDs at the PS1 and PS2 positions are very large, typical values being on the order of $450 \mathrm{~W} / \mathrm{mm}^{2}$ or higher. Designing for such heat flux levels and/or for large total heat load (on the order of 10-15 $\mathrm{kW}$ ) poses significant engineering ad material challenges. The result has been what may be termed a "grazing .ngle front end design." This is the only way one can handle the associated thermal and material problems associated with the planned IDs even with the enhanced heat transfer method available at the APS.

The design of the APS ID front ends includes two fixed masks and two photon shutters. In addition to confining the beam, the fixed masks serve to limit the length of the photon shutters placed immediately downstream.

An overview is given below for the major components of the APS ID front end as well as the current state of the research activity associated with a particular component.

\section{Overview and Design Description of ID Front End Components}

Exit Valve: This is an all metal valve and is UHV vacuum tight. It isolates the front end from the ring. Opening this valve is strictly controlled by the safety coordinator.

Photon Beam Position Monitor (PBPM): This device is a cooled multi-blade system, in horizontal and vertical disposition, placed in the fringes of the beam to detect the position of the beam. At the APS, there are two PBPMs, the second is placed approximately $3.6 \mathrm{~m}$ downstream of the first. Together they yield precise beam position information. When swept by the beam, the blades of the APS front end PBPMs generate photoelectrons. This, in turn, causes a microampere-level photocurrent in each blade that can be 
measured and reduced to correlate win the degree of deviation of the beam from its orbit. The beam missteering on the ring side is to be kept within ten percent in both position and divergence. When excessive deviations are detected, the output from the PBPMs is fed back into the ring correction (steering) magnets to adjust the beam's position and the angle at the ID center. In the extreme case of beam tracking loss, the PBPM can trigger a beam dump. PBPM signals are fed back to the ring for proper beam steering.

The APS machine side requires, with the two PBPMs spaced apart as described above, a precision of $\pm 3.3 \mu \mathrm{m}$ in the position and $\pm 0.14 \mu \mathrm{rad}$ in the angle of the particle beam. Given the power from the planned ID beams, early studies indicated that, with conventional blade materials, it would be very difficult to reliably meet these specifications. Therefore, we looked into new blade materials and introduced the use of metallized CVD diarnond blades for the ID front ends. The APS PBPM prototypes with such blades were tested at NSLS on the X-13 beamline, at CHESS on the APS/CHESS short undulator front end, and finally, again, at NSLS on the X-25 focused wiggler beamline. Partial results from these tests are presented in Figs. 6a through $6 \mathrm{e}$. These tests have proven beyond reasonable doubt that we can achieve submicron sensitivity (on the order of $0.2 \mu \mathrm{m}$ ) with CVD diamond blades under all conventional operation. The dynamic range of the current CVD diamond blades in synchrotron tests was shown to be at least $2 \mathrm{~mm}$. The current design and the research activity associated with the APS PBPMs are presented in [5].

The latest tests at NSLS on X-25 proved that our CVD diamond blades can be heated to over $1000^{\circ} \mathrm{C}$ under very adverse conditions with no loss of integrity or performance. However, the PBPM blades have been designed not to exceed $600^{\circ} \mathrm{C}$ under full beam missteering when the beam from a $5-\mathrm{m}$ undulator is allowed to directly impinge on the blade.[6].

Because the complete PBPM assembly (as shown in Fig. 7) comprises three parts, namely the mounting post, the stage assembly, and the blade head assembly, the error sum from these parts should meet the total error budget of $< \pm 1 \mu \mathrm{m}$. Table 6 lists various post choices subjected to a $1^{\circ} \mathrm{C}$ temperature change and the resulting thermal elongation. A dynamic analysis [7] of these post configurations proves that a post made of 3-mm thick steel, filled on the inside with conductive loose material, and thermally insulated on the outside will have large thermal inertia. Such a post (as demonstrated in Fig. 8) will expand/contract negligibly when subjected to a $\pm 2^{\circ} \mathrm{C}$ step change in the environment, requiring over a iull day to reach steady state. Therefore, such a post design is very resilient to the more relevant shorter term temperature fluctuations. 


\section{ADVANCED PHOTON SOURCE}

TABLE 6 Beam Position Monitor Suport Base Vertical Thermal Expansion for a $1 \mathrm{C}$ Temperature Change

Case Specification Thermal Expansion

1 SS Cylinder

$16.2 \mu \mathrm{m}$

2 SS Cylinder Filled

with Water At Constant

Temperature

$0.82 \mu \mathrm{m}$

3 Case \#2 with

Ceramic Paper

Insulation

$0.33 \mu \mathrm{m}$

$4 \quad$ Ceramic Base
Cylinder
$0.50 \mu \mathrm{m}$ 
The PBPM stage assembly consists of vertical, horizontal, and rotational stages. Because the commercially available vertical stages could not meet our specifications, we developed an in-house stage assembly. This stage assembly has been subjected to tests both in-house and also at the NSLS X-25 beamline. Partial resulis from the in-house tests are depicted in Fig. 9 under 200 lb.-load steppin kneasurements using our Laser Doppier Displacement Module. These tests prove that this vertical stage is reliable, and it attained a stepping resolution of $< \pm 0.2 \mu \mathrm{m}$.

The present PBPM head assembly design is shown schematically in Fig. 10. The first PBPM has six CVD diamond blades, four placed vertically in pairs and two single blades placed horizontally. The downstream PBPM also has six blades, however, now the vertical blades are placed singly, and the horizontals ones are in pairs. This configuration eliminates the blade shadowing problems. Undulator and wiggler PBPMs have fixed but two different horizontal blade settings. If desired, the horizontal blades can be made movable to accommodate various IDs (undulators, wigglers) via a stainless ribbon drive on the horizontal jaws of the PBPM. A pull on the ribbon acts against two springs under compression resulting in precise position adjustment. This design is under study. The current design for fixed but resettable blade configurations for both the undulators and wigglers is schematically depicted in Fig. 11. For the bending magnet front ends, the PBPM is much simpler, consisting of only two vertical blades.

Fixed Mask Assembly (Fixed Aperture): This is the first front end component to interact with the beam. The fixed mask (FM) may be exposed to the full beam or part of the beam and thus requires a careful design analysis. A similar mask is located further downstream on the front end. In the case of the APS, both assemblies are designed to contain the beam but not define it. Despite this, these assemblies are designed to absorb the full beam of any IDs at the APS planned for the first phase. An extensive heat transfer research and development program has been undertaken at the APS to find a generic but efficient tube configuration for enhanced cooling of the large heat loads that may be imposed on both the fixed and the movable mask walls. This will be detailed further in a later section.

A drawing for the first FM assembly is presented in Fig. 12. The second fixed mask is identically designed. Both masks are Electric Discharge Machined (EDMed) from a solid bar of OFHC copper to provide a central aperture as specified in Table 3. The sides of the aperture form a 3-degree included angle between both the horizontal and the vertical walls. Analysis proves that the horizontal walls are subject to the worse thermal loading. 
Therefore, the horizontal aperture walls are brazed with a thin $(3 \mathrm{~mm})$ Glidcop faceplate to offer a higher yield strength and better thermal fatigue resistance for the first phase ID front ends.

Cooling is affected outside the UHV envelope by water in channels machined right into the aperture walls (as shown in Fig. 14). The channels are subsequently filled with a porous copper matrix for higher convective heat transfer. The matrix is brazed to the aperture walls for good thermal contact.

The end walls of the aperture body are machined to be subsequently welded to the stainless steel UHV flanges.

Considerable amount of analysis has been carried out on the fixed masks $[8,9$, and 10]. Representative results from these analyses are presented in Figs. 13a through 13j. The analyses were carried out using the ANSYS code as well as closed form solutions. Results from both usually agree within $5 \%$. Figure 13a depicts the beam on the mask wall. Figure 15b is a 3D depiction of the heat flux distribution in the beam used in the ANSYS code. Table 7 is a summary of the maximum temperatures and the stress values calculated for the mask at various interfaces. The maximum temperature at the Glidcop surface is $200^{\circ} \mathrm{C}$, and the maximum stress is about $260 \mathrm{MPa}$. These values are within our parameters for Glidcop. Figures 13c through 13g show the parametric study (trend curves) of the maximum temperature and the maximum stress values in the FM1 walls as a function of the Glidcop faceplate thickness and the convective heat transfer coefficient in the enhanced heat transfer cooling scheme. Figure 13h shows the yield stress curves for various copper materials at elevated temperatures and their comparison to Glidcop. Finally, Fig. 13i shows the yield stress change in Glidcop after a high temperature brazing process. These data indicate that Glidcop is a very suitable material to use in high temperature and high stress environments.

Photon Shutter (Movable Mask): This component completely intercepts the x-ray photon beam via a fast-acting mechanism in order to isolate the downstream components from the source. Closing time may be as long as a few seconds (NSLS) or as short as $55 \mathrm{~ms}$ (ESRF). In our current design, we are using a slow actuator with a closing time of about one second. For future use, a fast closing option $(50 \mathrm{~ms})$ is under research and development. The photon shutter also acts as a safety device to protect the safety shutter from direct beam impingement. Therefore, the photon shutter is interlocked to close before the closing of the safety shutters (two of which are required as per the APS Preliminary Safety Analysis Report, PSAR). The positions of both the photon shutter and the safety shutters are redundantly indicated. That is, the photon shutter must be first closed and last opened and 


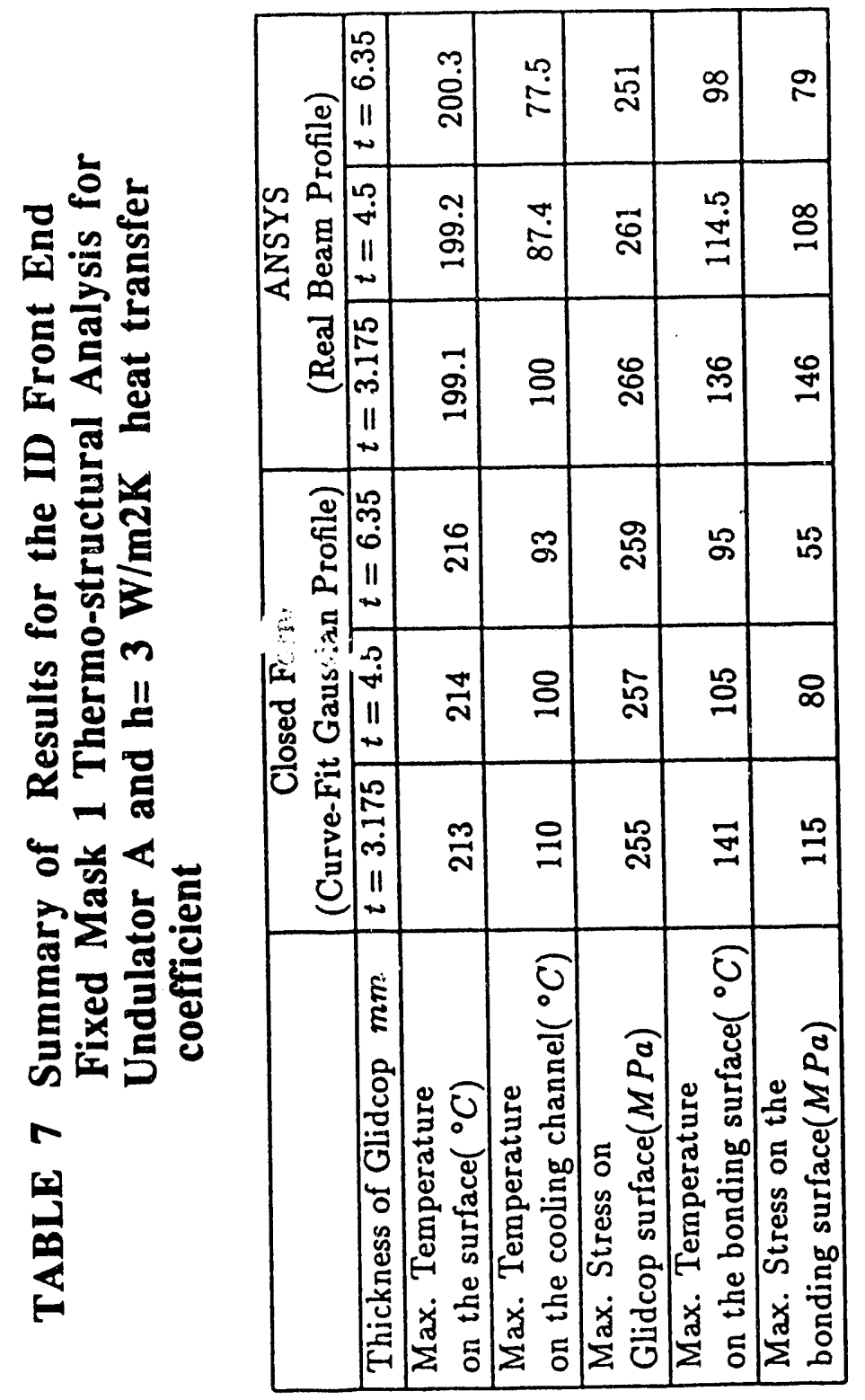


has redundant closed-position indication (fail-safe). The position of the safety shutter is redundantly indicated in both up (open) and down (closed) positions.

Figure 14 is a drawing of the first photon shutter assembly. The shutters of both PS1 and PS2 have the same configuration employing a "hockey stick" shaped copper absorber blade. The first photon shutter serves as the traditional shutter in the front end and is interlocked to the front end vacuum system. As such, it is acted upon during injection and during vacuumtriggered shut-down events. This reduces the actuation frequency for the first photon shutter very significantly mitigating the common bellows-type failure in such devices. The second photon shutter is used exclusively by the experimenters and, as such, is very frequently actuated. The hockey stick absorber blade is hinged from both ends (Fig. 15), and the complete assembly can be removed intact from the flanged side for replacement or maintenance. The first photon shutter blade is set to the beam at a 1.5 degree grazing angle, and the second one is at a 2 degree grazing angle. The photon shutters offer common features such as:

- Common tube design

- UHV containment

- Cooled containment against reflected/scattered radiation

- Fail-safe design

- Replaceable absorber tube

- Initial alignment viewing ports

The absorber tube is hinged from the flange end using no-slack flexural couplings. Likewise, from the actuator side it is connected with a flexural coupling.

At the APS, the fixed mask and the photon shutters use a common and generic coolant tube with enhanced heat transfer capabilities [ 8 and 11]. The tube is filled with a copper foam (copper wool) brazed to the inside walls of the tube for good thermal contact. The heat transfer enhancement available from such tubes is shown in Fig. 15. In addition to casuing highly enhanced heat transfer, the presence of the copper wool (porous filler) in the flow tube provides other benefits. At the expense of an increased pressure drop (Fig. 16), the porous matrix in the tube makes these tubes very quiet, nearly jitter free. This is an important consideration for critical components such as PBPMs, masks, and, potentially, slits and first optics crystals where flowinduced jitter can become a serious concern. Additionally, these tubes require a relatively small amount of flow to achieve high convective heat transfer coefficients, an important consideration from an operational point of view. 
Thus far in laboratory studies, we have achieved enhanced heat transfer coefficients $\left(\mathrm{h}>4 \mathrm{~W} / \mathrm{cm}^{2} \mathrm{~K}\right)$ in such tubes using a variety of meshes. Our design goal is to obtain an $h$ value of $3 \mathrm{~W} / \mathrm{cm}^{2} \mathrm{~K}$ with about $2.5-3.0 \mathrm{psi}$ in pressure drop. The APS ID front ends have many components requiring very robust cooling due to the high heat loads imposed on them from very powerful IDs. Conventional techniques for cooling would have resulted in an order of magnitude higher flow requirements in the front end. Research is continuing at the APS to optimize the tube geometry and the porosity.

A great deal of analysis has been conducted on the thermal, structural, and the vibrational problems of both photon shutters. These are included in references [12 through 15$]$. The analyses seem to prove that the most critical component of the front end, the first photon shutter (PS1) as designed will satisfy the stringent thermal, structural, and vibrational requirements during operation with the 2.4-m Undulator A of the APS (which will be the initial source). Partial results on the calculated maximum temperatures and stresses for PS1 are presented in Table 8 for both the closed form and the ANSYS solutions. Examination of this table shows that the maximum temperature on the Glidcop faceplate will about $200^{\circ} \mathrm{C}$ and the maximum stress about 240 $\mathrm{MPa}$. These values are somewhat lower than those of the FM1 because the FM1 is closer to the source. Even for the special IDs with very large total heat loads, the expected resulting temperatures and stresses are within our design limits. Results from these calculations are summarized in Tables 9 and 10 , respectively, for source parameters and thermo-structural values at two values of $h\left(2\right.$ and $\left.3 \mathrm{~W} / \mathrm{cm}^{2} \mathrm{~K}\right)$.

The technical requirements for the future 4.8-m Undulator A, including a design safety factor, are very challenging, and the research and development effort is continuing into an engineering solution for the thermal problems of the photon shutter and the fixed mask.

Collimators: These components are required to define the line of sight to the source point and to allow a cone of the beam to pass through. Portions of the beam outside the predefined cone and any other scattered $x$ rays as well as the bremsstrahlung are absorbed by the collimator body. The APS front end collimators are at least $30 \mathrm{~cm}$ (12 in) lead equivalent in length as per the PSAR.

Slow Valve: This is an all-metal remotely actuated UHV valve that seals to isolate the ring from any vacuum breach in the downstream transport piping. The closing time of this valve is usually 1-2 seconds. However, it cannot accept the heat load from the photon beam and therefore has to be interlocked to close only when beam is NOT present or the photon shutter is 


\section{TABLE 8 Summary of Analytical Results for the ID Front End Photon Shutter 1 ior Undulator $A$ and $h=3 \mathrm{~W} / \mathrm{m} 2 \mathrm{~K}$ heat transfer coefficient}

\begin{tabular}{|c|c|c|c|c|c|c|}
\hline & $\begin{array}{r}\mathrm{C} \\
\text { (Curve-Fi } \\
\end{array}$ & $\begin{array}{l}\text { osed For } \\
\text { Gaussia }\end{array}$ & Profile) & (Real & $\begin{array}{l}\text { ANSYS } \\
\text { Beam } \mathrm{Pr}\end{array}$ & file) \\
\hline Thickness of Glidcop $\mathrm{mm}$ & $t=3.175$ & $t=4.5$ & $t=6.35$ & $t=3.175$ & $t=4.5$ & $t=6.35$ \\
\hline $\begin{array}{l}\text { Max. Temperature } \\
\text { on the surface }\left({ }^{\circ} \mathrm{C}\right)\end{array}$ & 198 & 200 & 202 & 187 & 186 & 185 \\
\hline $\begin{array}{l}\text { Max. Temperature } \\
\text { on the cooling channel }\left({ }^{\circ} \mathrm{C}\right)\end{array}$ & 104 & 96 & 87 & 95 & 84 & 75 \\
\hline $\begin{array}{l}\text { Max. Stress on } \\
\text { Glidcop surface }(\mathrm{MPa})\end{array}$ & 236 & 240 & 243 & 247 & 242 & 233 \\
\hline $\begin{array}{l}\text { Max. Temperature } \\
\text { on the bonding surface }\left({ }^{\circ} \mathrm{C}\right)\end{array}$ & 132 & 118 & 107 & 130 & 110 & 95 \\
\hline $\begin{array}{l}\text { Max. Stress on the } \\
\text { bonding surface }(\mathrm{MPa})\end{array}$ & 115 & 80 & 55 & 137 & 103 & 75 \\
\hline
\end{tabular}




\section{TABLE 9 Design Parameters for Various Insertion Devices for the Analysis of ID Front End Components}

\begin{tabular}{|c|c|c|c|}
\hline Parameters & U3.3 & UW5.5 & $W A_{I I I}$ \\
\hline Period Length $[\mathrm{cm}]$ & 3.3 & 5.5 & 15.0 \\
\hline Device Length [m] & 2.38 & 2.4 & 4.8 \\
\hline No. of Periods & 72 & 44 & 32 \\
\hline Max. Magnetic Field $B_{0}[T]$ & 0.72 & 1.14 & 1.0 \\
\hline Char. Energy $E_{C}[\mathrm{keV}]$ & 23.6 & 37.2 & 32.6 \\
\hline Max. Defection Parameter, $\mathrm{K}$ & 2.23 & 5.86 & 14.0 \\
\hline Total Power $[\mathrm{kW}]$ & 3.8 & 9.8 & 14.9 \\
\hline Incident Beam Angle ${ }^{\circ}$ & 1.5 & 1.5 & 1.5 \\
\hline Distance from the Source to PS1 [m] & 16.9 & 19.3 & 18.1 \\
\hline Peak Heat Flux @ PSI $\left[\frac{W}{\mathrm{~mm}^{2}}\right]$ & 12 & 9 & 6.6 \\
\hline
\end{tabular}


TABLE 10 Summary of Results for the ID Front End Photon Shutter 1 Thermo-structural Analysis for IDs in Table 8 and $h=2$ and $3 W / m 2 K$ heat transfer coefficient

\begin{tabular}{|l|c|c|c|c|c|c|}
\hline & \multicolumn{2}{|c|}{ U3.3 } & \multicolumn{2}{c|}{ UW5.J } & \multicolumn{2}{c|}{ W III } \\
\hline Thickness of Glidcop mm & $t=3$ & $t=5$ & $t=3$ & $t=5$ & $t=3$ & $t=5$ \\
\hline $\begin{array}{l}\text { Max. Temperature } \\
\text { on the Surface }\left({ }^{\circ} \mathrm{C}\right)\end{array}$ & 173 & 177 & 214 & 219 & 170 & \\
\hline $\begin{array}{l}\text { Max. Temperature } \\
\text { on the Cooling Channel }\left({ }^{\circ} \mathrm{C}\right)\end{array}$ & 75 & 68 & 107 & 96 & 88 & \\
\hline $\begin{array}{l}\text { Max. Stress on } \\
\text { Glidcop Surface }(\mathrm{MPa})\end{array}$ & 220 & 220 & 253 & 247 & 191 & \\
\hline $\begin{array}{l}\text { Max. Temperature } \\
\text { on the Bonding Surface }\left({ }^{\circ} \mathrm{C}\right)\end{array}$ & 110 & 92 & 152 & 132 & 124 & \\
\hline $\begin{array}{l}\text { Max. Stress on the } \\
\text { Bonding Surface }(\mathrm{MPa})\end{array}$ & 105 & 75 & 152 & 110 & 104 & \\
\hline
\end{tabular}

$$
\mathrm{PS} 1, h=3 \frac{W}{\mathrm{~cm}^{2}{ }^{\circ} \mathrm{C}}
$$

\begin{tabular}{|l|c|c|c|c|c|c|}
\hline & \multicolumn{2}{|c|}{ U3.3 } & \multicolumn{2}{c|}{ UW5.5 } & \multicolumn{2}{c|}{ W AIII } \\
\hline Thickness of Glidcop mm & $t=3$ & $t=5$ & $t=3$ & $t=5$ & $t=3$ & $t=5$ \\
\hline $\begin{array}{l}\text { Max. Temperature } \\
\text { on the Surface }\left({ }^{\circ} \mathrm{C}\right)\end{array}$ & 160 & & 199 & & 158 & \\
\hline $\begin{array}{l}\text { Max. Temperature } \\
\text { on the Cooling Channel }\left({ }^{\circ} \mathrm{C}\right)\end{array}$ & 64 & & 90 & & 76 & \\
\hline $\begin{array}{l}\text { Max. Stress on } \\
\text { Glidcop Surface }(M \mathrm{~Pa})\end{array}$ & 205 & & 240 & & 180 & \\
\hline $\begin{array}{l}\text { Max. Temperature } \\
\text { on the Bonding Surface }\left({ }^{\circ} \mathrm{C}\right)\end{array}$ & 98 & & 138 & & 112 & \\
\hline $\begin{array}{l}\text { Max. Stress on the } \\
\text { Bonding Surface }(\mathrm{MPa})\end{array}$ & 96 & & 145 & & 96 & \\
\hline
\end{tabular}


closed. Closing of the slow valve occurs after the closing of the fast valve (below), which helps to retard the vacuum conductance upstream in case of a vacuum breach.

Fast Valve: The fast valve is positioned immediately downstream of the slow valve. The modern all-metal-seal fast valves close in as little as 5 to 9 $\mathrm{ms}$, thereby retarding the vacuum progression upstream. This valve, however, does not seal and cannot support even instantaneous exposure to a full photon beam without physical damage. Therefore, it is interlocked to the photon shutter during operation. On vacuum failure, the photon shutter is activated, which triggers immediate beam dump. Once the photon shutter is down, the fast valve closes, followed by the closing of the slow valve. In our laboratory tests, a V.A.T fast valve has been cycled more than 100 times with less than $7 \mathrm{~ms}$ closing time.

Filters: The front end filters, if and when used, are designed to protect the window thermally and structurally. Filters are typically pyrolitic graphite foils and absorb and dissipate heat from unwanted portions of the photon beam spectra. They are radiatively and/or conductively cooled. Cooling is provided by passing water around the filter frame directly or through the filter holder box walls in an indirect fashion. While provision has been made to install such filters in the ID front ends, research proves that it is virtually impossible to reliably design filters and windows for certain undulator-type IDs that can meet the photon flux and/or photon energy requirements of the users. In such cases, a filter box will be removed for windowless operation of the front end. A differential pump replaces the window in these cases, which may constitute a majority of the APS ID front end designs, and will be explained further in the following.

Safety Shutters: These shutters (two independently but simultaneously operated shutters are required per front end per APS PSAR) absorb bremsstrahlung radiation from scattering of the particle beam during injection of the beam into the Storage Ring. Therefore during each injection mode (maybe every 8-10 hrs. of operations), these shutters are closed (down). Conventional material for the safety shutter is a block of lead or tungsten. This shutter is usually not cooled, but does absorb all the bremsstrahlung radiation coming through the line. Because it is not cooled, it should not be exposed to the photon beam. Therefore, the upstream photon shutter 2 is interlocked and sequenced to close (down) before the safety shutter is closed (down).

In conventional designs, such shutters are designed as "dumb" blocks. When they are lowered for bremsstrahlung shielding, they completely block 
the possible line of sight of the radiation cone from upstream as seen from downstream. In our design, we have contrived a "smart" shutter by combining the "shuttering" with a "collimation" function [16]. The result is our "integral shutter/collimator," which is shown in Fig. 17. The shutter block, made of special UHV-compatible tungsten, consists of two parts. The smaller upper part (about $40 \mathrm{lbs}$.) is raised and lowered into the fixed and heavy lower part (about $200 \mathrm{lbs}$.) to provide collimation in the raised position and complete shuttering in the lowered position. The overall dimensions are $200 \mathrm{~mm}$ wide, $120 \mathrm{~mm}$ high, and $300 \mathrm{~mm}$ long. The adequacy of the heavy metal length has been reaffirmed by a recent study on the radiation shielding [17].

The current design has resulted in:

- compactness, saving axial space

- a light duty actuator

- faster shuttering

- small stroke in actuation

- increased reliability of the UHV bellows

- much improved collimation in the front end

- conductiveness for future "top-off mode" operation

Window: The window is a vacuum separator and is positioned as needed between different vacuum transports and/or experimental stations. The front end window is located at the end of the front end transport and separates the ring vacuum (front end vacuum) from the experimental beamline vacuum. For easy maintenance and access purposes, the window is located outside the synchrotron tunnel on the First Optics Enclosure (FOE) side and is separated from the front end via a UHV valve. The APS window is a dual diaphragm assembly with a tag gas in between. Dual window diaphragms lend added assurance for two reasons. The second window on the downstream side does not absorb much heat because most of the absorbable soft x-ray photons are absorbed by the first window. As such, the second window remains structurally strong to absorb atmospheric shock. Also, should one of the window diaphragms fail, the other one can assure vacuum integrity until the failed window is replaced. The traditional window material is beryllium, although the high heat loads expected from APS undulators may force us to seek alternate window materials such as diamond-coated beryllium or CVDdiamond wafers. These windows as well as the upstream filter assembly are currently under research and development at the APS [18]. 
The tag gas is traditionally helium, although other gases may also be considered. The purpose of the gas is to keep the wafer surfaces free from oxidation/carbonization and to indicate when a vacuum breach occurs. The gas space is interlocked for beam stoppage/dumping when a vacuum breach is sensed by the gas system. Design of the filters and the windows in APS front ends is a very important issue and the subject of considerable current research building on earlier studies [19 and 20].

As a matter of philosophy, the APS believes that the beam filtering in the front end should be the ninimum required to maintain the structural integrity of the window and, thereby, assure the requisite vacuum safety in the front end. The filter assembly is designed so that only the unwanted portions of the beam energy are absorbed; thus, the window is thermally (hence, structurally) protected. Otherwise, a user-selectable filter box is located on the beamline to satisfy different optical requirements by the experimenter.

It should be noted that the APS ID front ends are not designed to have vacuum delay tanks (BM front ends do have vacuum delay tanks for particular reasons). The engineered and intrinsic ample aperturing in the ID front end is expected to provide good vacuum delay. The present vacuum analyses indicate that, with the excessive distributed aperturing and the front end length (approximately $24 \mathrm{~m}$ for ID lines and $22 \mathrm{~m}$ for BM lines), the APS ID front ends afford intrinsic vacuum delay. This will be verified in laboratory tests.

\section{Bending Magnet Front Ends}

Although the operational philosophy of the BM front end is the same as that for the ID front end, the power and the power densities that are handled by various components in BM front end are significantly smaller. Hence, the engineering of the $\mathrm{BM}$ components is less challenging. A brief description of the component assemblies is provided here.

In Fig. 18, the conceptual design of the APS BM front end plan and the elevation views are shown. The BM front end components, in order of their appearance in Fig. 18, are:

1. All metal exit valve

2. Fixed mask 1

3. Photon beam position monitor 1

4. Fixed mask 2 

5. Photon shutter 1
6. Slow valve
7. Fast valve
8. Vacuum delay tank
9. Photon beam position monitor 2
10. Fixed mask 3
11. Photon shutter 2
12. Safety shutters
13. Ratchet wall penetration
14. Be window

Due to the configuration of the ring lattice, the position of the exit valve on the BM front end is closer (at $7.2 \mathrm{~m}$ ) to the source point than that of the ID front end (at about $16 \mathrm{~m}$ ). Also, as is seen in the plan view in Fig. 6, the BM front end transport intercepts the neighboring ID vacuum chamber support system. Hence, downstream of the exit valve a special spool piece is provided (rectangular in cross section) to clear the ID vacuum chamber. A $170 \mathrm{l} / \mathrm{s}$ ion pump assures good vacuum close to the ring in this upstream end of the BM front end. The first fixed mask reduces the horizontal beam aperture providing for a large missteering allowance during commissioning of the ring in the early commissioning stage to the design beam aperture of \pm 3 mrad. The first PBPM is placed downstream of the FM1 wherever the ratchet wall geometry allows sufficient room to place the support table for the PBPMs. From this point on, placement of the front end components is similar to that of the ID front end with the exception that a two-meter length of the six-inch-diameter vacuum transport is used as a vacuum delay tank following the slow and fast valves. The reason for this is as follows. The vacuum pipe in the BM front end is normally six inches in diameter and increases to eight inches in diameter at the location of the window outside the ratchet wall. The large size of this vacuum line (unlike that for the ID front ends) coupled with the simpler component designs due to the lower heat loads on the BM line does not afford an intrinsic vacuum delay in the BM front ends. Hence, the large size of the BM vacuum line is used to fashion a delay tank in an unused twometer portion of the vacuum transport by inserting eight baffles with apertures.

Note also thai in the BM front ends, the PBPMs can be located seven meters apart with expected excellent vertical beam position resolution from the two conventional and inexpensive vertical metallic blades used in them. 
The BM front end fixed masks and photon shutters are made of OFHC copper and are ruggedly designed. Extensive analyses followed by prototype tests of the photon shutter using a high power $\mathrm{CO}_{2}$ laser prove that the photon shuiuer can stand up to large thermal loads and heat fluxes far exceeding even the future operational requirements at $300 \mathrm{~mA}$ current of the ring.

A pne imatically actuated double safety shutter is the last element on the BM front end behind the shield wall. The BM safety shutters are the same design as the ID front end safety shutters except they have larger apertures to accommodate the +3 mrad horizontal radiation fan. Unlike the ID front ends, all BM front ends are equipped with double Be windows. Windows are placed in the first optics enclosure (FOE) behind an 8-inch O-ring valve that is used for maintenance purposes.

\section{The Front End Vacuum}

A strict rule applies to all synchrotron vacuum systems: there can be no water/vacuum joints in the beam transport, and all such joints and connections are isolated from the UHV by venting directly to the atmosphere. The direct link between the front end and the ring also dictates an additional engineering rule: the front end vacuum components should be durable, require little maintenance, and be highly reliable. Therefore, complex and unproved engineering practices are shunned. Materials are carefully chosen to function in a UHV environment.

The APS front end vacuum is designed to be a UHV system that is in the same range as the ring vacuum (10-11 Torr ). Therefore, ultimate care is taken to maintain vacuum integrity and quality in the front end so as not to jeopardize the ring vacuum. In the space available, a $170 \mathrm{1} / \mathrm{s}$ ion pump is placed immediately after the exit valve to make sure that the ring side of the front end does maintain ring quality vacuum. On the FOE side, the front end vacuum is separated from the beamline vacuum via a double window in all BM front ends. On the ID front ends, the same is true whenever possible. Otherwise, a differential pump replaces the window in the ID front ends. Thus far at the APS, we have designed and experimented with two different differential pumps. A differential pump made of three in-line $220 \mathrm{l} / \mathrm{s}$ ion pumps with large apertures for undulator/wiggler operation has demonstrated nearly a five decade difference. A second design employing two $220 \mathrm{l} / \mathrm{s}$ inline pumps with a variable (10 to $14 \mathrm{~mm}$ ) vertical and $78 \mathrm{~mm}$ horizontal aperturing has demonstrated nearly a three decade difference in simulated downstream gas loading with excellent time delays over $100 \mathrm{~ms}$. Thus, it is clear that our differential pumps will be able to function very well. Research 
and development is underway to make sure that, with the differential pump operation, the vacuum safety in the front end and hence in the ring is not compromised even under vacuum venting in beamlines. In the months ahead, the requisite vacuum sensing and interlock systems to be used with the differential pump operation will be completely tested until we are convinced that the APS front ends can operate safely in a windowless configuration. This would give the users full use of the most brilliant and powerful ID beams. Figure 19 is the ID front end configuration with the differential pump operation. Note that the filter box is replaced by a short spool piece in this windowless operation.

The APS ID front end vacuum pumping calculations show god pumpdown characteristics. Adequate ion pumps standardized at the $170 \mathrm{l} / \mathrm{s}$ size supplemented with removable NEG pumps (at $600 \mathrm{l} / \mathrm{s}$ ) „ave been provided in all front ends.

\section{Power Load Limits and Design Requirements}

This section provides a general overview of total power (Watts) and power density (Watts per unit solid angle) of various APS sources and the incident heat flux (Watts per unit area) on different front end components. It also examines their significance in the thermal and structural aspects of the front end component design.

A major challenge in the engineering of the front end components for high power ID-based synchrotron radiation facilities is the ability to keep the thermally induced stresses and deformations in the component materials within the accepted safety limits. While the total power imposed by the $x$-ray beam on a given component is of serious consequence, it is often the peak power density associated with the beam's profile that sets up thermal gradients in the material causing excessive thermal stresses and deformations. Table 1 lists the total power, peak power density, and the resulting heat fluxes on the critical front end component for the planned sources of the APS in the first phase. In this phase, the stored positron current is $100 \mathrm{~mA}$, and most of the insertion devices are 2.4 meters long. Wiggler $A$ and Undulator A combine very high peak fluxes with very large total power. For example, at the location of the first photon shutter (PS1), the peak heat fluxes at normal incidence are 469 $\mathrm{W} / \mathrm{mm}^{2}$ and $223 \mathrm{~W} / \mathrm{mm}^{2}$ with total power of $3.8 \mathrm{~kW}$ and $7.4 \mathrm{~kW}$, respectively. Such heat fluxes are unprecedented and even exceed those encountered in rocket nozzles or in fusion reactors. The tools available to the design engineers and analysts to handle such large heat loads are a combination of the following: designing the heat load out by altering the geometry (use of grazing angles), use of the most effective cooling techniques (enhancement of 
the convective heat transfer coefficient in single phase heat transfer), and the use of structurally strong heat sink materials (Glidcop, Be, diamond, unisotropic carbon materials, cubic boron nitrates, etc.).

Fortunately, the front end components that are directly exposed to the $\mathrm{x}$-ray beam, such as the fixed masks and photon shutters, can be designed to intercept the beam at grazing angles (1.5 to 3 degrees). Likewise, the beam position monitor blade edges can be set to the beam at shallow angles (10 to 20 degrees). The APS front end fixed masks and the photon shutters are designed to receive $15-20 \mathrm{~W} / \mathrm{mm}^{2}$ peak heat flux levels on their surfaces. In addition, employing a highly enhanced heat transfer technique developed at the APS (brazed porous copper mesh in cooling channels) with single phase water cooling, the maximum surface temperatures are kept at $<200^{\circ} \mathrm{C}$. The enhanced convective heat transfer coefficient attained is usually $3 \mathrm{~W} / \mathrm{cm}^{2} \mathrm{~K}$ or higher at modest water flow rates (the flow velocity is usually at about 1-1.5 $\mathrm{m} / \mathrm{s}$ range). Even under these favorable conditions, the resulting thermal gradients in the fixed masks and the photon shutters give rise to appreciable thermal stresses, which are usually over $240 \mathrm{MPa}$ and should be compared with the published yield strength of $400 \mathrm{MPa}$ for special high strength copper such as Glidcop. More powerful x-ray beams (generated, for example, by higher ring energy or particle beam current) will necessitate additional ingenuity in solving the thermo-mechanical problems of fixed masks and photon shutters. The heat flux and the linear power density (which is found by dividing the total power by the horizontal extent of the beam) of the APS sources are known to be 4-5 fold higher than any contemporary synchrotron sources including the ESRF. The linear power density is the more meaningful measure of the resulting severity of the thermal stresses in components such as filters and windows, which are conduction limited. The linear power density from the APS undulators (at closed gap) is about three times higher than that for any other synchrotron source.

In summary, it seems fair to say that the heat flux and power levels generated by APS IDs are the highest that can currently be managed, and substantial changes both in concept and design will be necessary to accommodate more powerful sources. 


\section{References}

[1] G. K. Shenoy et al., "Status of Advanced Photon Source Project," The International Symposium on X-Ray Synchrotron Radiation and Advanced Science \& Technology, The Institute of Physical and Chemical Research (RIKEN), Japan Atomic Energy Research Institute (JAERI), Feb. 1990.

[2] D. Shu, J. Barraza, T. Sanchez, R. W. Nielsen, J. T. Collins, and T. M. Kuzay, "Front End Designs for the 7-GeV Advanced Photon Source," Nucl. Instrum. Meth. Phys. Res. A319 (1992) 63-70.

[3] G. K. Shenoy, P. J. Viccaro, and D. M. Mills, "Characteristics of the 7GeV Advanced Photon Source: A Guide for Users," APS Report, ANL-88-9, Feb. 1988.

[4] Private communication, $\mathrm{S}$. $\mathrm{Xu}$, unpublished study of ray tracing of the APS sources, APS/ANL, 1992.

[5] D. Shu, B. Rodricks, J. Barraza, T. Sanchez, and T. M. Kuzay, "The APS $\mathrm{X}$-Ray Undulator Photon Beam Position Monitor and Tests at CHESS and NSLS," Nucl. Instrum. Meth. Phys. Res. A319 (1992) 56-62.

[6]. Z. Wang, D. Shu, A. M. Khounsary, and T. M. Kuzay, "Thermal and Stress Analysis of Beamline Position Monitors for the 7-GeV Advanced Photon Source," PVP - Vol. 231, Fluid-Structural Interaction, Transient Thermal-Hydraulics, and Structural Mechanics, Editors: C. Y. Wang, F. J. Moody, and Y. W. Shin, Book No. G00666-1992, pp. 97-103.

[7] Z. Wang, "'Tnermal Behaviour of BPM Support Column," XFD/APS Memo, June, 1991.

[8] T. M. Kuzay, Fixed Mask Assembly Research for APS Insertion Devices, ANL-90/20, Jan. 1990. 
[9] H. L. T. Nian, T. M. Kuzay and I. C. A. Sheng, "Thermo-Mechanical Parametric Studies of Fixed Mask 1 and Photon Shutter 2 for APS Front Ends," APS Light Source Note LS-208, Sept. 1992.

[10] H. L. T. Nian, T. M. Kuzay and I. C. A. Sheng, "Therrno-Mechanical Optimization of Fixed Mask 2 for APS Front Ends," APS Light Source Note LS-204, July 1992.

[11] T. M. Kuzay, J. T. Collins, A. M. Khounsary, and G. Morales, "Enhanced Heat Transfer With Metal-Wool-Filled Tubes," Proc. ASME/JSME Joint Conf., Book No. I0309E-1991, pp.451-459.

[12] H. L. T. Nian, T. M. Kuzay and I. C. A. Sheng, "Thermo-Mechanical Optimization of Photon Shutter 1 for APS Front Ends," APS Light Source Note LS-205, July 1992.

[13] H. L. T. Nian, I. C. A. Sheng, and T. M. Kuzay "Thermal Analysis of a Photon Shutter for APS Front Ends," Nucl. Instrum. Meth. Phys. Res. A319 (1992) 197-206.

[14] Z. Wang, D. Shu, and T. M. Kuzay, "Vibration Analysis of the Photon Shutter Designed for the Advanced Photon Source," Nucl. Instrum. Meth. Phys. Res. A319 (1992) 71-76.

[15] H. L. T. Nian, XFD/APS Memo, Thermo-Mechanical Analysis of the Front End Photon Shutter 1 for Various Insertion Devices, Oct. 1992.

[16] D. Shu, T. Sanchez, and T. M. Kuzay, "An Integrated Bremsstrahlung Safety Shutter and Collimator Designed for the APS Front Ends Operating in the Top-up Mode," APS Light Source Note LS-192, April 1992.

[17] Nisy Ipe, personal communication, "Shielding Calculations," SLAC memo, Cot 20,1992

[18] Z. Wang, XFD/APS Memo, Thermal and Structural Analyses of Filter and Window Assembly and Comparison with Experimental Data, Sept. 1992. 
[19] A. M. Khounsary, P. J. Viccaro, and T. M. Kuzay, "Filter and Window Assemblies for High Power Insertion Device Synchrotron Radiation Sources," SPIE Vol. 1345, Advanced X-Ray/EUV Radiation Sources and Applications (1990), 42-54.

[20] A. M. Khounsary, and T. M. Kuzay, "On Diamond Windows for High Power Synchrotron X-ray Beams," Nucl. Instrum. Meth. Phys. Res. A319 (1992) 233-239. 


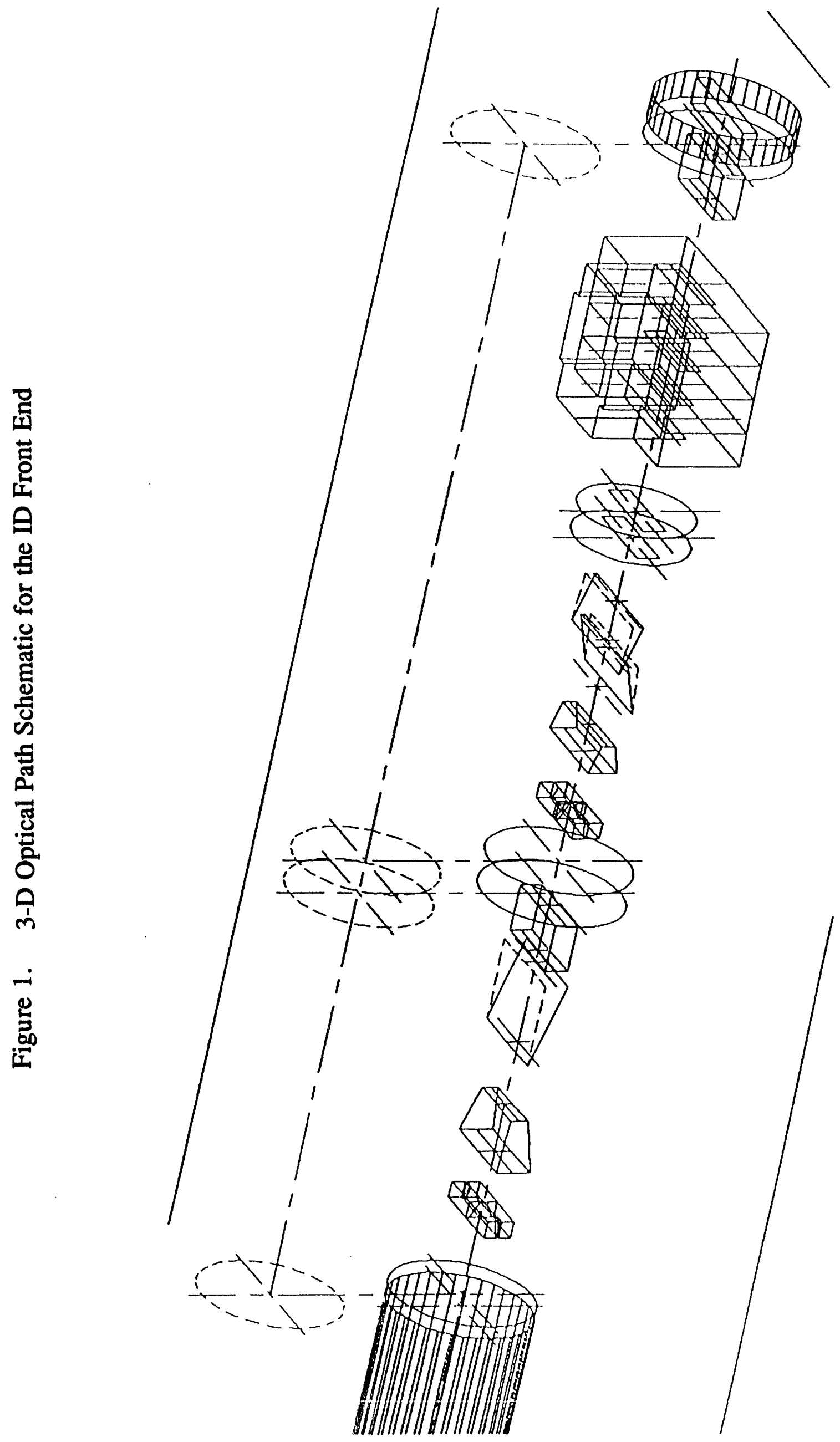




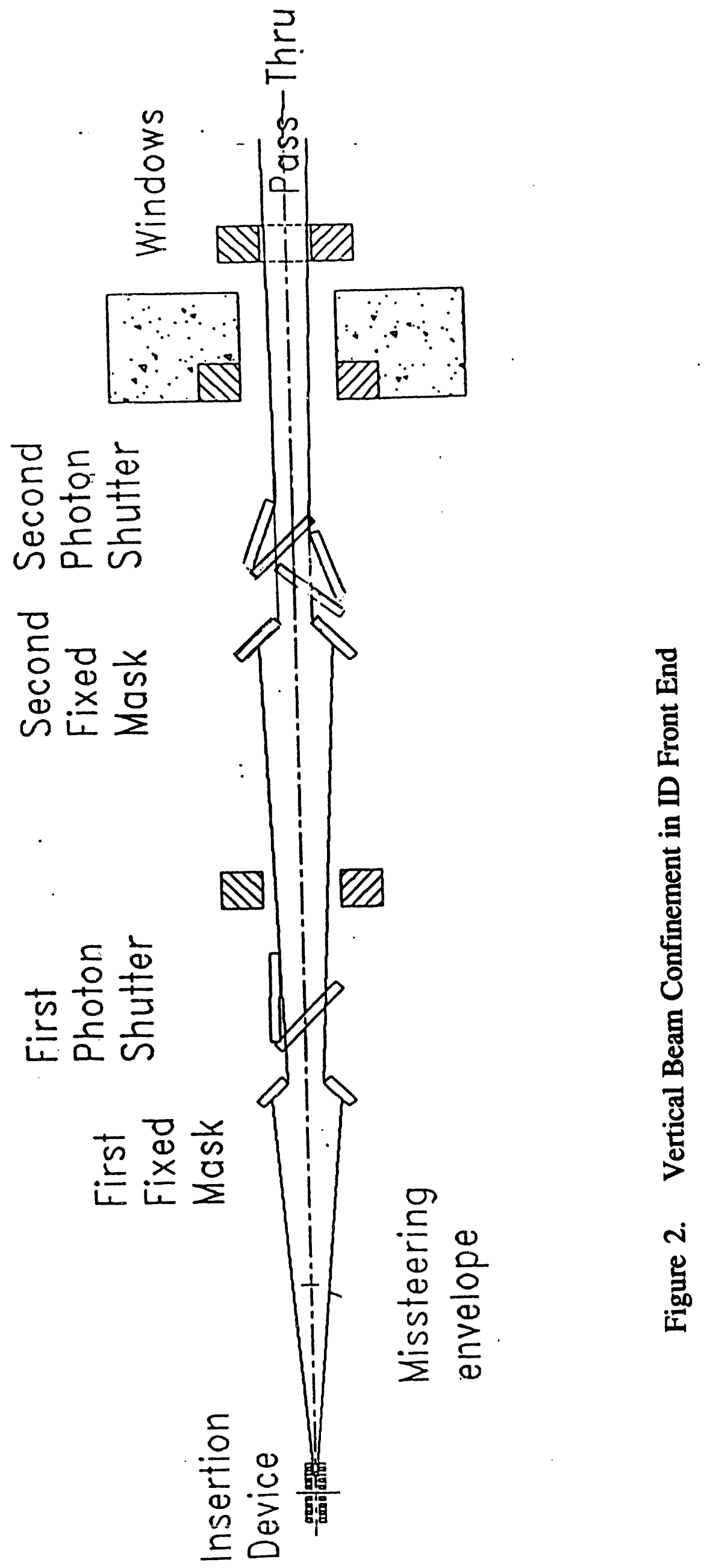



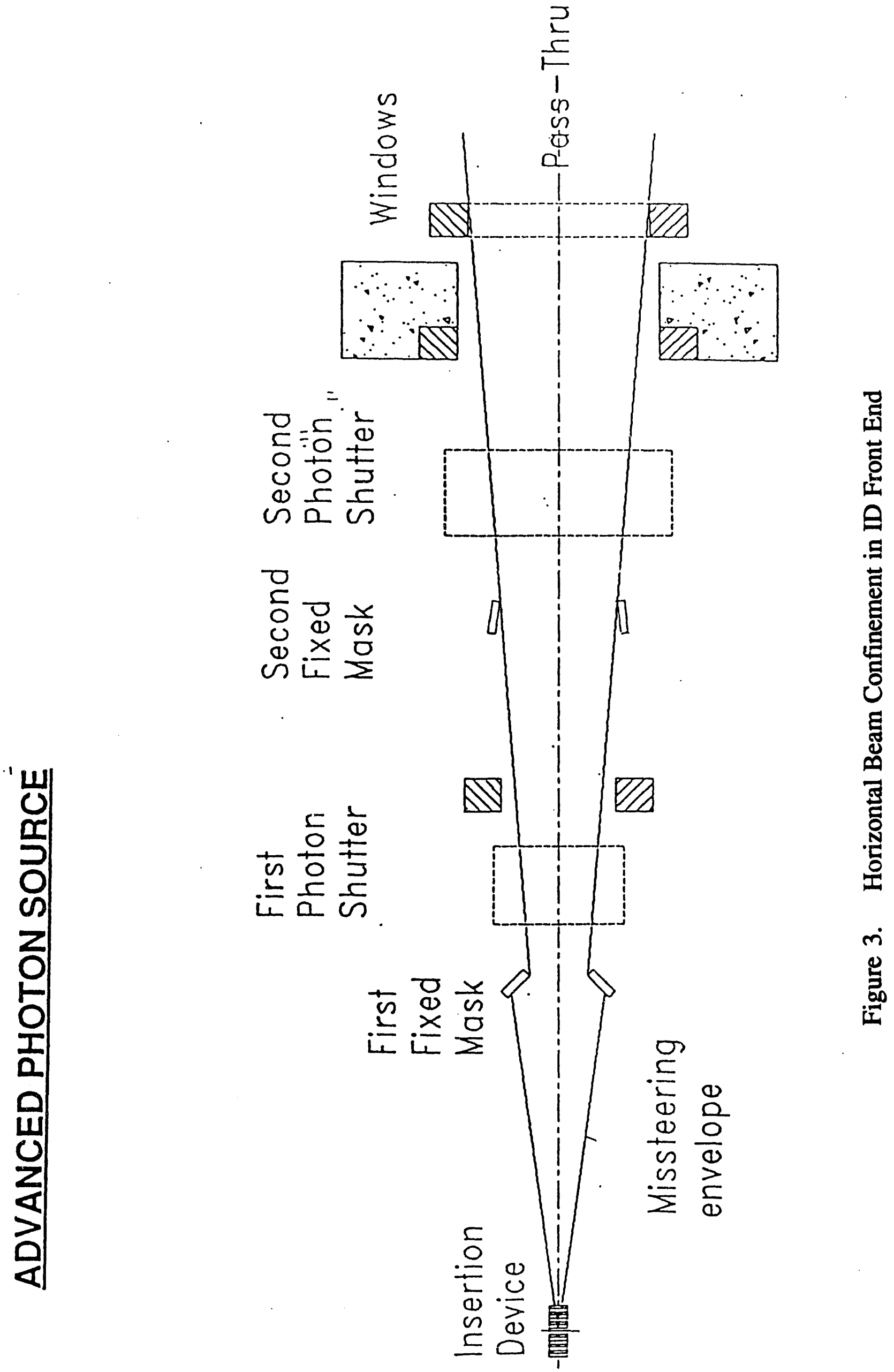


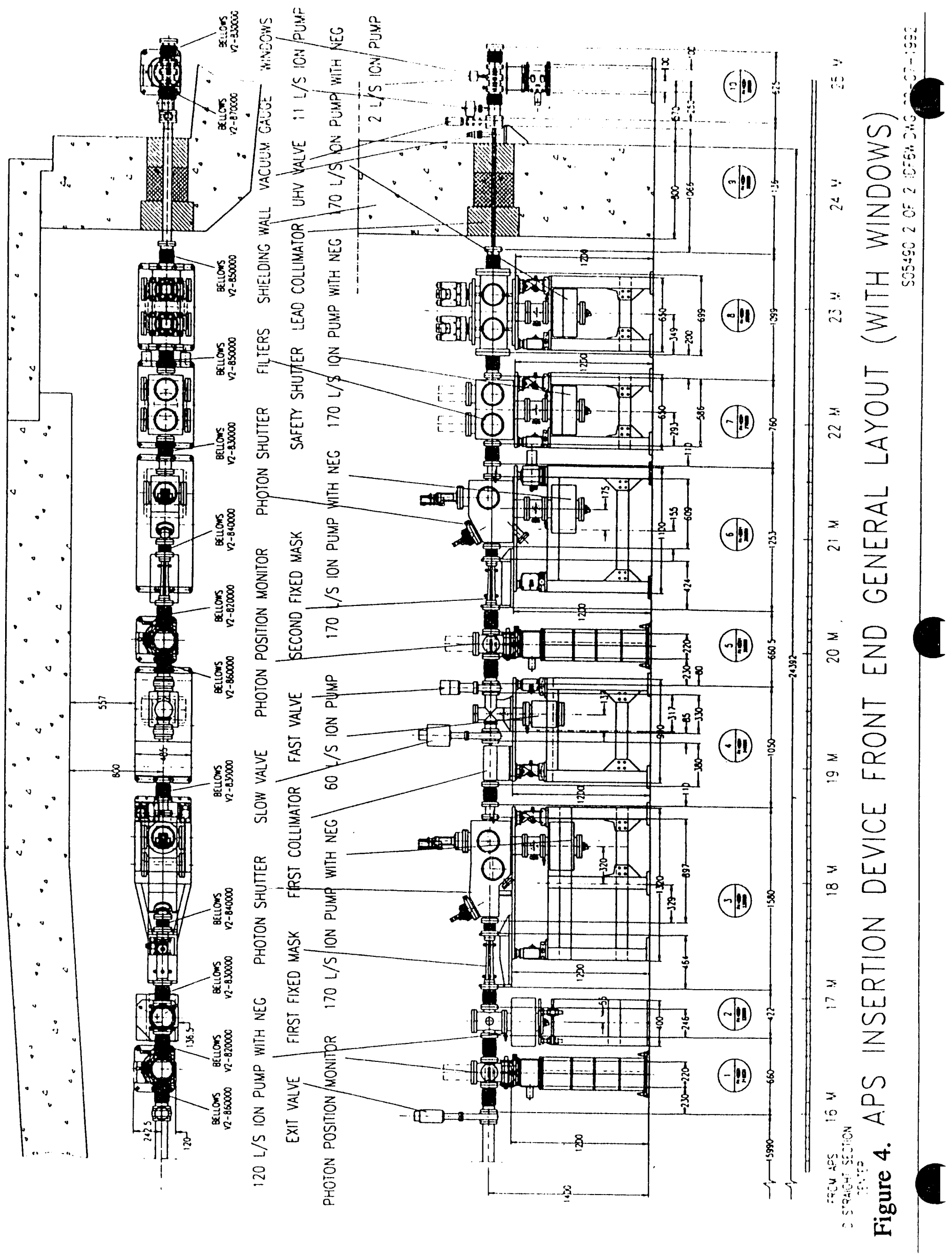


APSD10:[XUS.SHADOW]SCREEN.0101
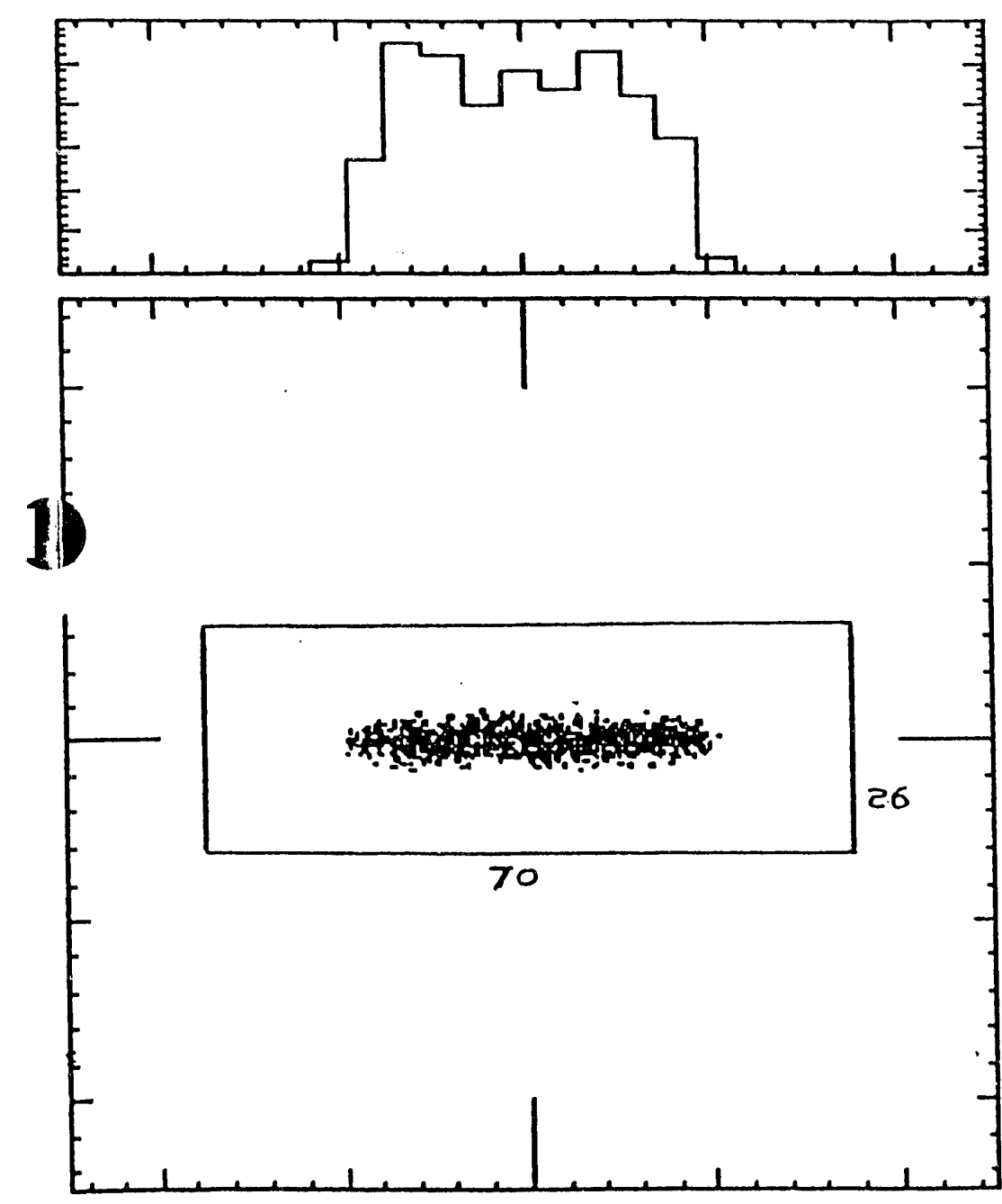

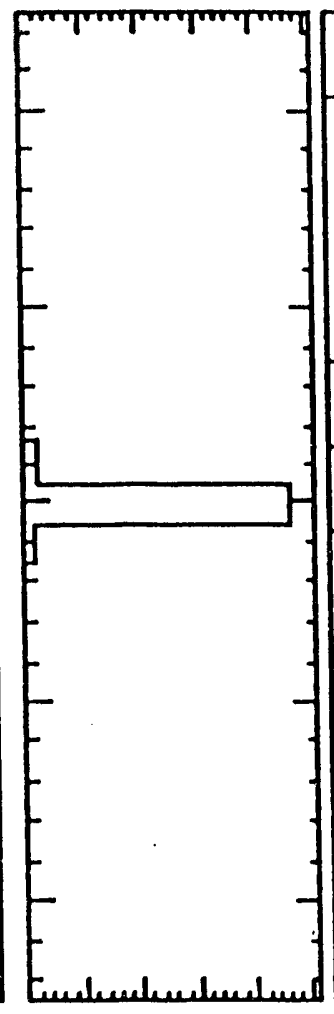

1-NOV-92 10:12:22

$H$ Length 10.000

H center $0.00000 \mathrm{E}+00$

$V$ Longth 10.000

$V$ conter $0.00000 E+00$

EXTERNAL

--GOOD ONLY

TOT - 1000

LOST $=0$

Horizontal: 1

Vortical:

3

Figure 5a. SHADOW ray tracing for BPM1 of the ID front end 
APSD10:[XUS.SHADOWISCREEN.0102
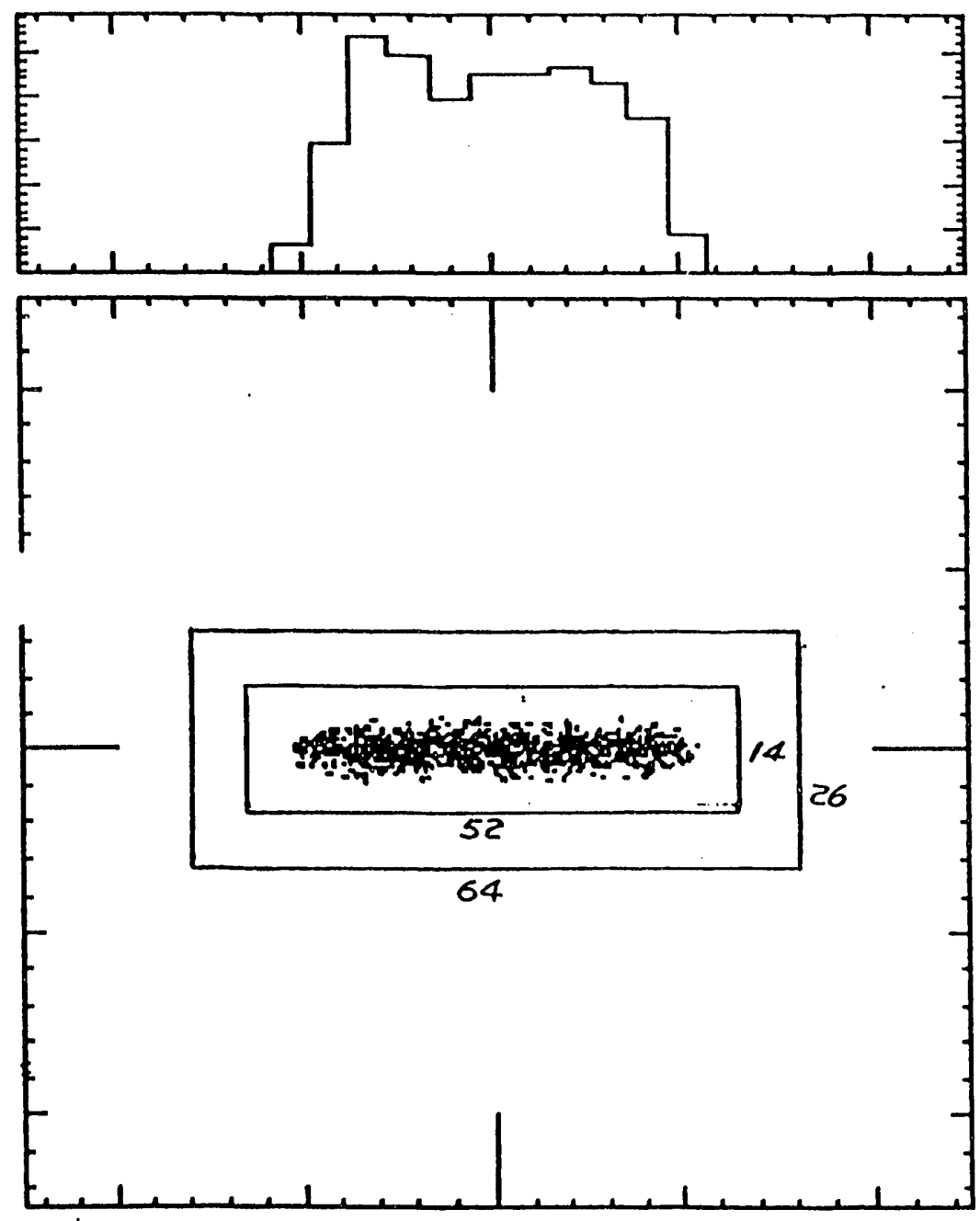

1-NOV-1982 10:01

FM1 at $10.755 \mathrm{~m} 52 \times 14$ $\mathrm{mm} \quad 64 \times 26 \mathrm{~mm}$

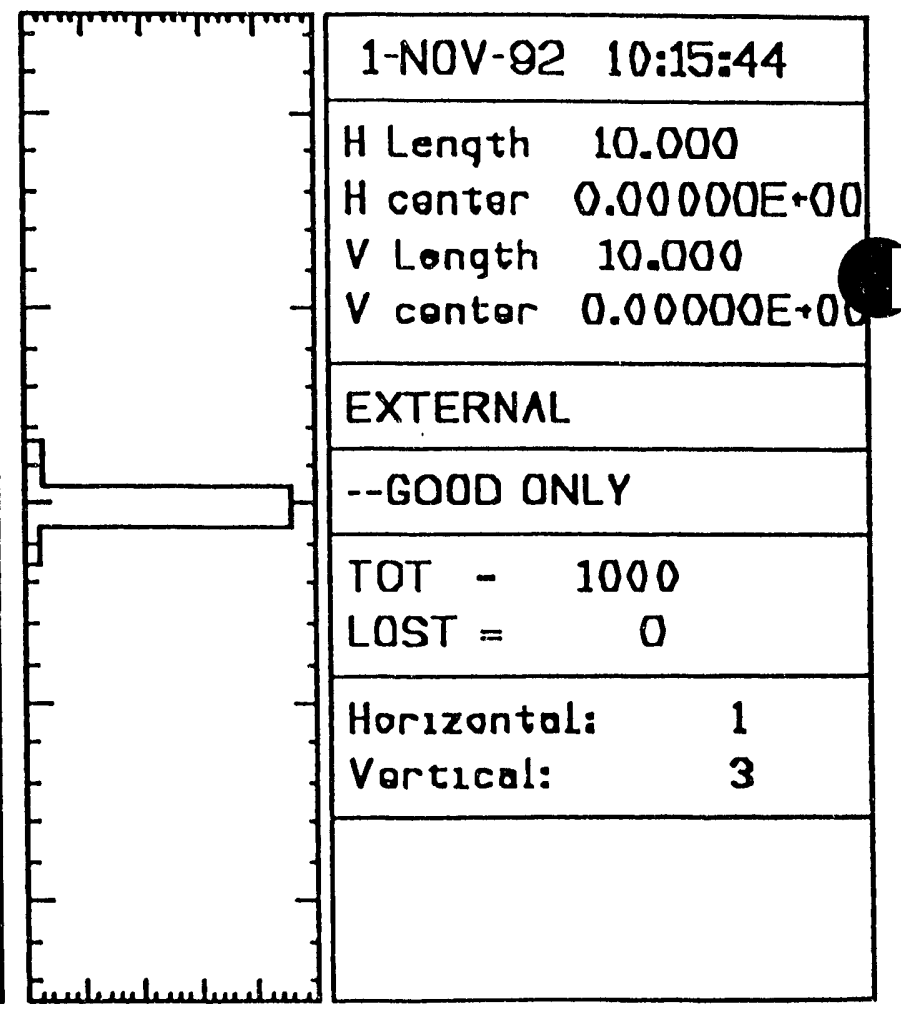

Figure 5b. SHADOW ray tracing for FM1 of the ID front end 
APSDI0:IXUS.SHADOWISCREEN.0103

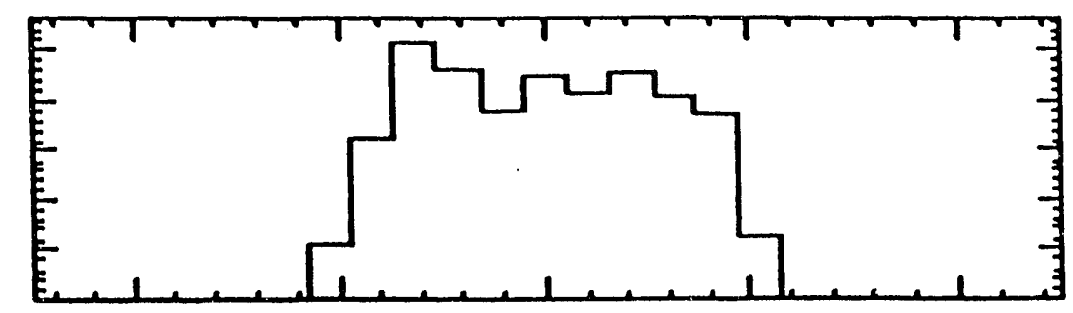

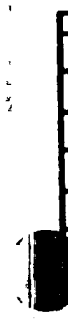

1-NOV-10日2 10:01

PS1 at $20.532 \mathrm{~m} 70 \times 1$

$6 \mathrm{~mm}$
1-NOV-92 10:18:02

$H$ Length 10.000 $H$ center $0.00000 E+00$ $V$ Longth 10.000 $V$ conter $0.00000 E+00$

EXTERNAL

--GOOD ONLY

TOT - 1000

LOST $=0$

Horizontali 1

Vortzcal:

Figure 5c. SHADOW ray tracing for PS1 of the ID front end 


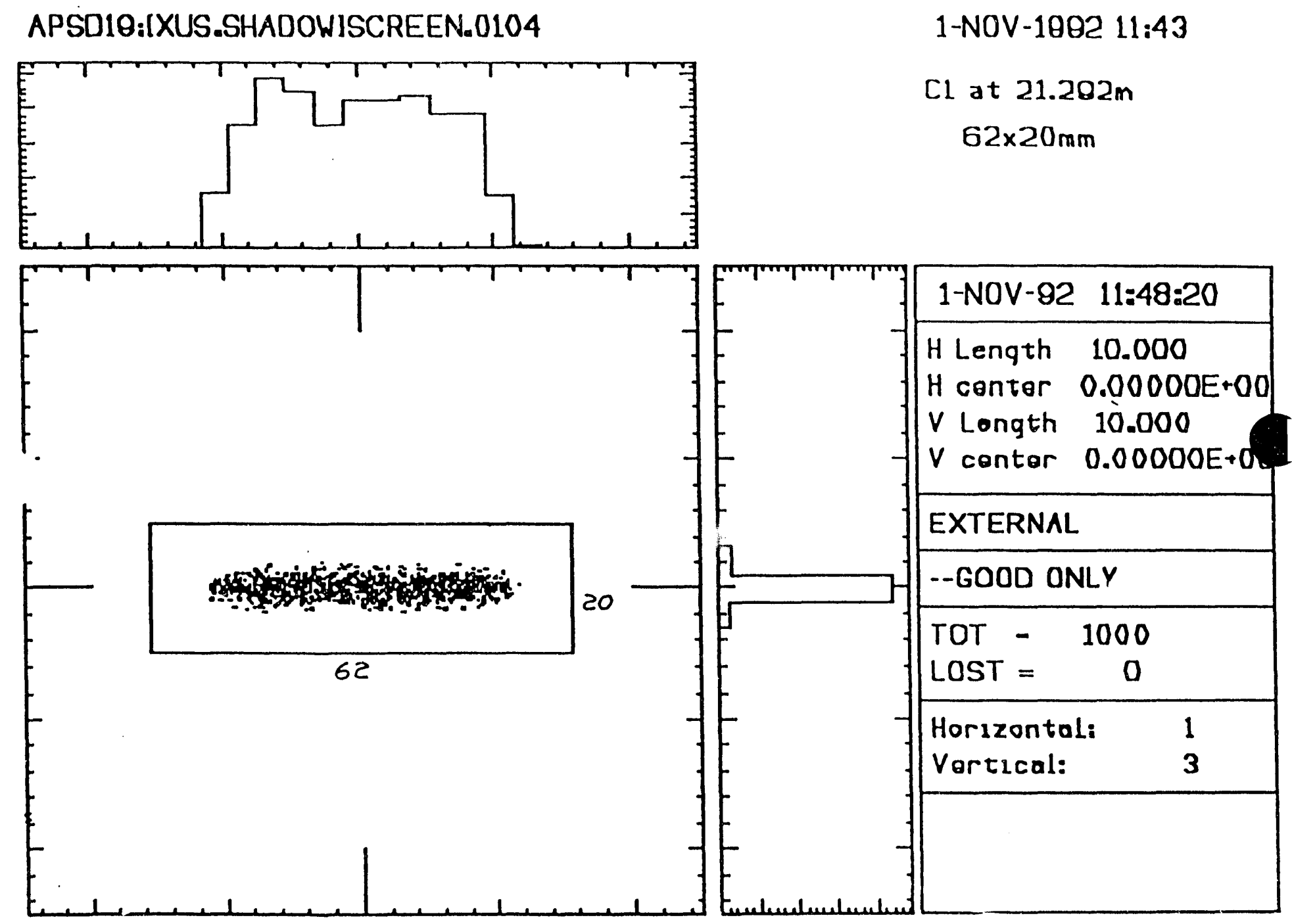

Figure 5d. SHADOW ray tracing for Collimator 1 of the ID front end 
APSDIO:XXUS.SHADOWISCREEN.0104
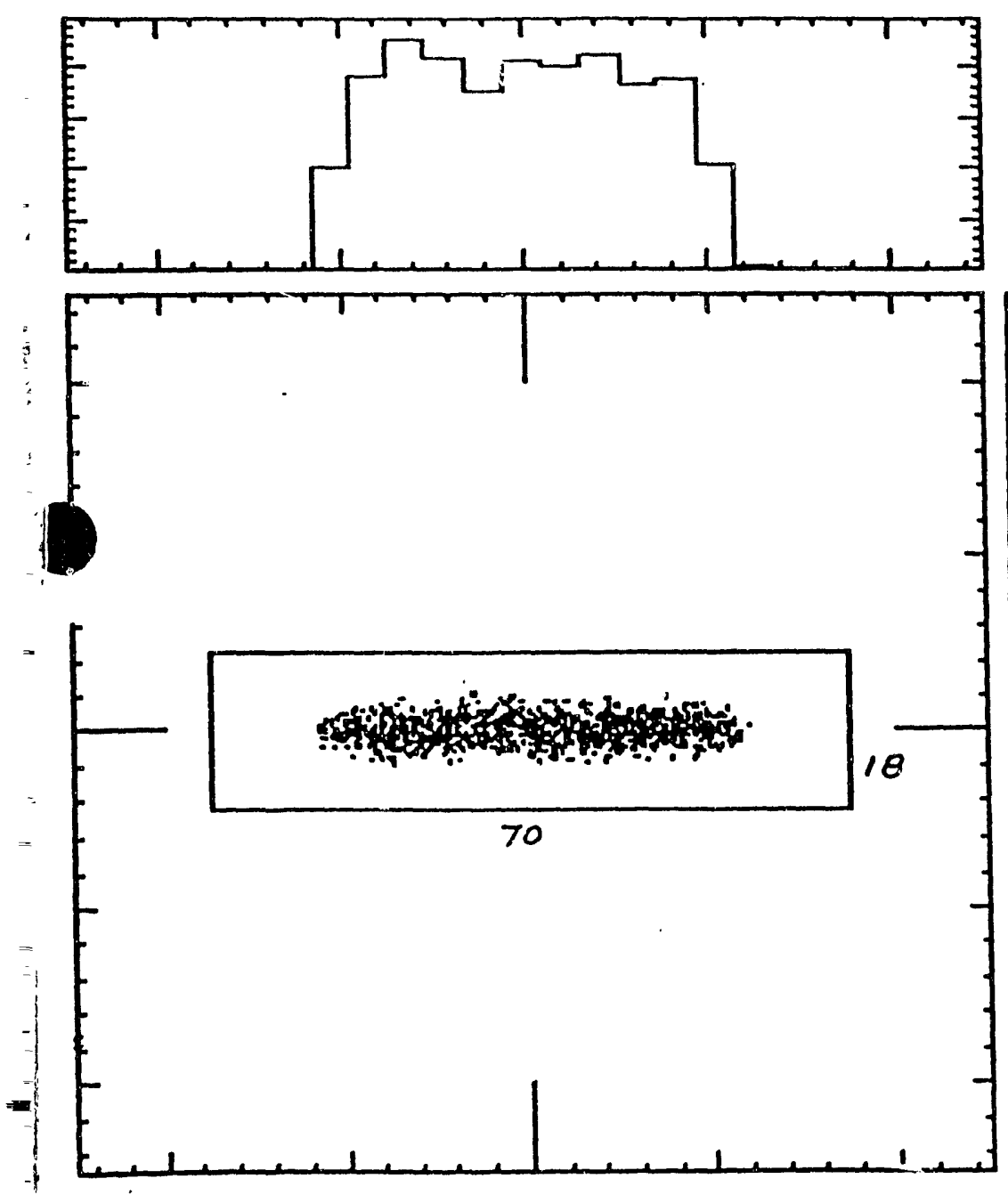

Figure 5e. SHADOW ray tracing for FV of the ID front end
1-NOV-18日2 10:01

FV at $21.046 \mathrm{~m} 70 \times 18$ $\mathrm{mm}$

1-NOV-82 10:40:33

$H$ Length 10.000 H conter 0.00000E+00 $V$ Longth 10.000 $V$ contar $0.00000 E+00$

EXTERN \% $S$

--Godo OPSY

TOT - 1000 LOST $=0$ Horizontal: 1 Vortical: $\quad 3$ 
APSD10:[XUS.SHADOW]SCREEN_0105
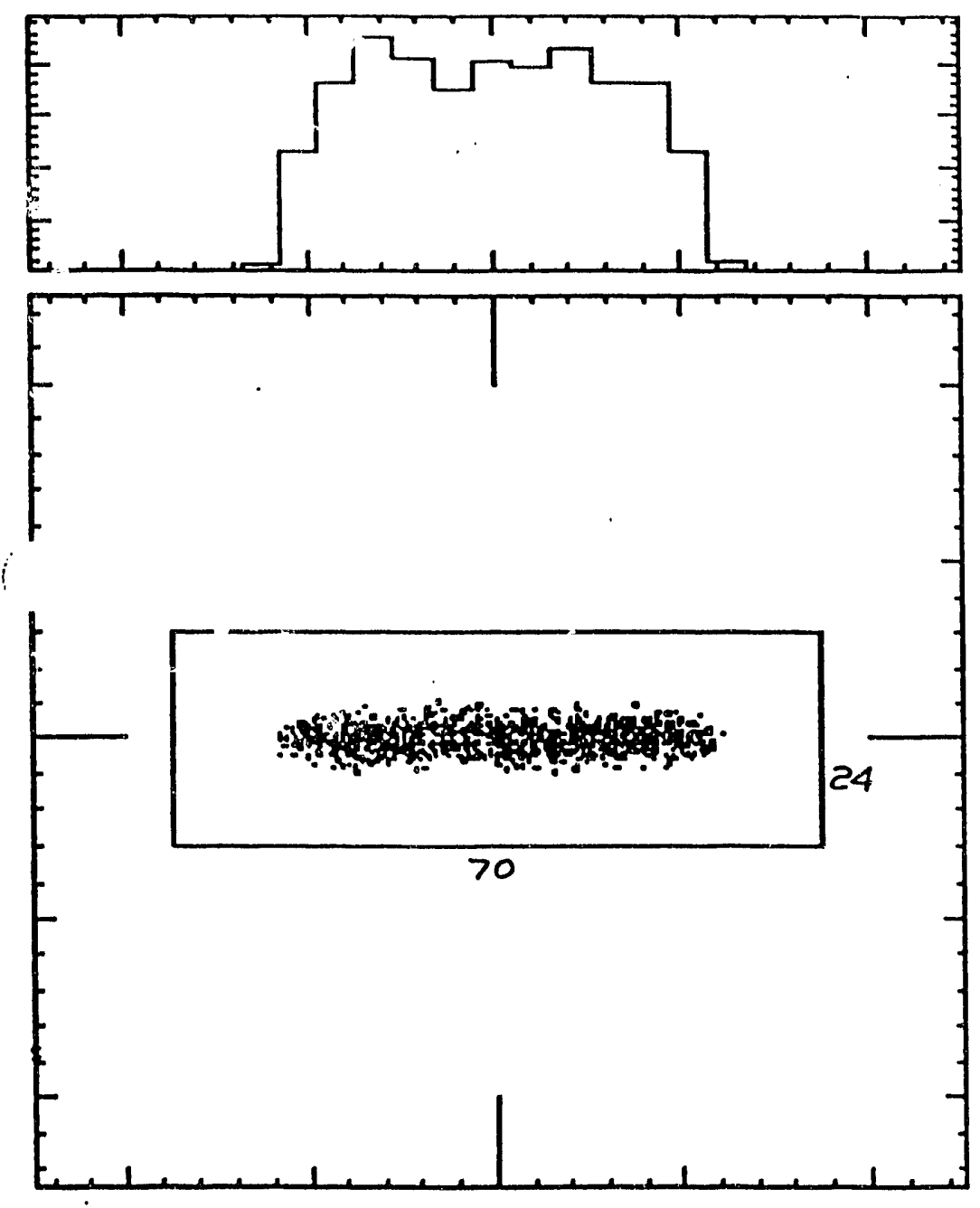

Figure 5f. SHADOW ray tracing for BPM 2 of the ID front end
1-NOV-1892 10:01

BPM2 at $22.365 m 70 \times 2$ $4 \mathrm{~mm}$

1-NOV-92 10:48:42

$H$ Length 10.000

$H$ center $0.00000 E+00$

$V$ Longth 10.000

$V$ contor $0.00000 E+0$

EXTERNAL

--GOOD ONLY

TOT - 1000

LOST $=0$

Horizontal: 1

Vortical: $\quad 3$ 
APSOI0:IXUS.SHADOWISCREEN.0106
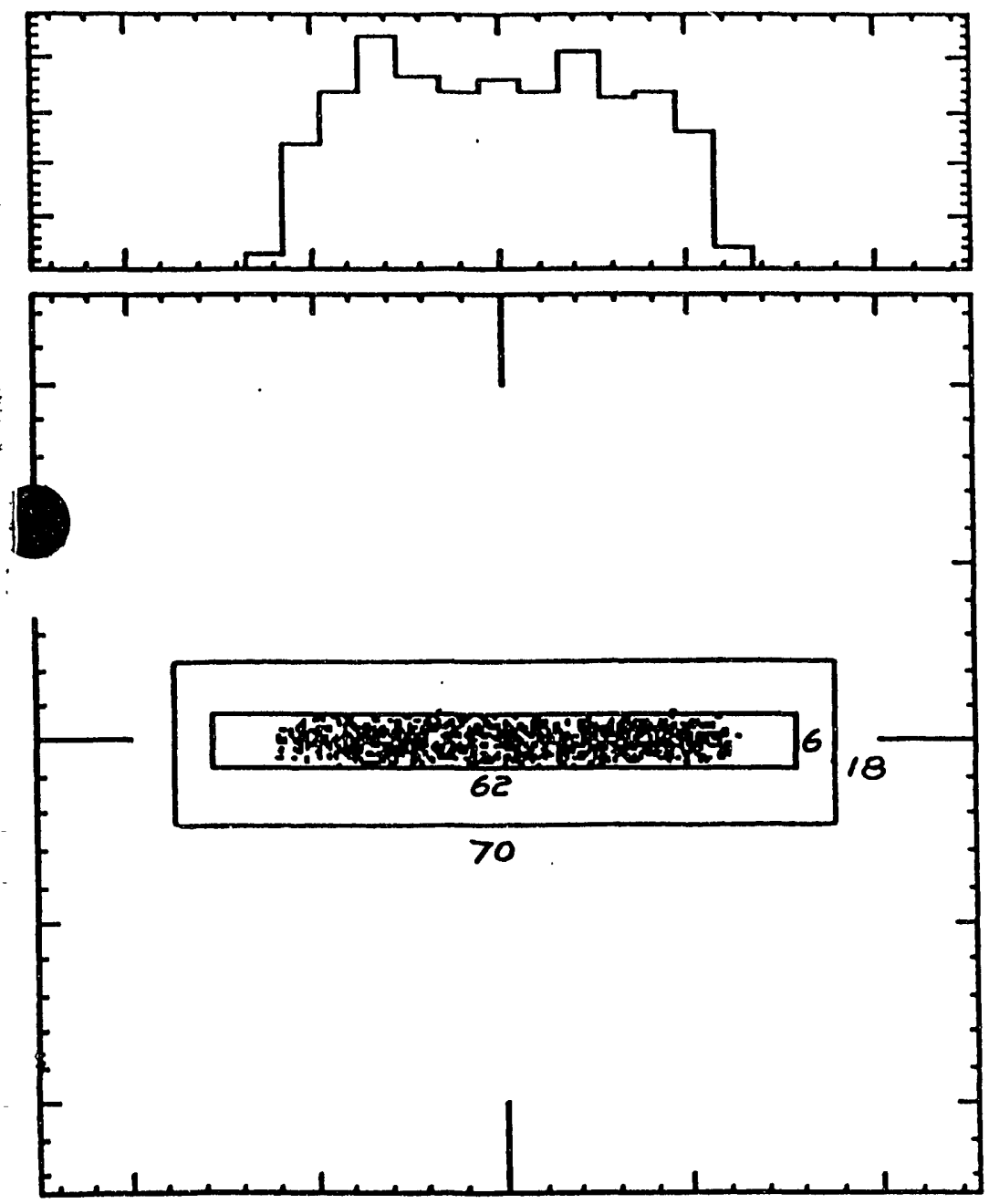

1-NOV-1982 10:01

FM2 at $23.049_{m} 62 \times 6 m$

m $70 \times 18 \mathrm{~mm}$
1-NOV-92 10:52:24

$H$ Length 10.000

H center 0.00000E+00

$V$ Longth 10.000

$V$ contor $0.00000 E+00$

\section{EXTERNAL}

--GOOD ONLY

TOT - 1000

LOST $=\quad 44$

Horizontal: 1

Vortical: $\quad 3$

Figure 5g. SHADOW ray tracing for FM 2 of the ID front end 
APSD10:IXUS.SHADOWISCREEN.0107
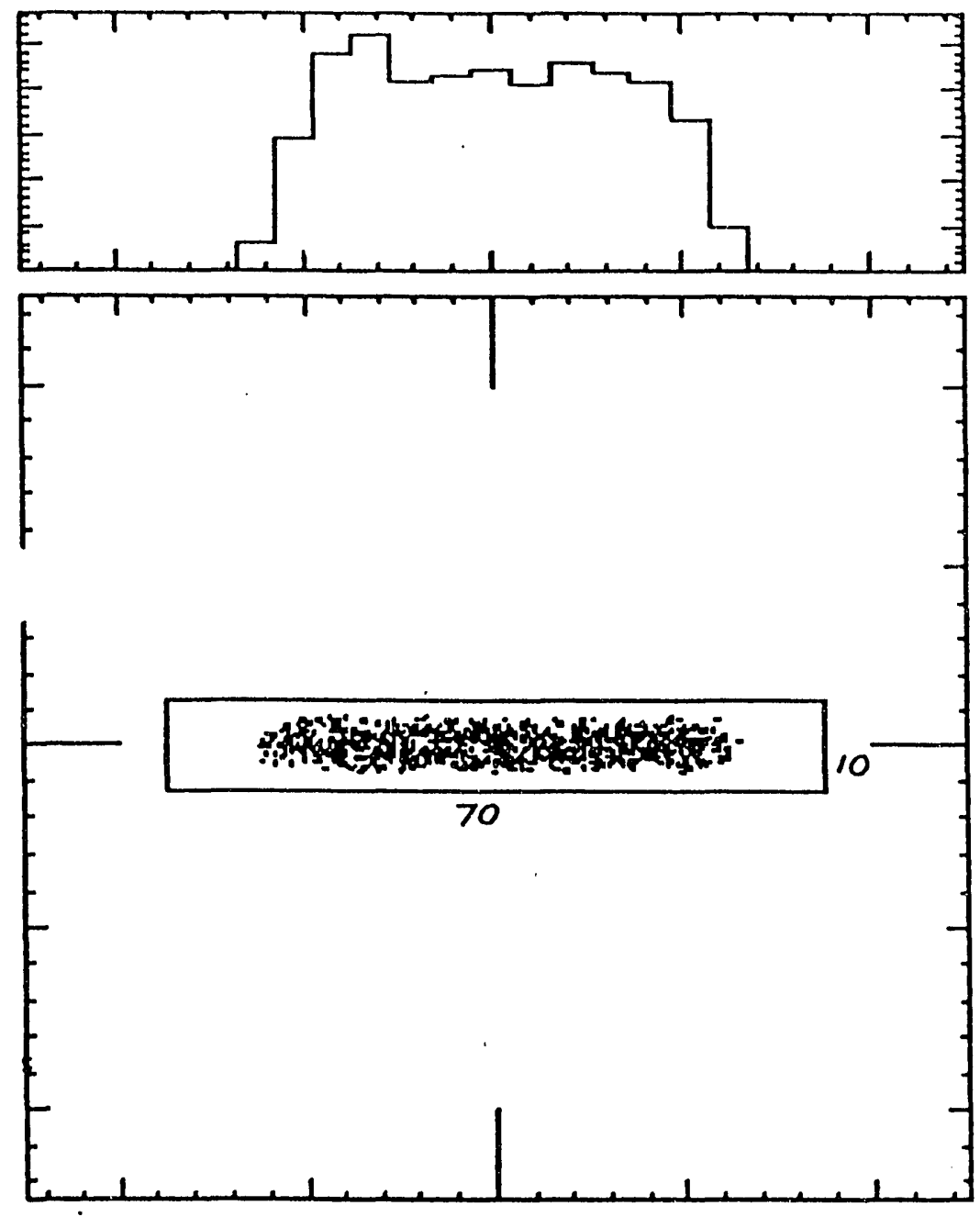

1-NOV-1982 10:01

PS2 at $23.848 m 70 \times 10$ $\mathrm{mm}$

\begin{tabular}{|c|c|c|}
\hline$\cdot$ & \multicolumn{2}{|c|}{$1-N 0 V-92 \quad 10: 55: 03$} \\
\hline & \multicolumn{2}{|c|}{$\begin{array}{l}H \text { Length } 10.000 \\
H \text { center } 0.00000 E+00 \\
V \text { Longth } 10.000 \\
V \text { center } 0.00000 E+00\end{array}$} \\
\hline & \multicolumn{2}{|l|}{ EXTERNAL } \\
\hline & \multicolumn{2}{|c|}{--GOOD ONLY } \\
\hline & \multicolumn{2}{|c|}{$\begin{array}{lr}\text { TOT }= & 1000 \\
\text { LOST }= & 44\end{array}$} \\
\hline & \multicolumn{2}{|l|}{$\begin{array}{l}\text { Horizontal: } \\
\text { Vortical: }\end{array}$} \\
\hline & & \\
\hline
\end{tabular}

Figure 5h. SHADOW ray tracing for PS 2 of the ID front end 
APSD10:[XUS.SHADOWISCREEN_0108
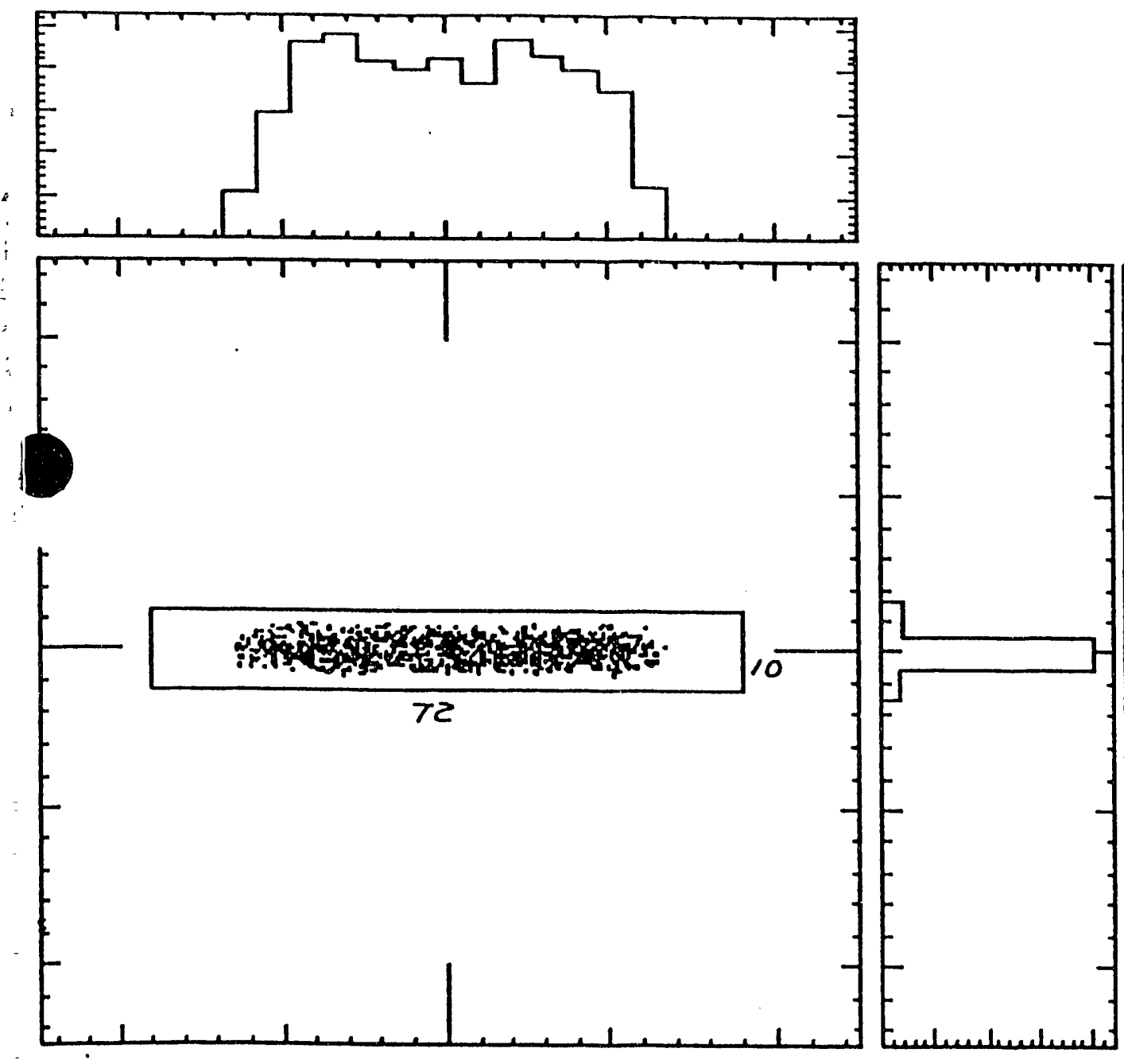

1-NOV-1982 10:01

FL at $24.675 \mathrm{~m} 72 \times 10 \mathrm{~m}$

m

1-NOV-92 11:00:11

$H$ Length 10.000

$H$ center $0.00000 E+00$

$V$ Longth 10.000

$V$ center $0.00000 E+00$

EXTERNAL

--GOOD ONLY

TOT - 1000

LOST $=44$

Horizontal: 1

Vortical: $\quad 3$

Figure 5i. SHADOW ray tracing for filter assembly of the ID front end 
APSD10:IXUS.SHADOWISCREEN.0100
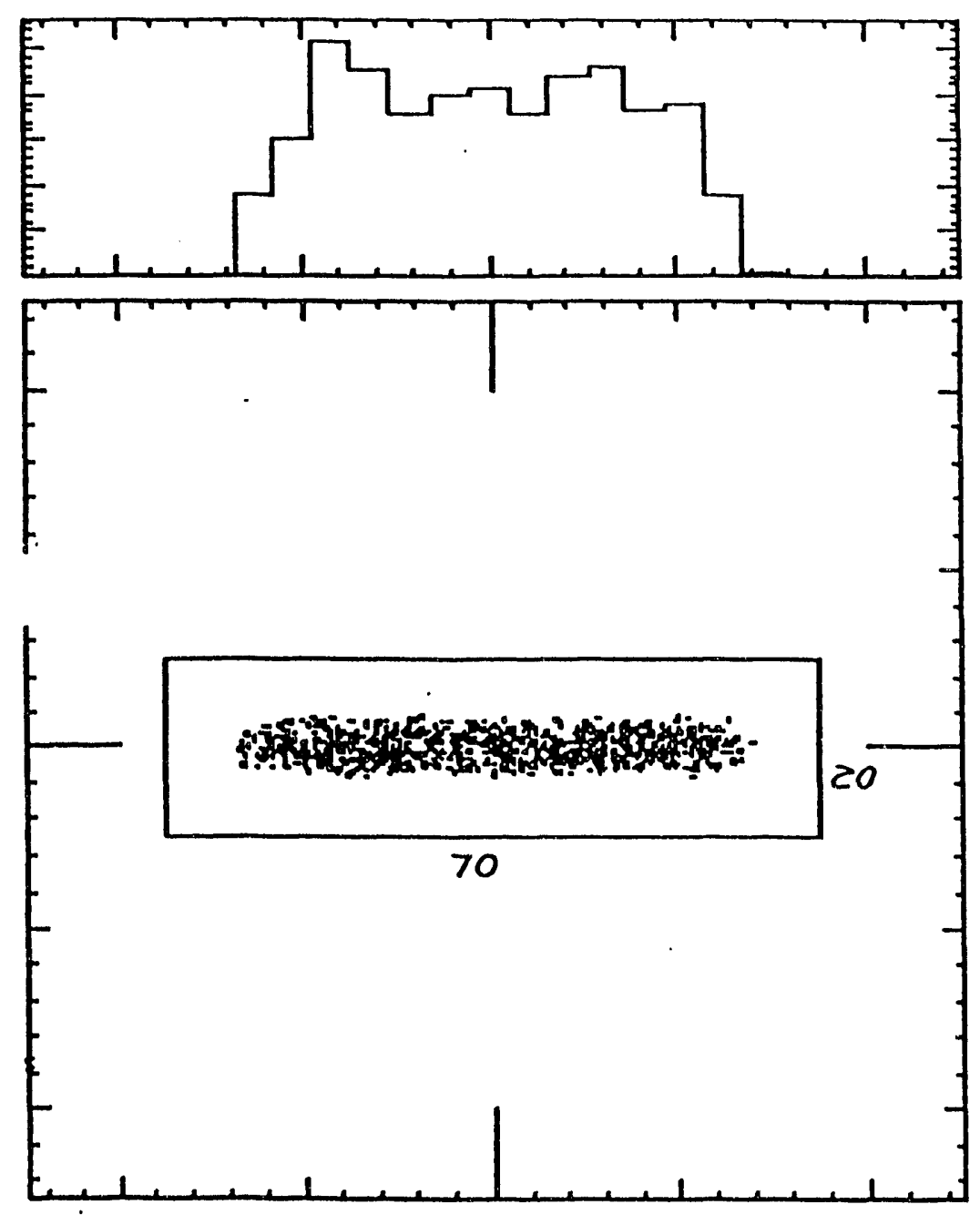

1-NOV-1082 10:01

SS at $25.764 \mathrm{~m} 70 \times 20 \mathrm{~m}$ m

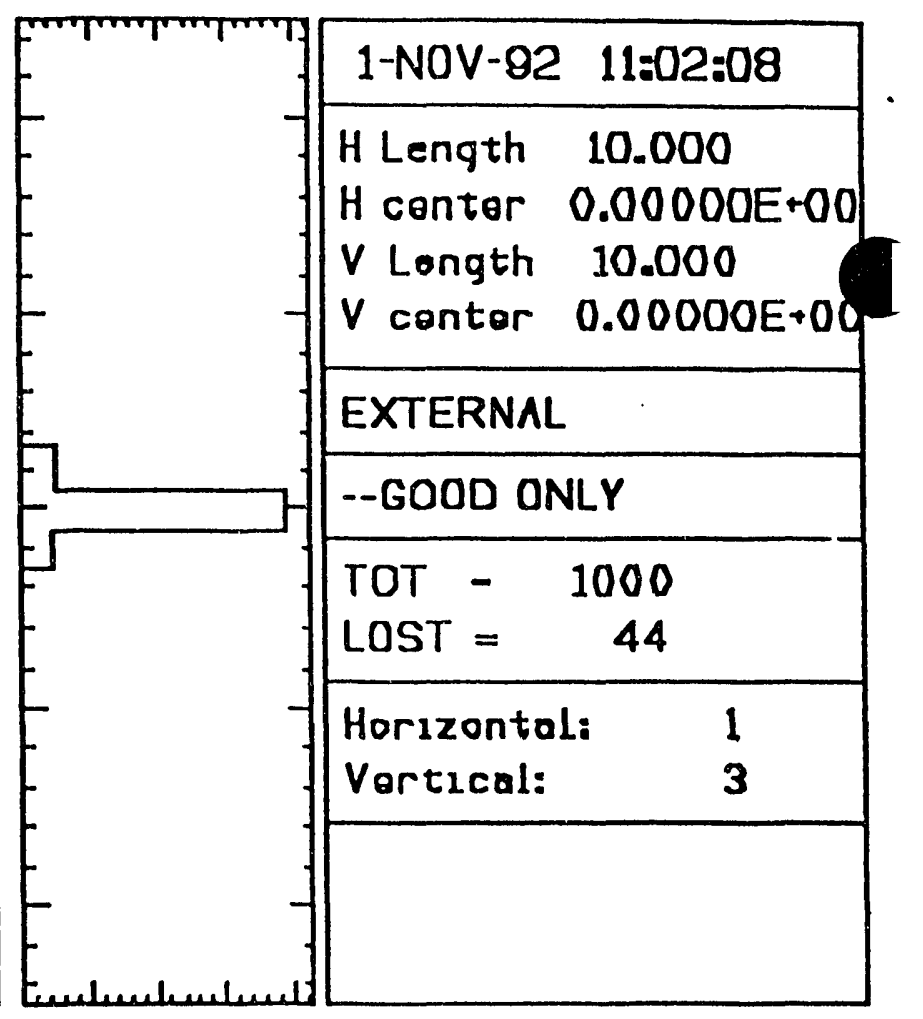

Figure 5j. SHADOW ray tracing for safety shutter/collimator of the ID front end 


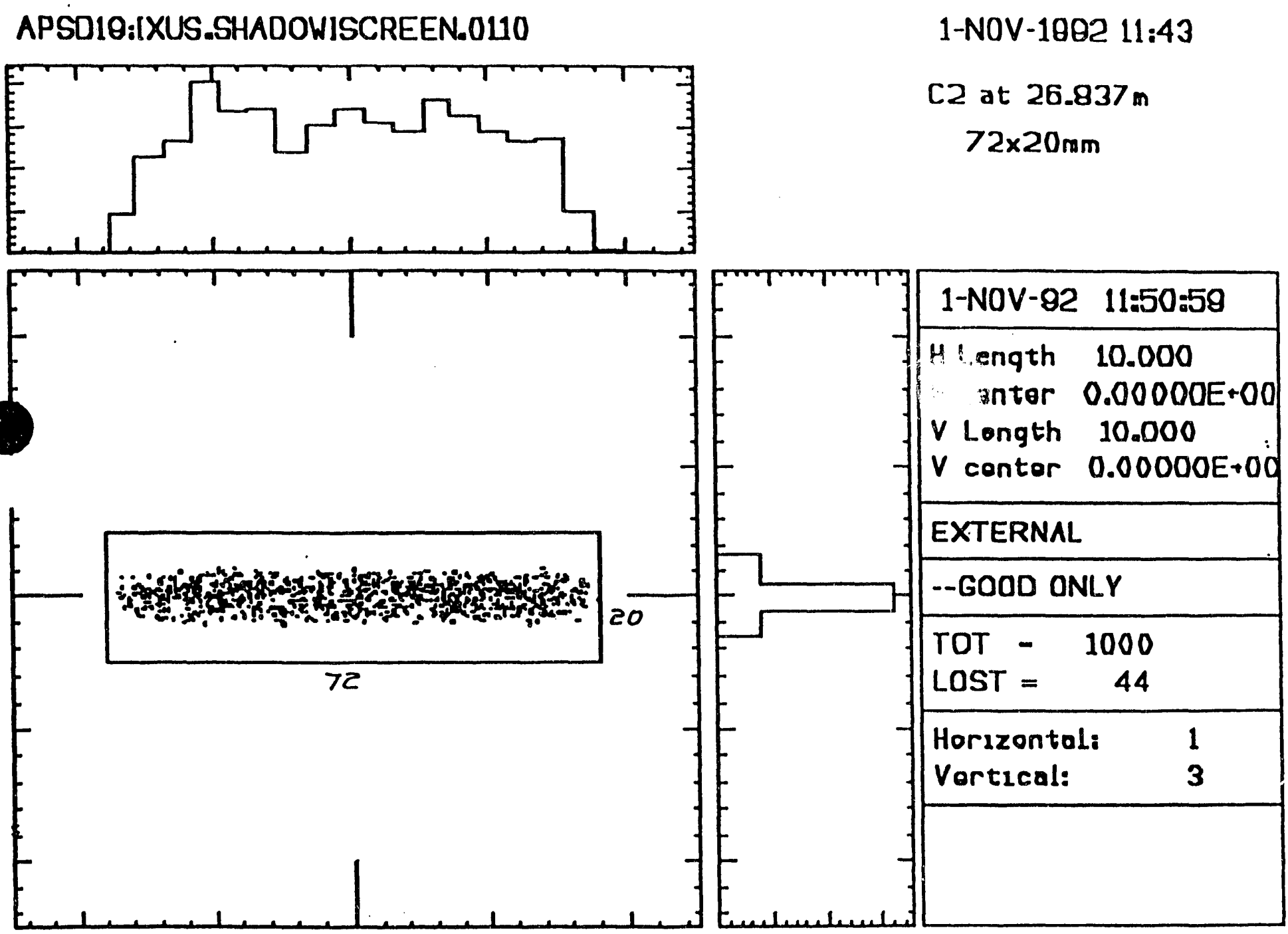

Figure 5k. SHADOW ray tracing for collimator 2 of the ID front end 
APSDI0:IXUS.SHADOWISCREEN.0110
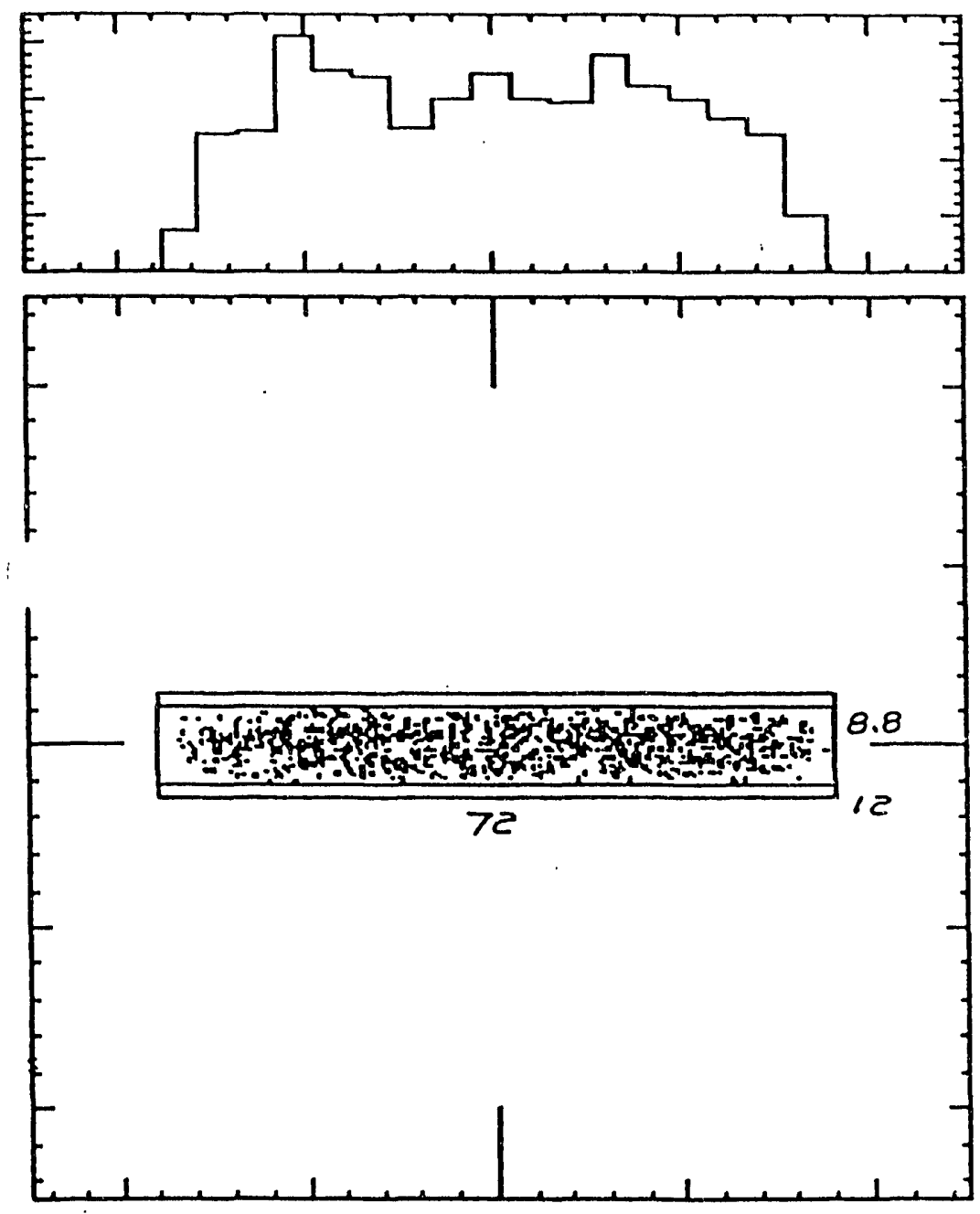

1-NOV-1902 10:01

Window at $27.369 \mathrm{~m} 72$ $\times 8.8 \mathrm{~mm} 72 \times 12 \mathrm{~mm}$

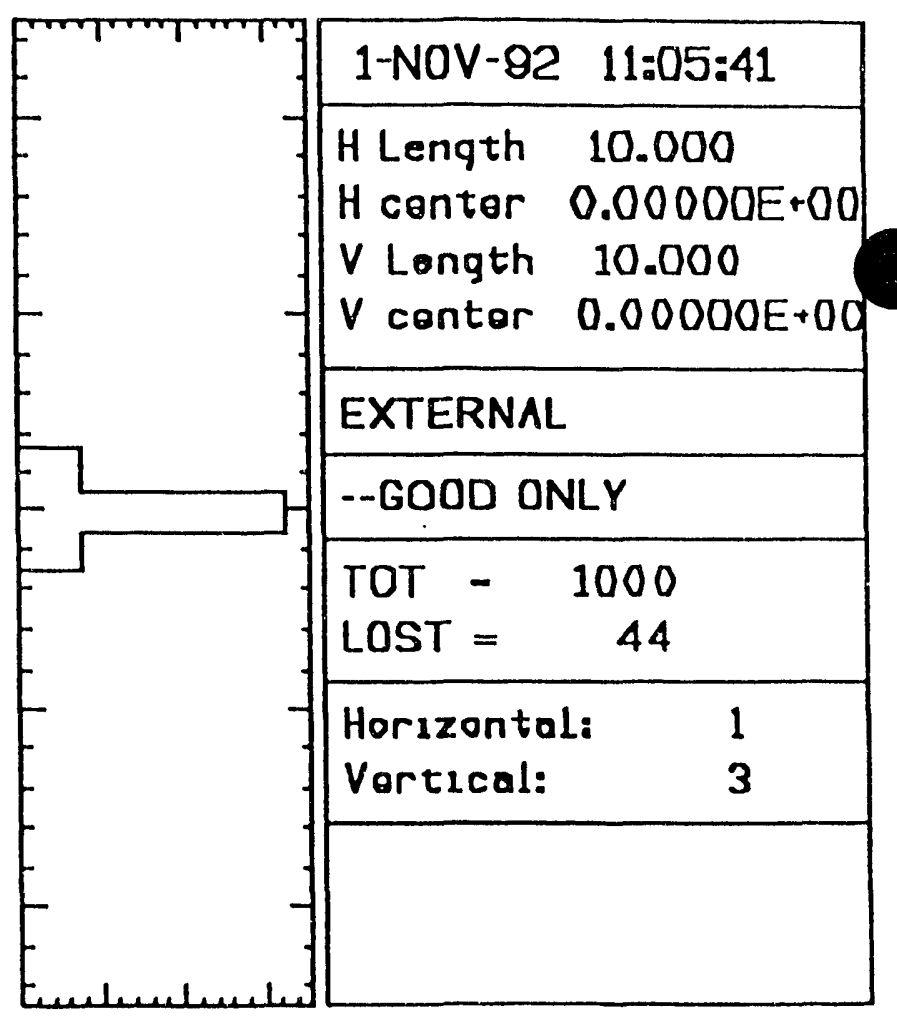

Figure 51. SHADOW ray tracing for window of the ID front end 


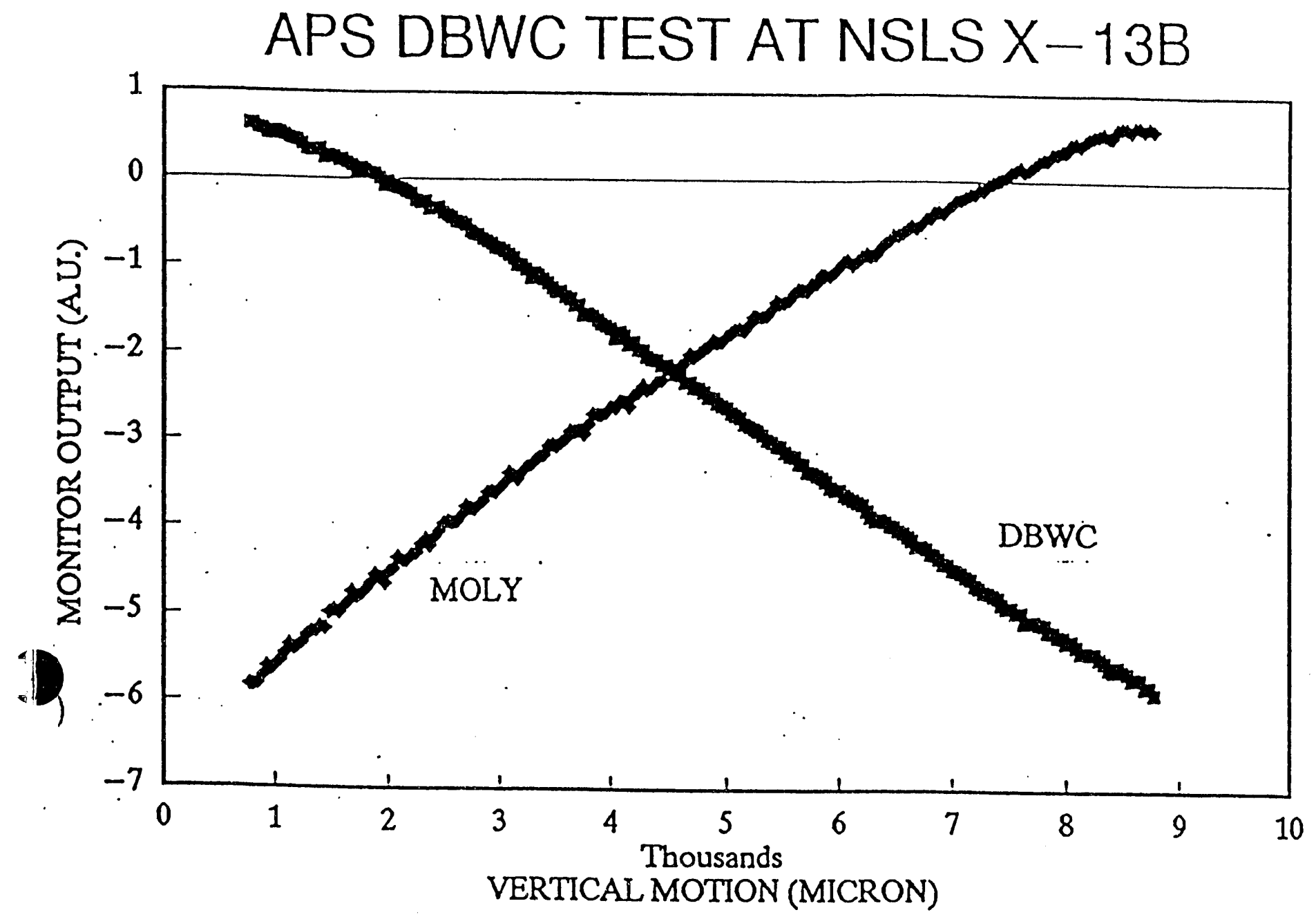

Figure 6a. Photoelectron emmission from molybdenum and the CVD diamond blade at NSLS X-13B tests 

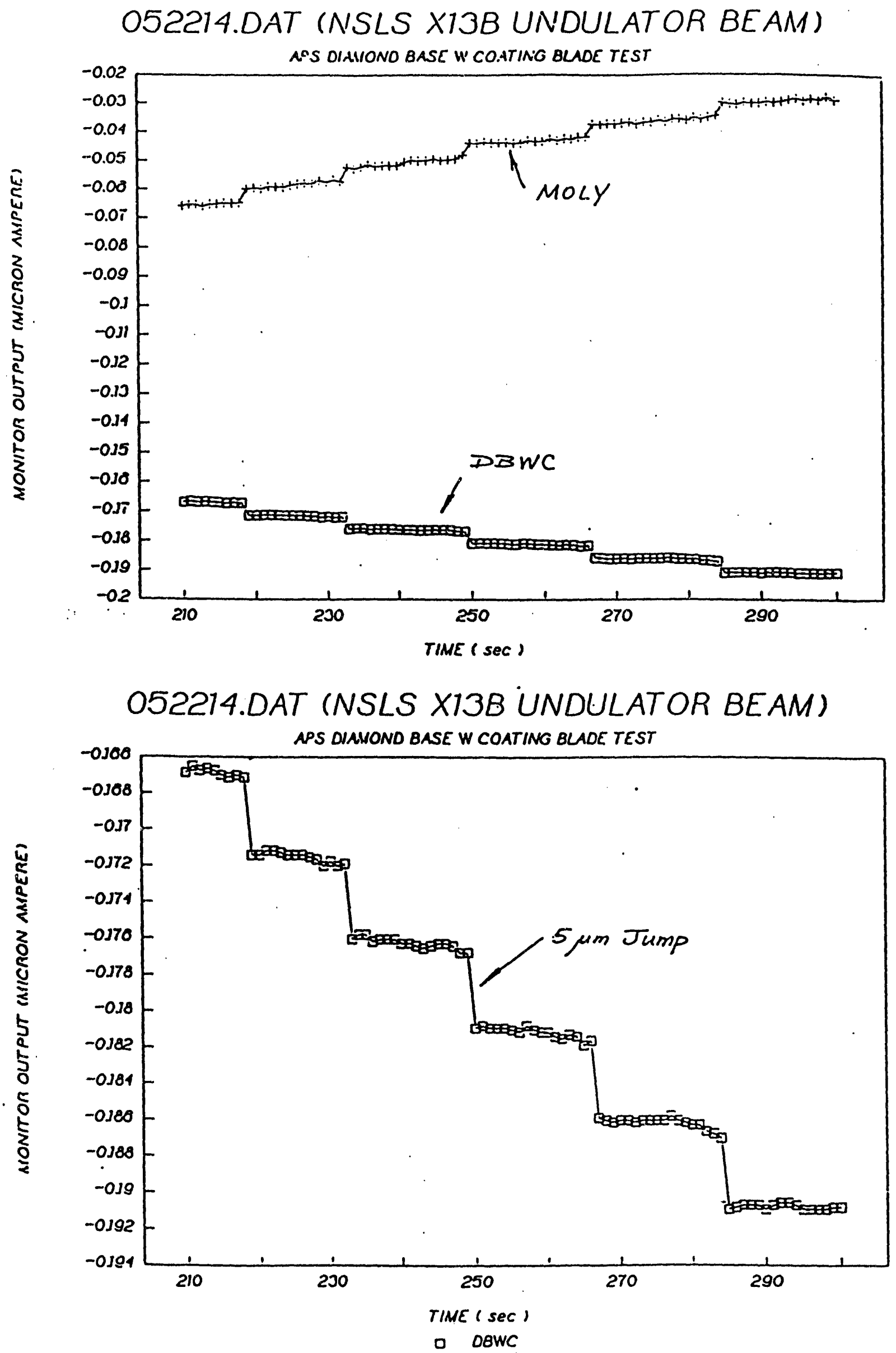

Figure 6b. 5-micron stepping tests for molybdenum and the CVD diamond biade at NSLS $X-13 B$ tests 


\section{APS DBWC TEST AT CHESS}

5 MICRON JUMPS

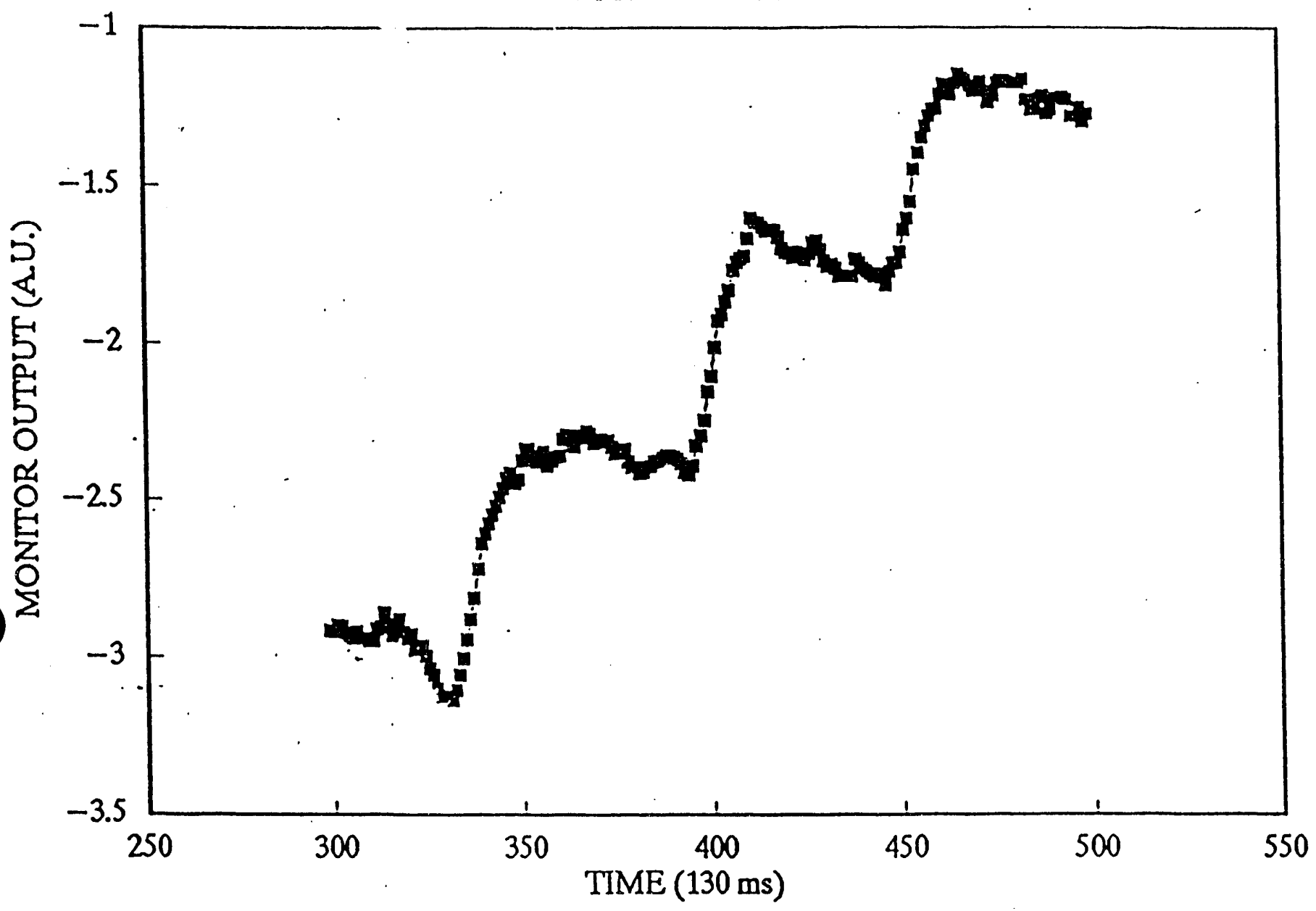

Figure 6c. CVD diamond blade 5 micron stepping tests at CHESS 


\section{ADVANCED PHOTON SOURCE}

APS/XFD Photon Transmitting Beam Position Monitor (PTBPM) Test AT NSLS X-25 NSLS92/051022B.DAT

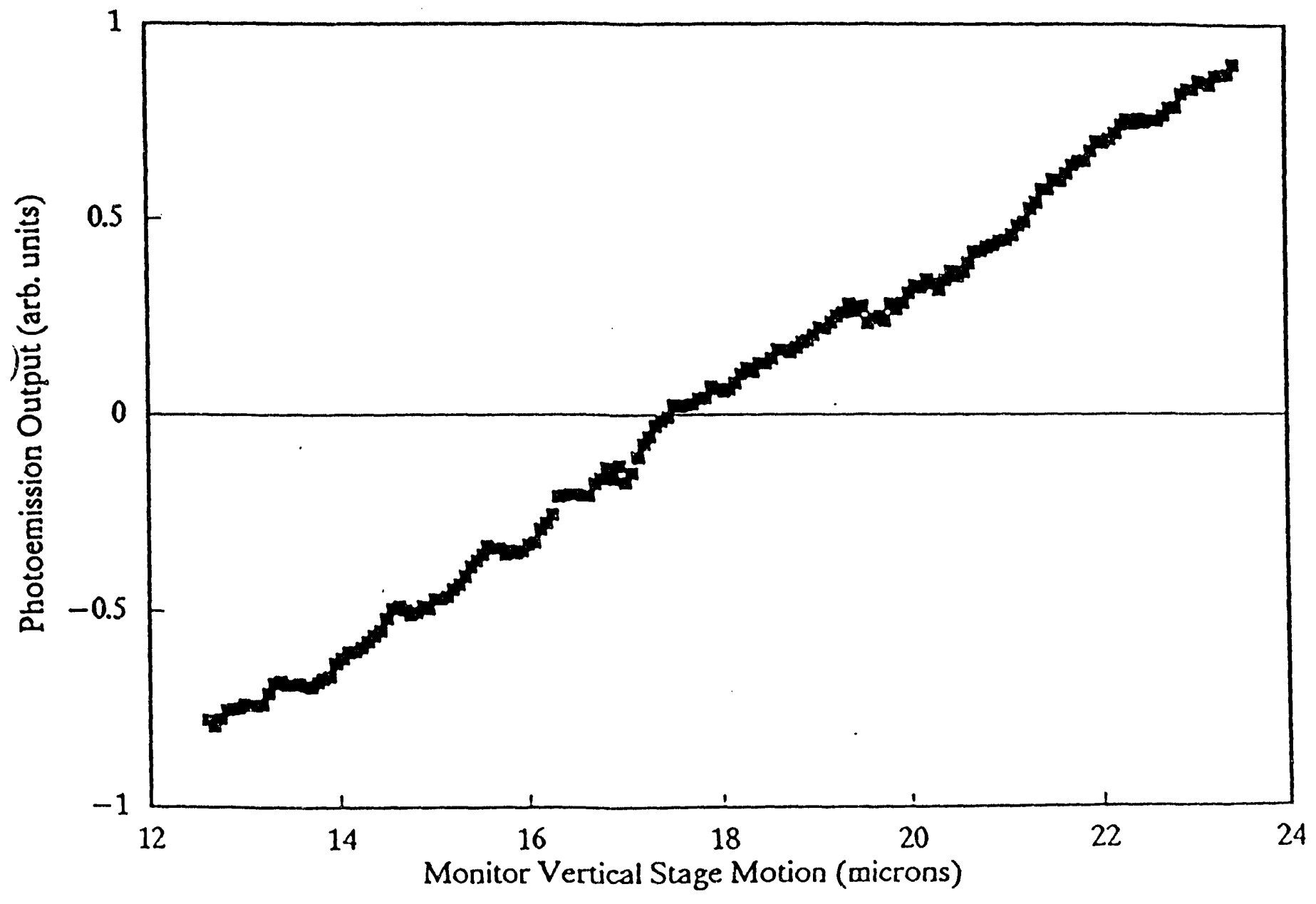

Figure 6d.Photoemmission output of the CVD diamond blade at NSLS X-25 tests during steady beam 
D ADVANCED PHOTON SOURCE

APS/XFD Photon Transmitting Beam Position Monitor (PTBPM) Test AT NSLS X-25 NSLS92/051022A.DAT

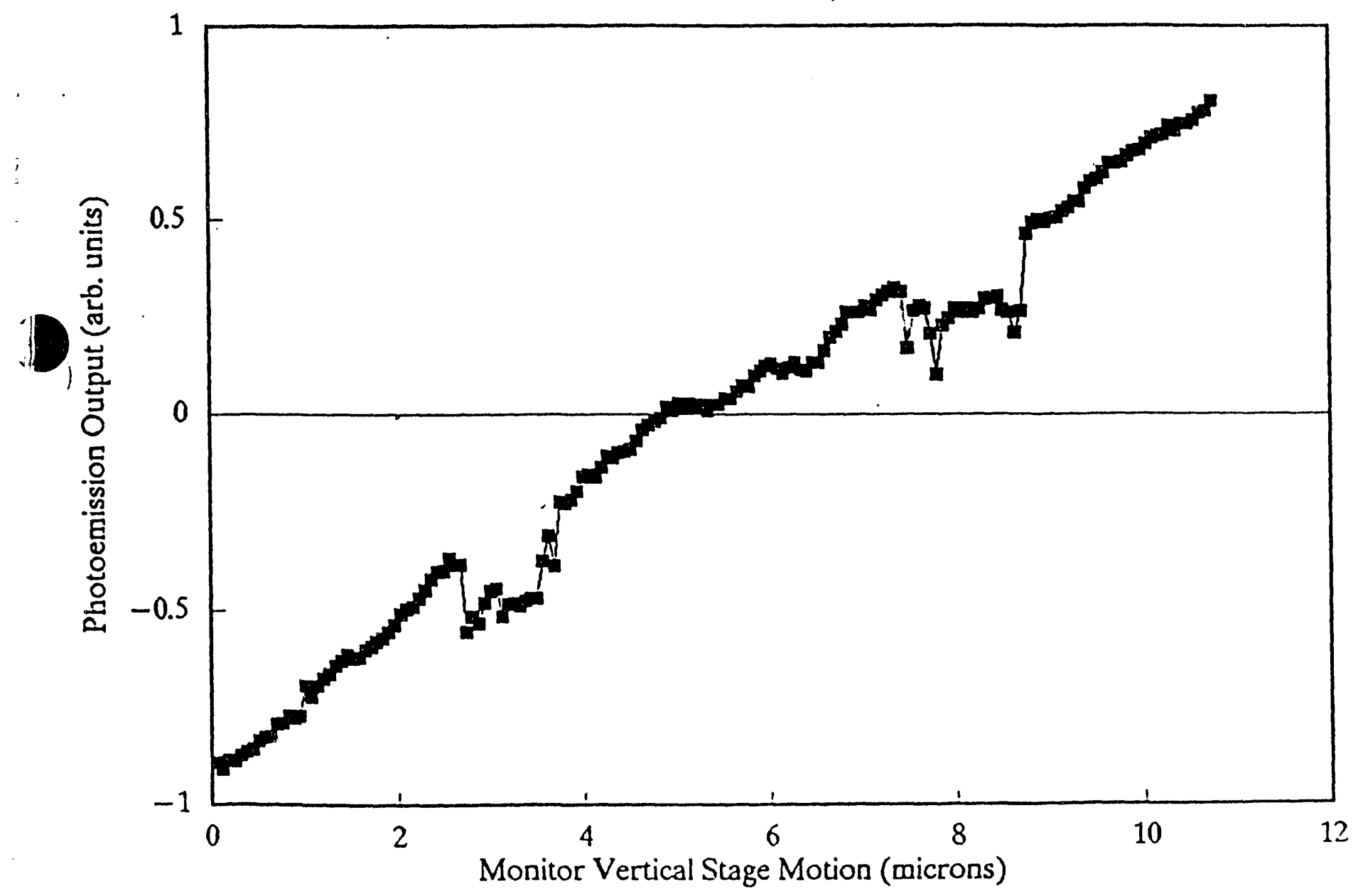

Figure 6e. Photoemmission output of the CVD diamond blade at NSLS X-25 tests during unsteady beam 


\section{ADVANCED PHOTON SOURCE}

Conceptual Design of the APS Photon Beam Position Monitor
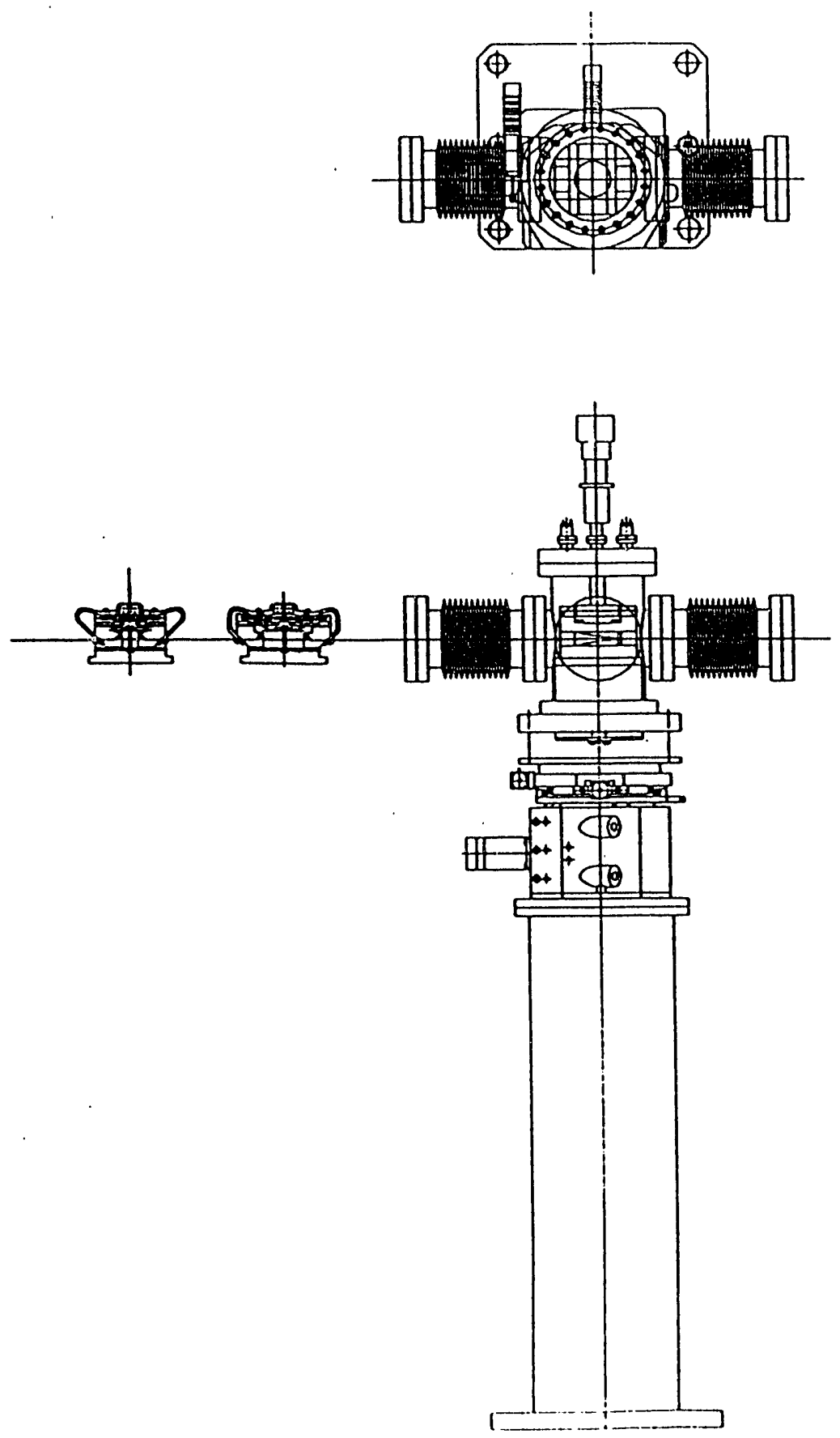

Figure 7. Design of the APS Photon Beam Position Monitor 


\section{ADVANCED PHOTON SOURCE}

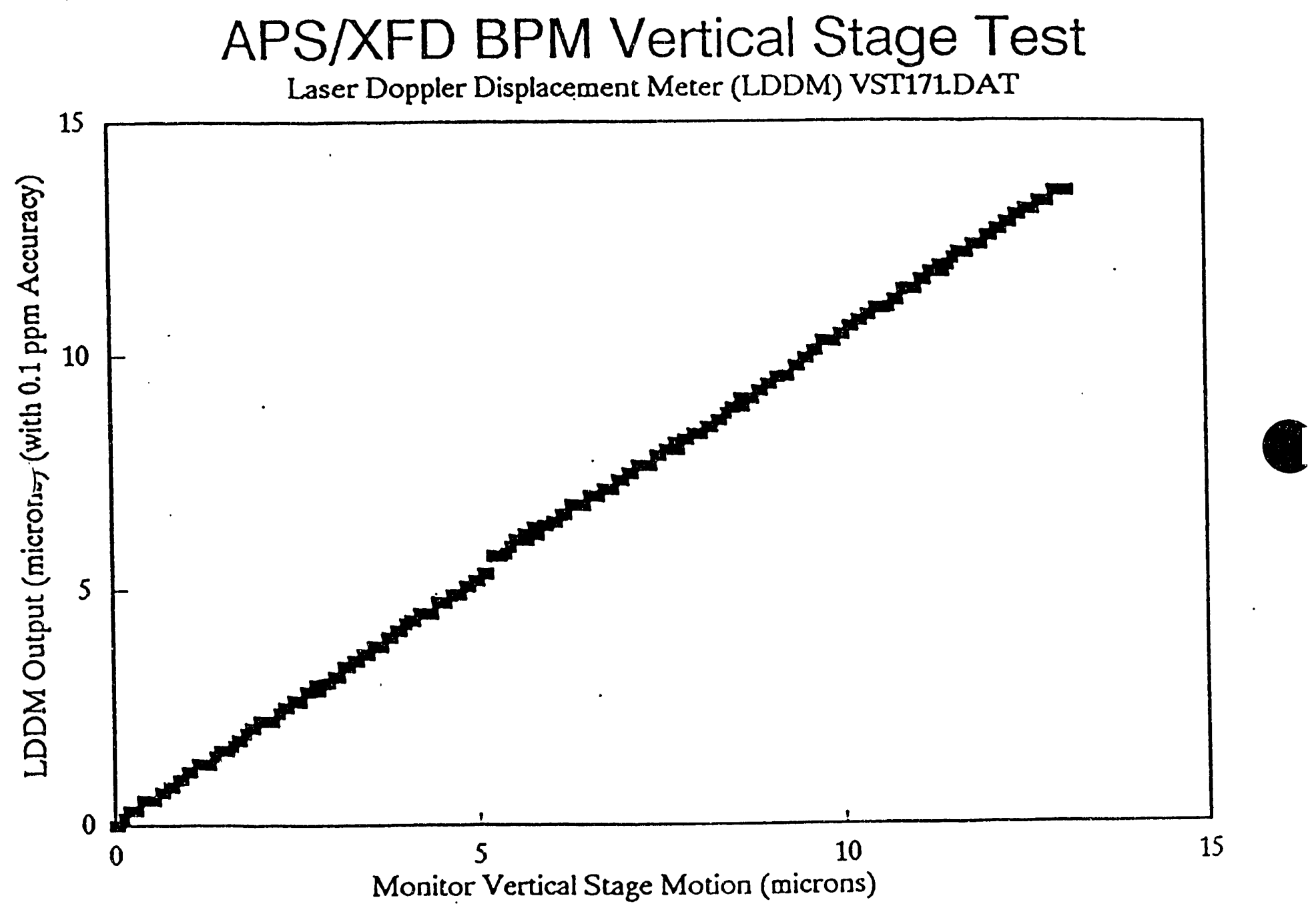

Figure 9. The PBPM vertical stage stepping tests under a 200-lb load 


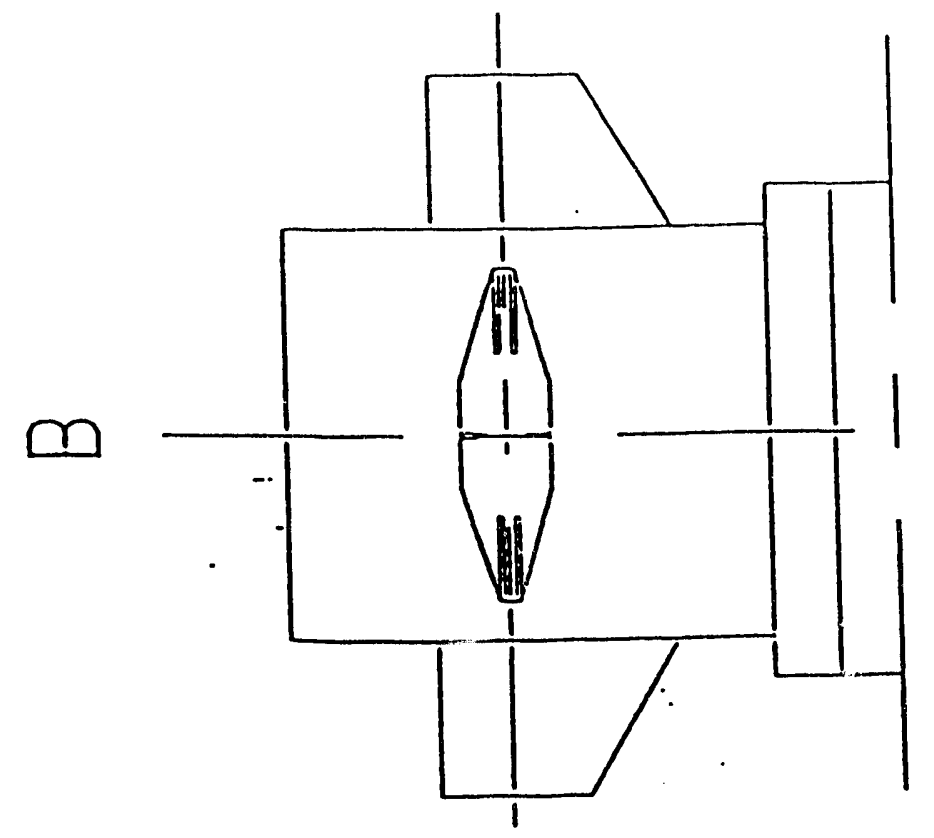

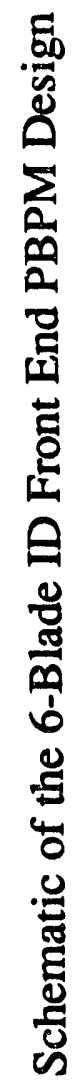

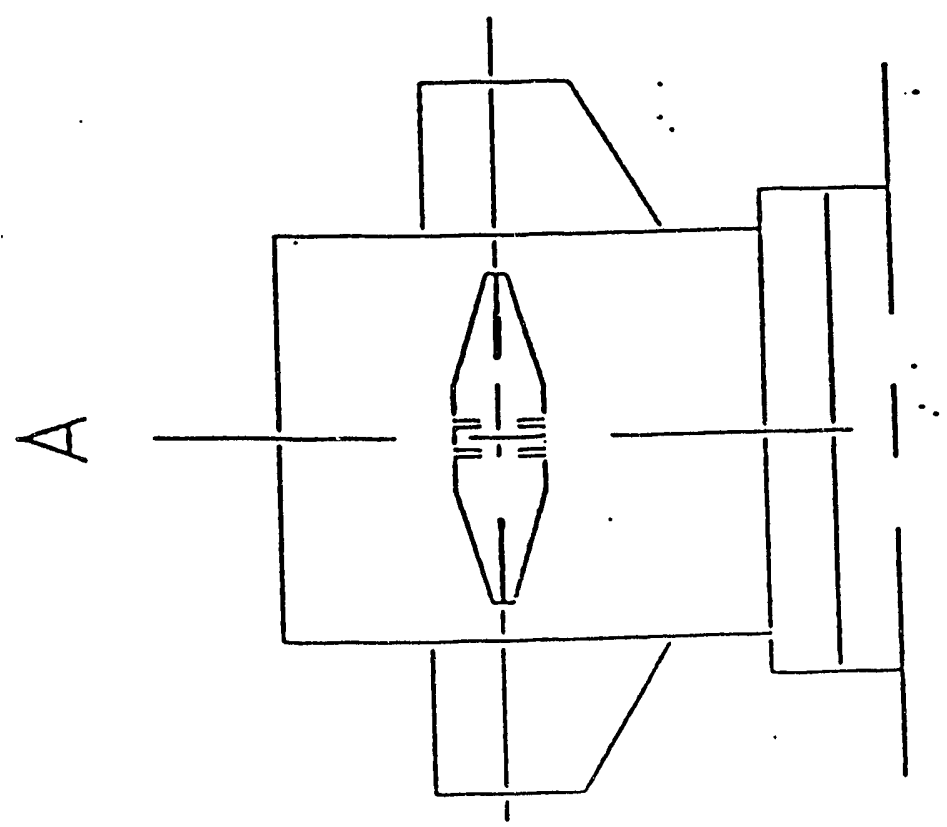

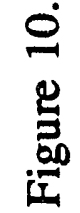



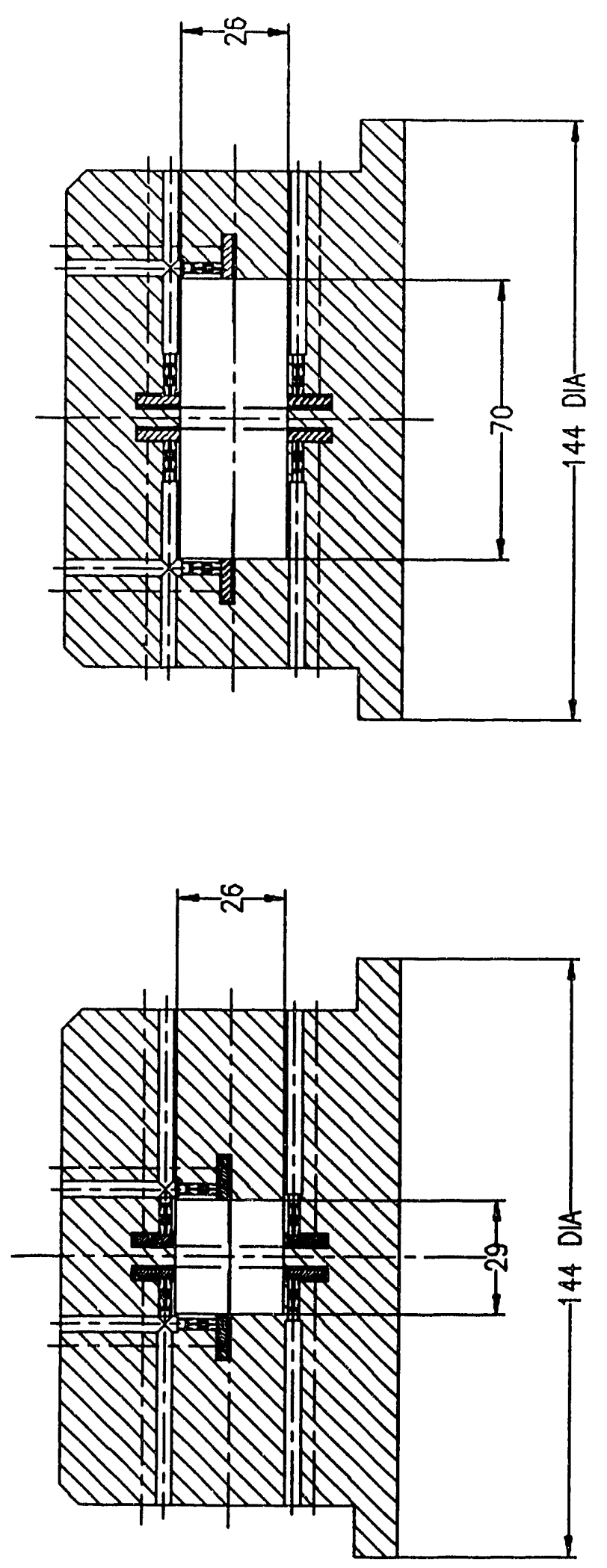

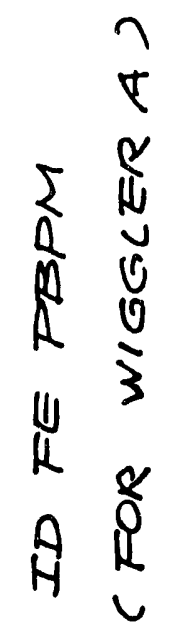



茕

$\sum \frac{2}{0}$

要

은

동

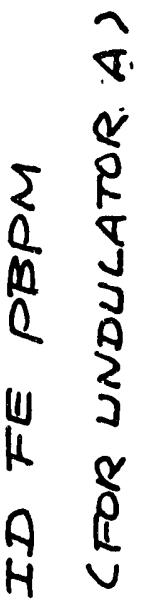

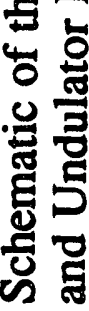

$\stackrel{\Xi}{\beth}$ 


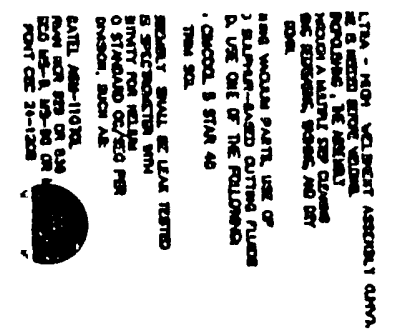
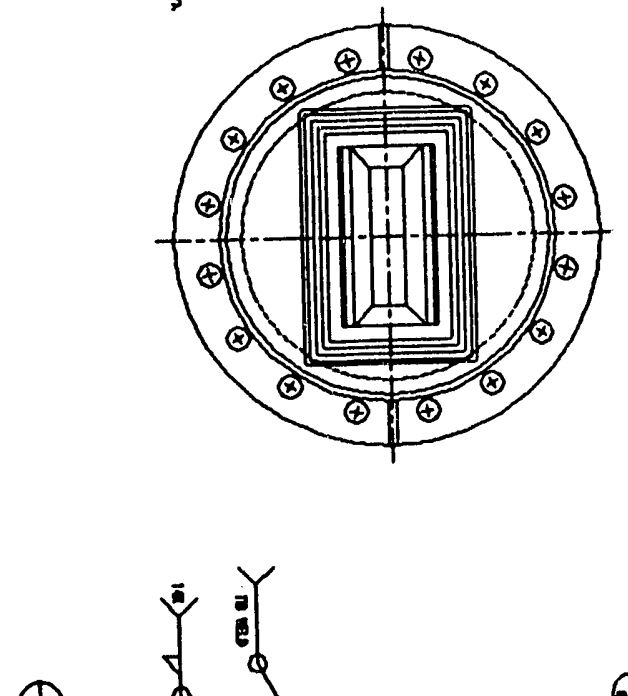

(1)
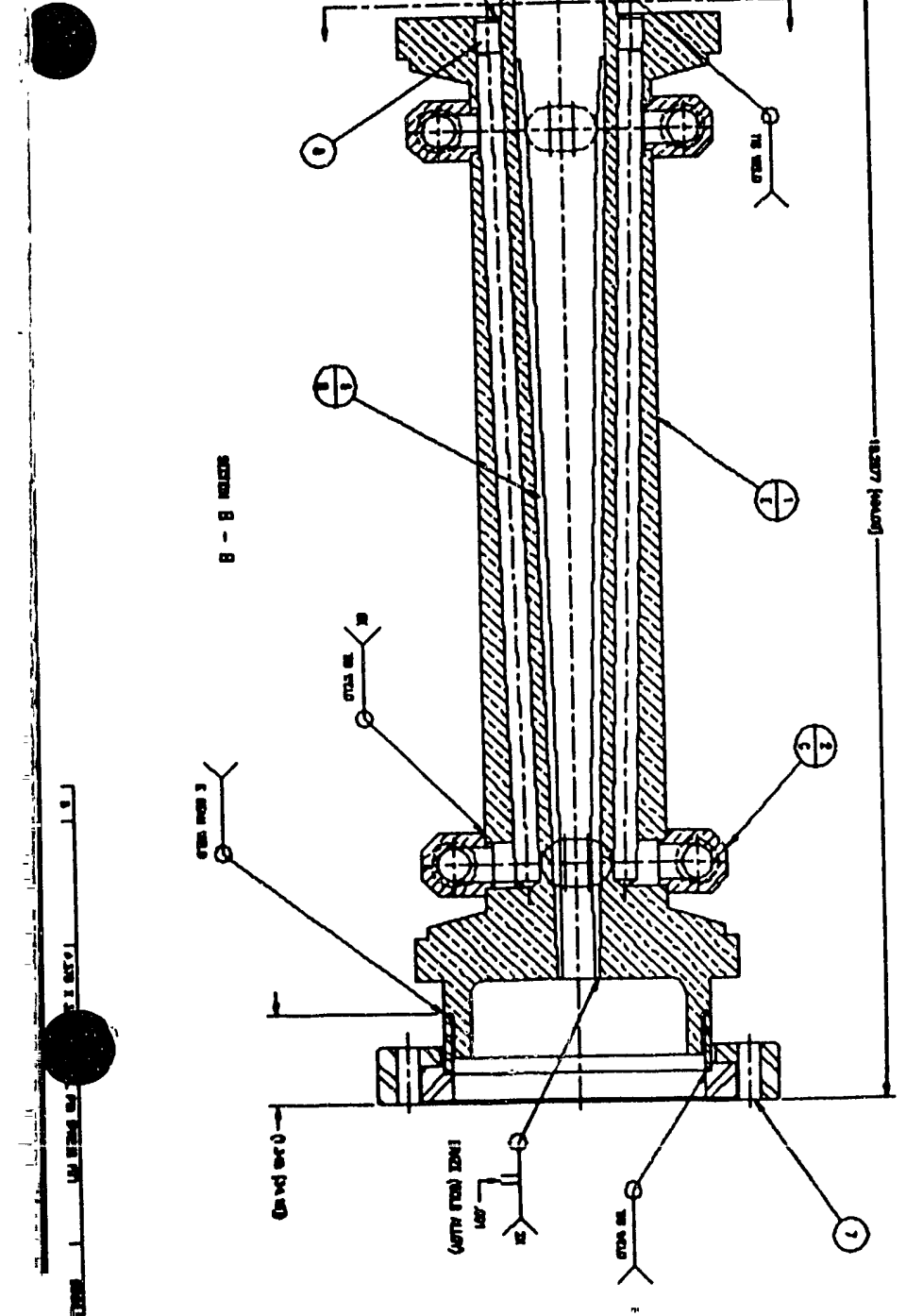

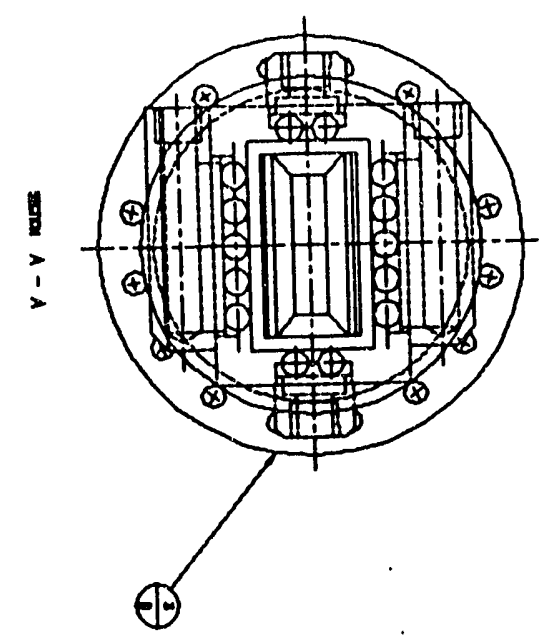

司
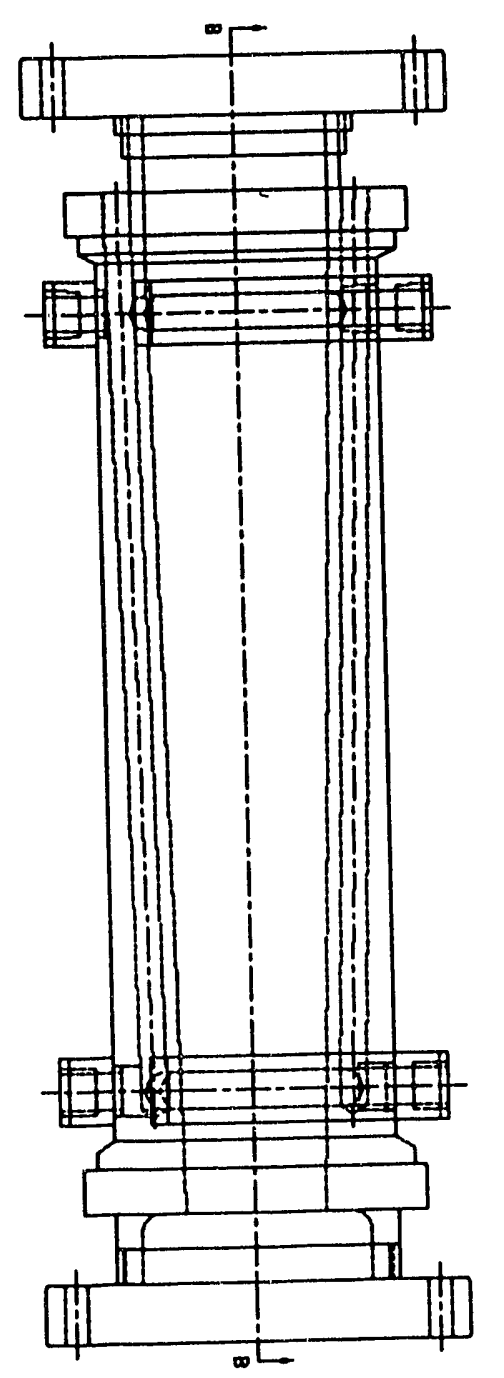

N 


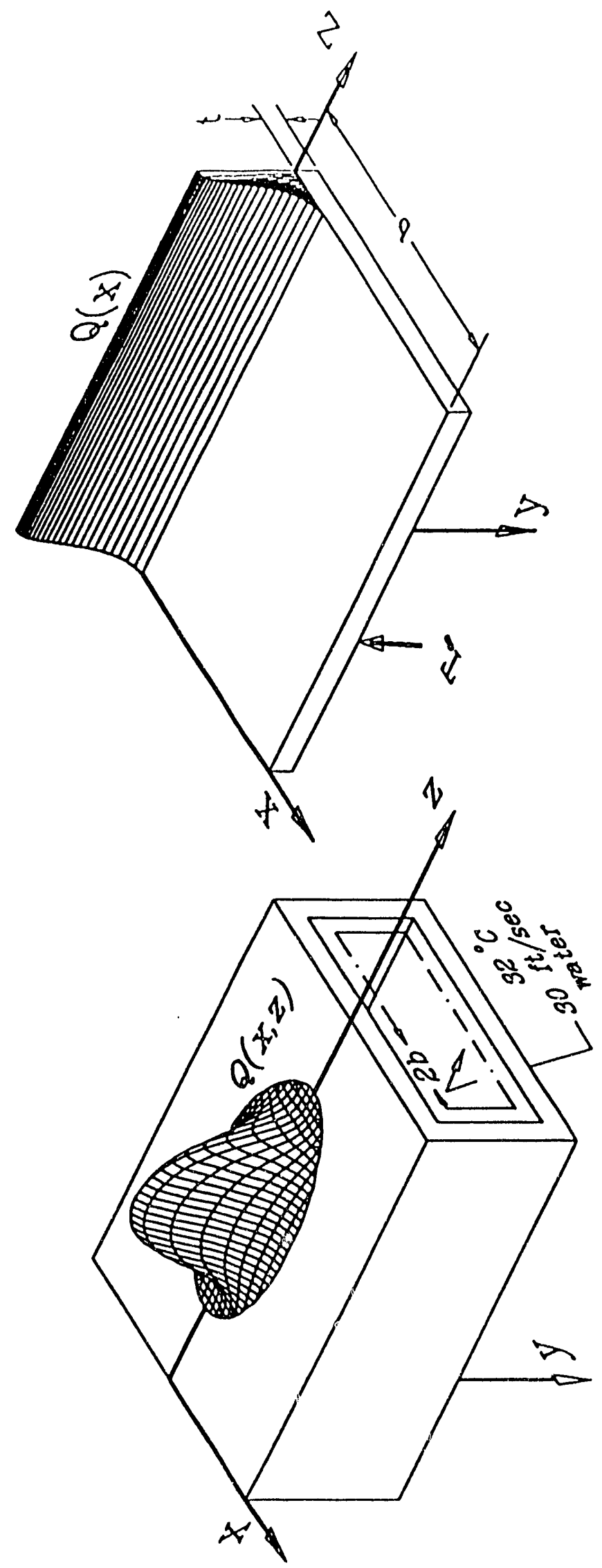

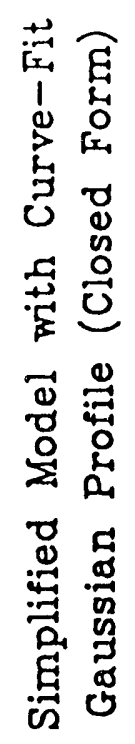

$\Xi$
0
0
0
0
0

E

远

응

远

疍

น

Z

\&

은

용

E

은

过

Ф

离

要要

离兽

志

窇 

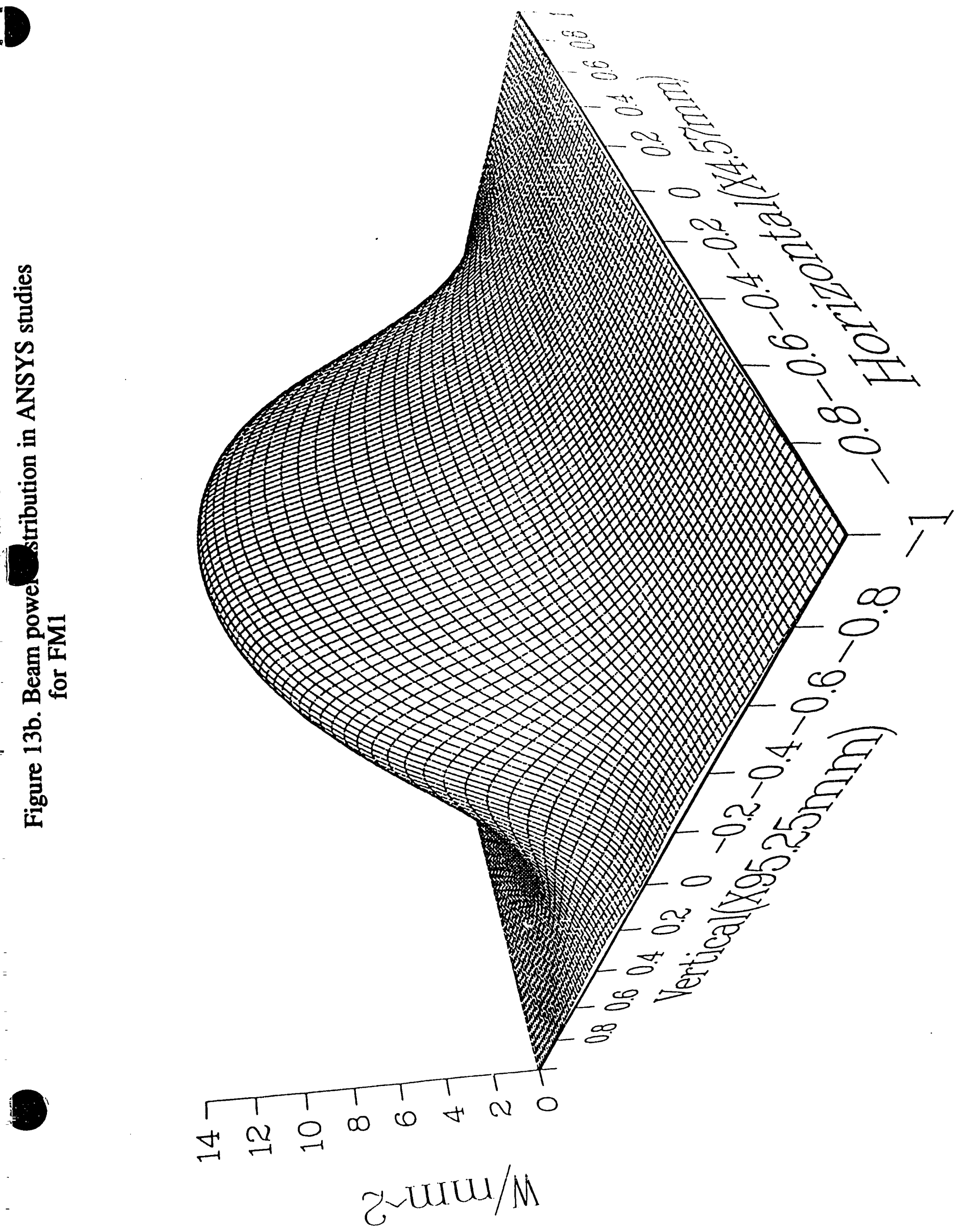


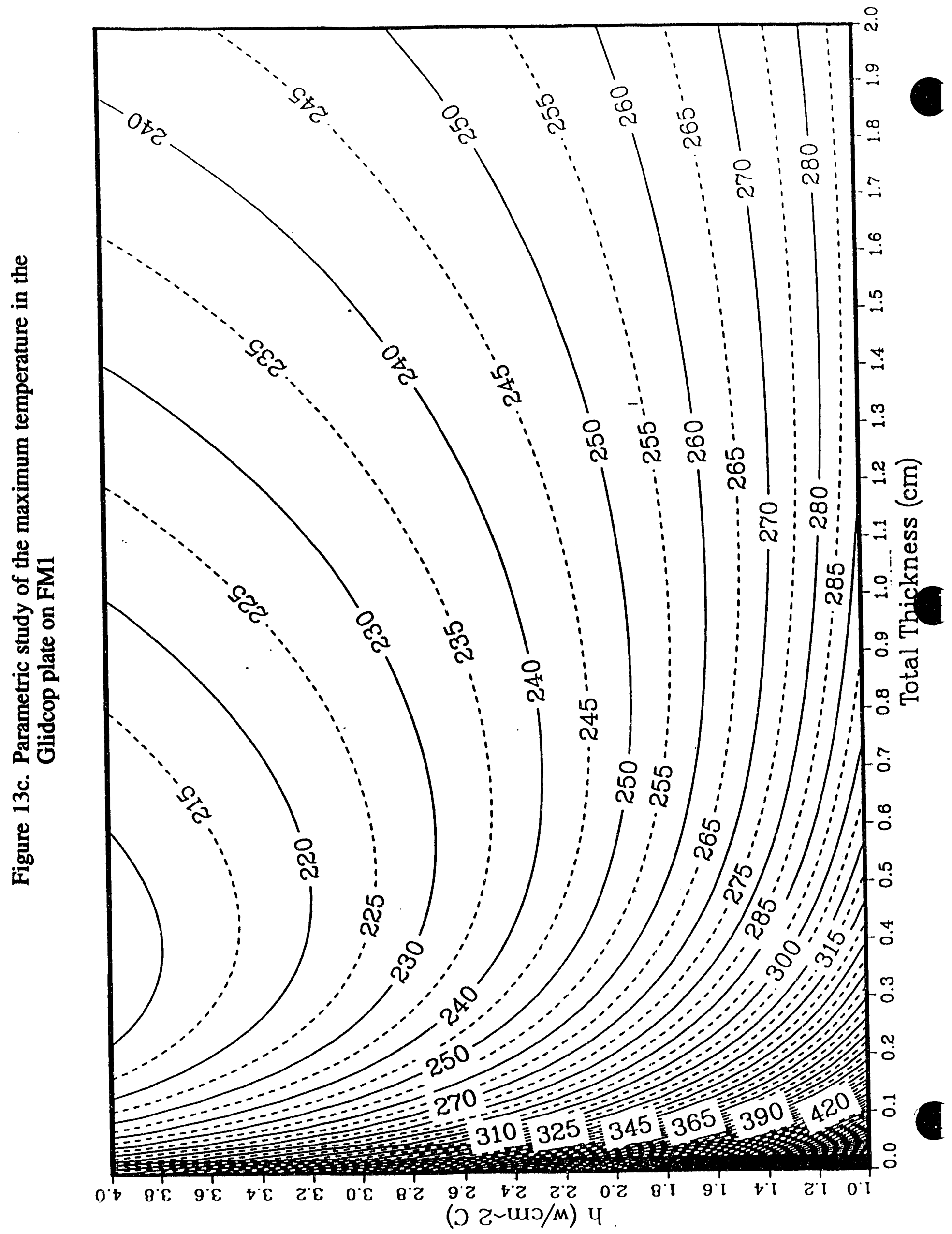




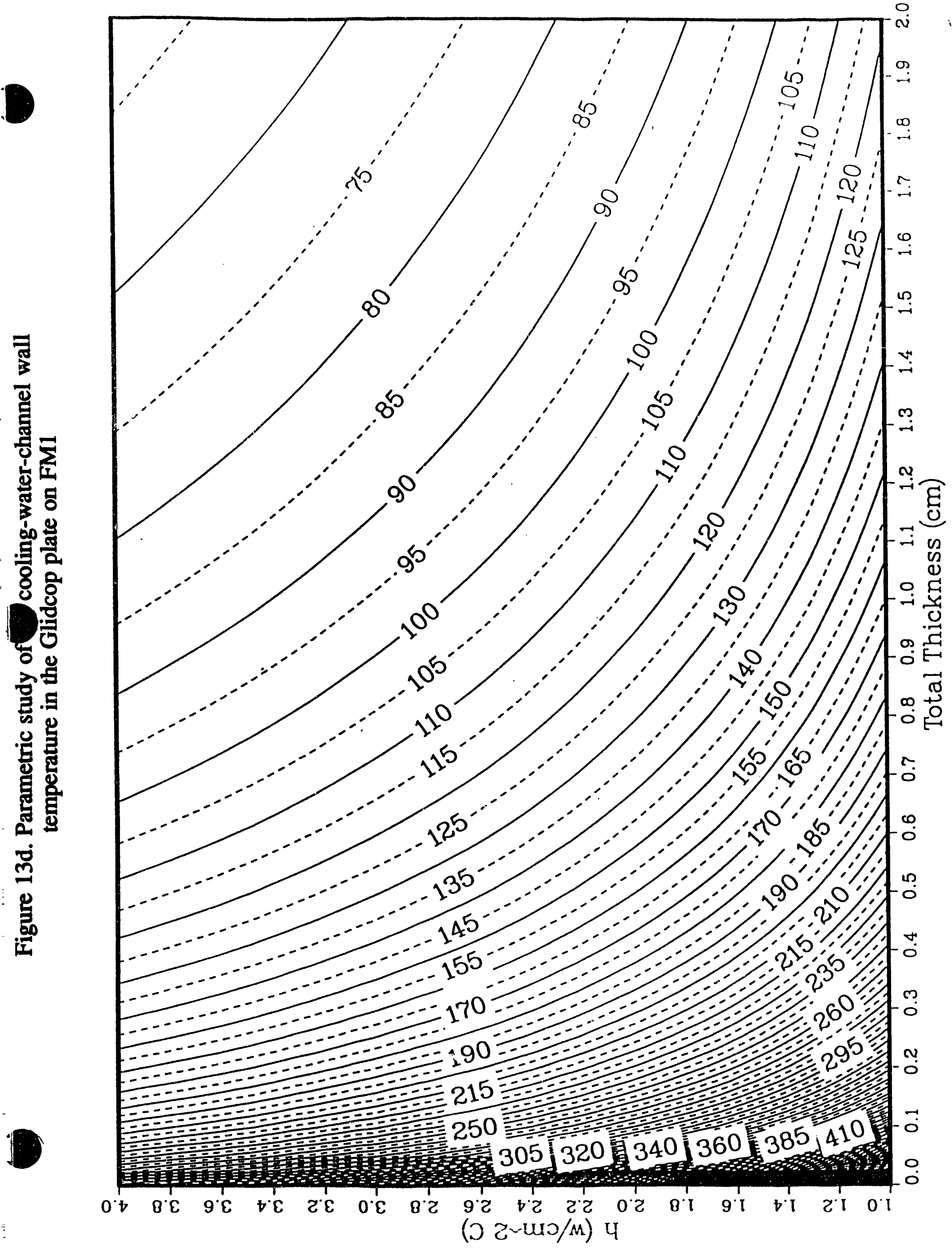




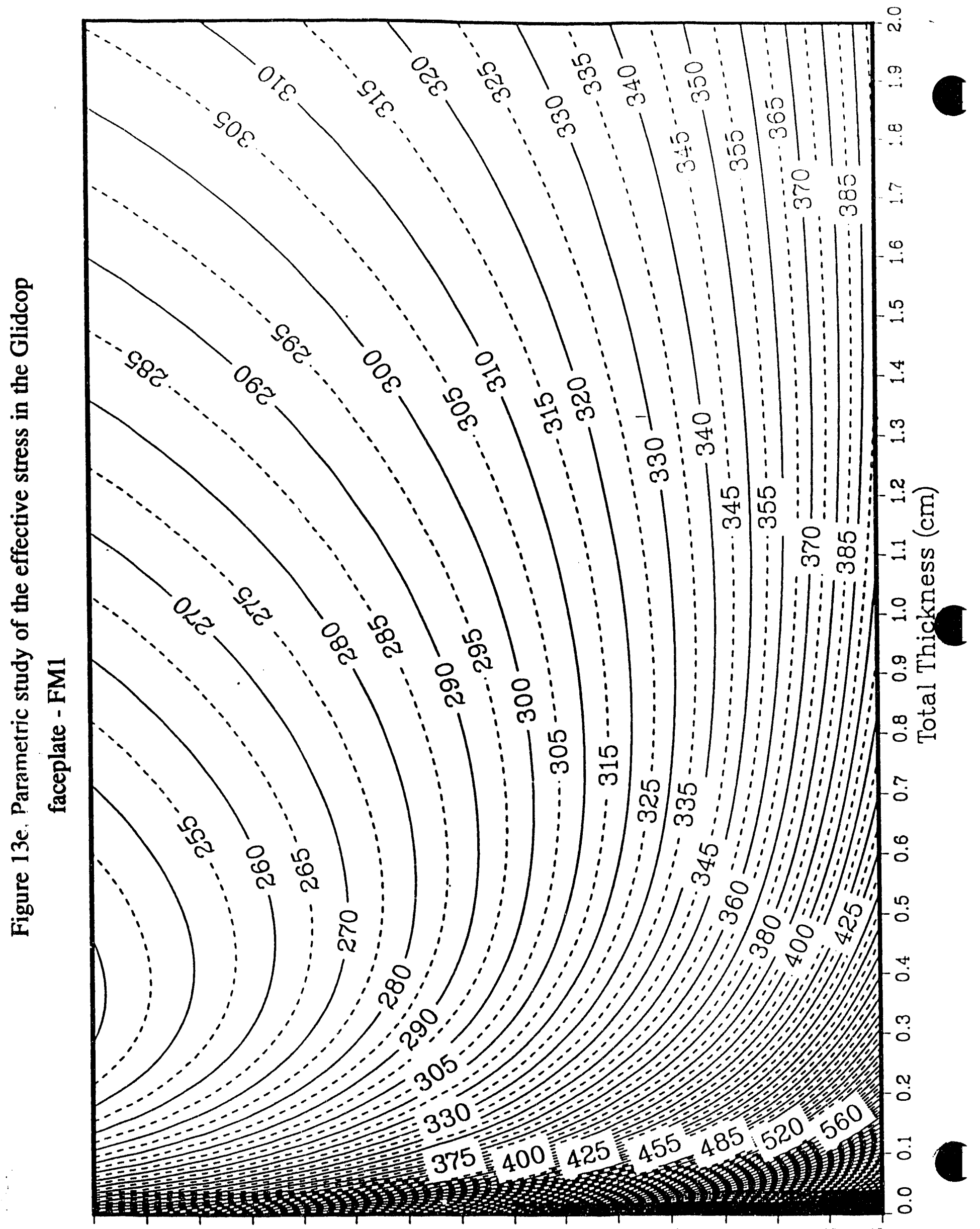

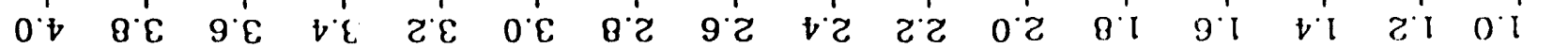
(a) z-us/M) 4 


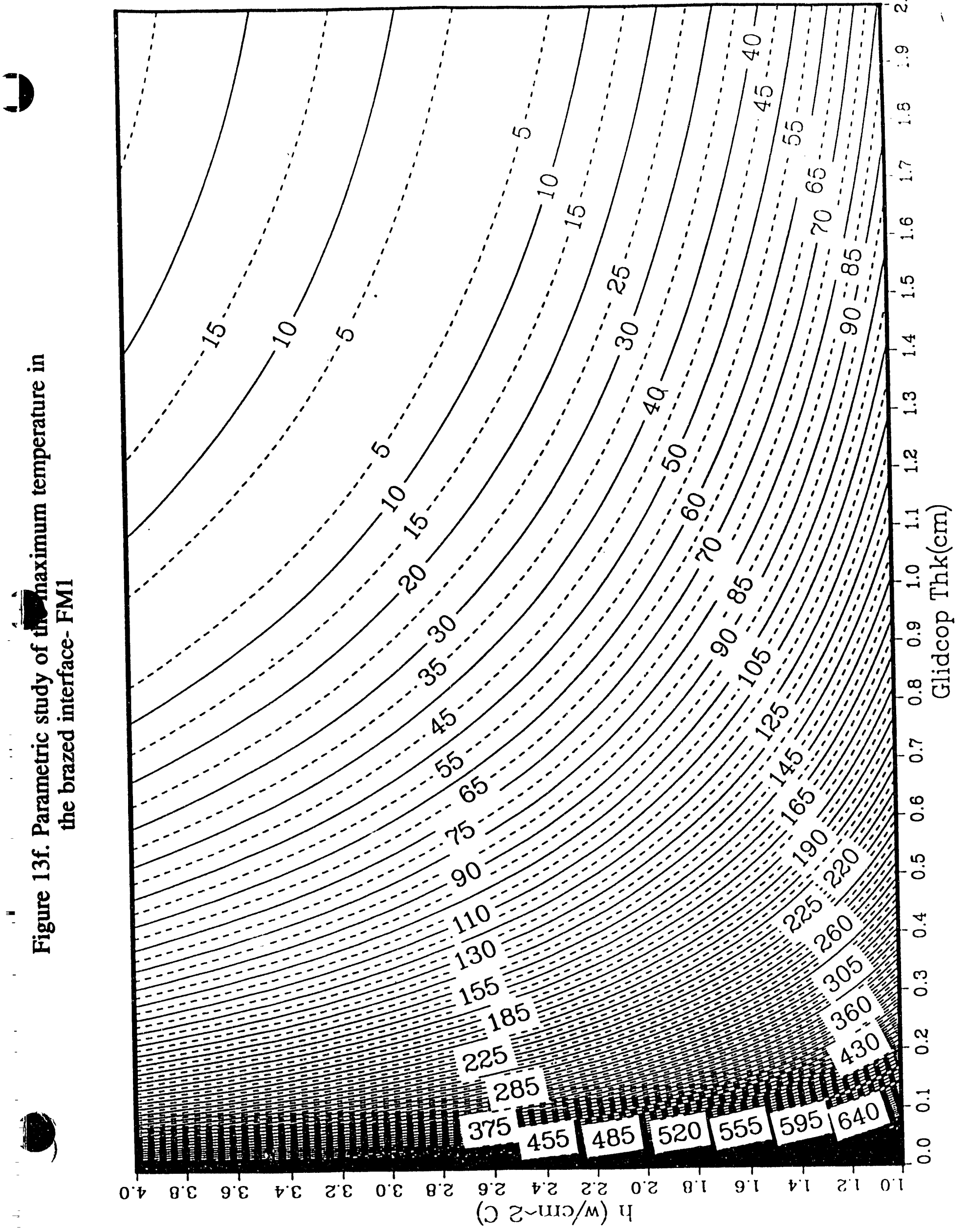




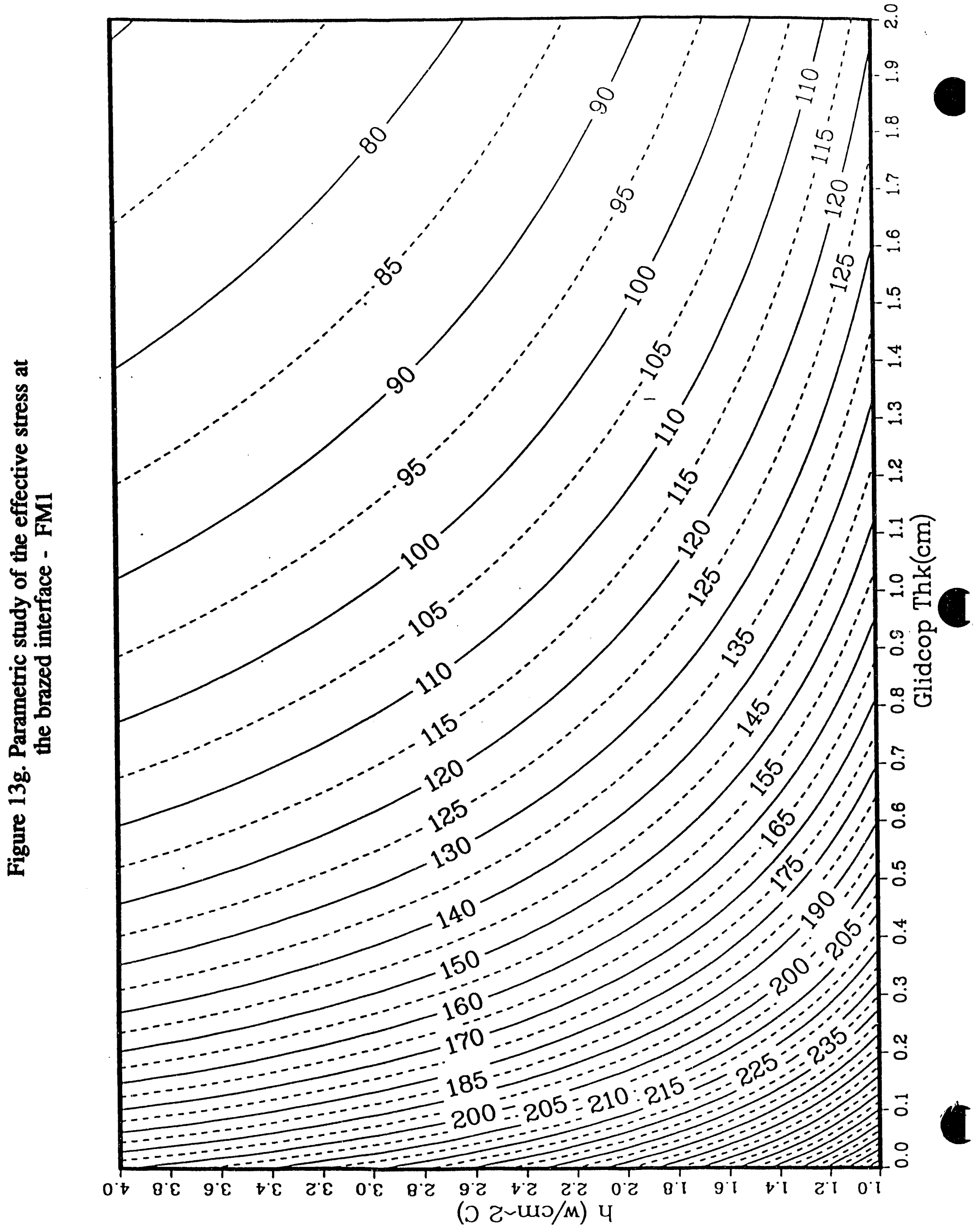


Figure 14. ID front end PS1 design

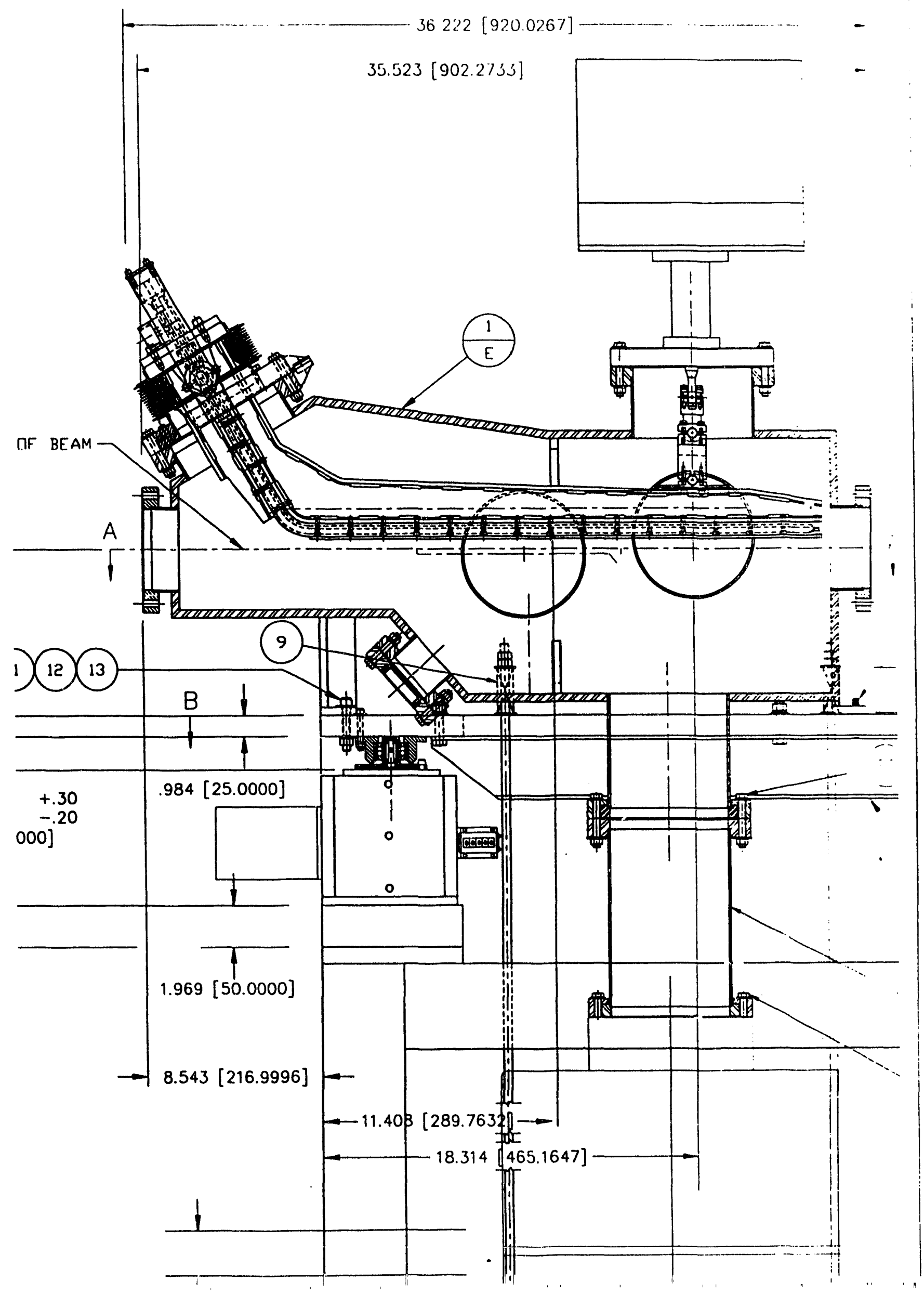



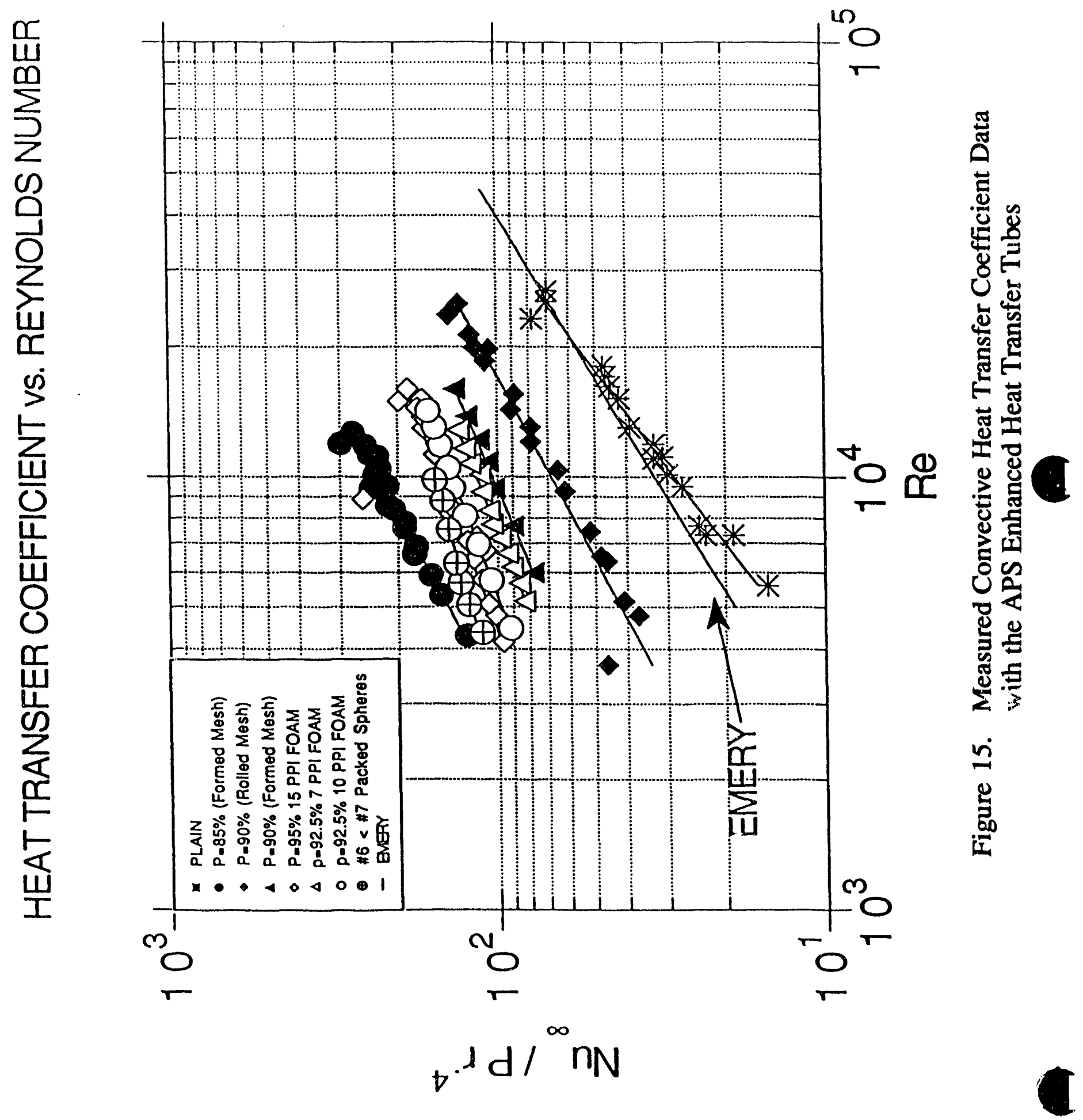


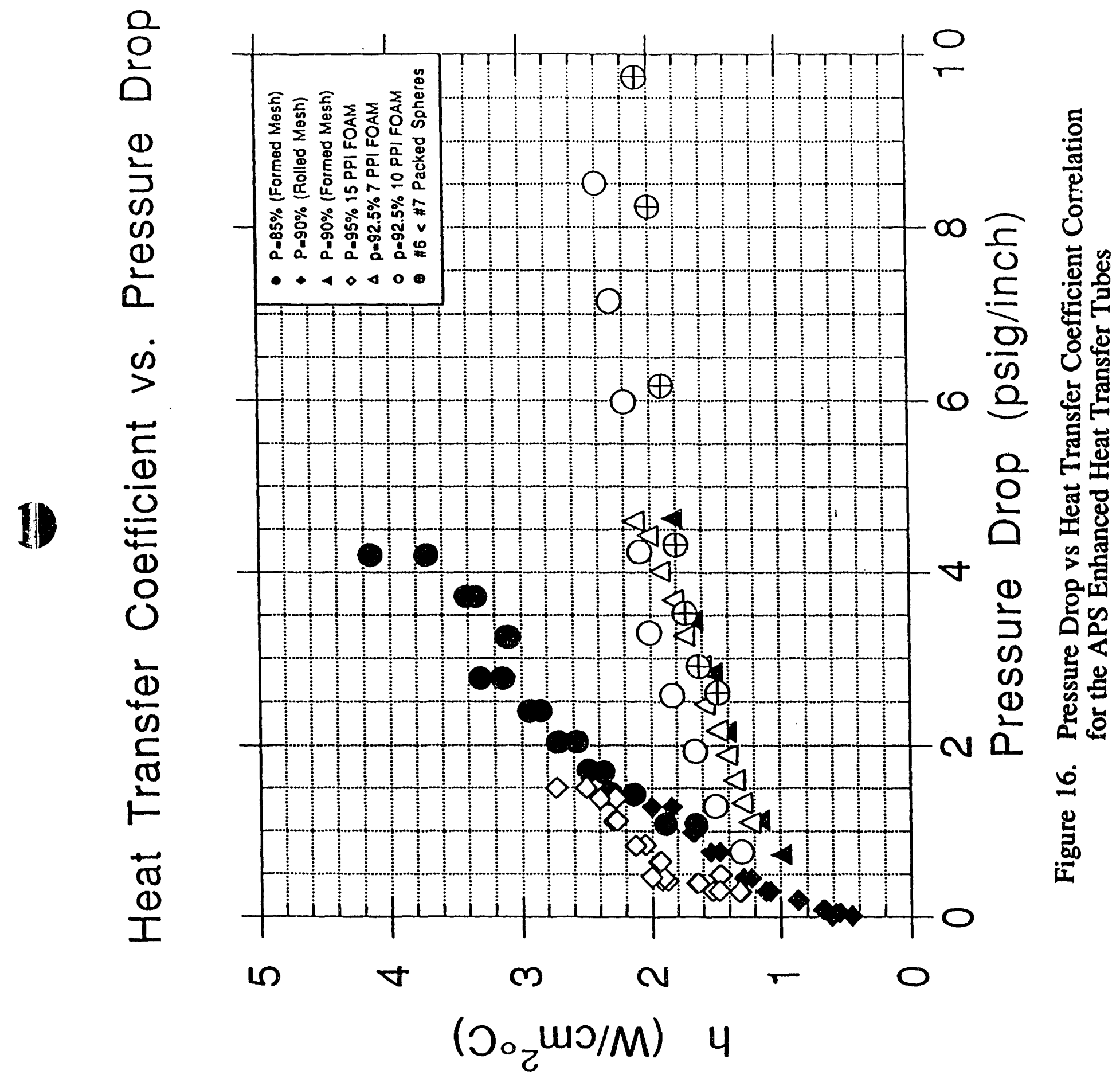




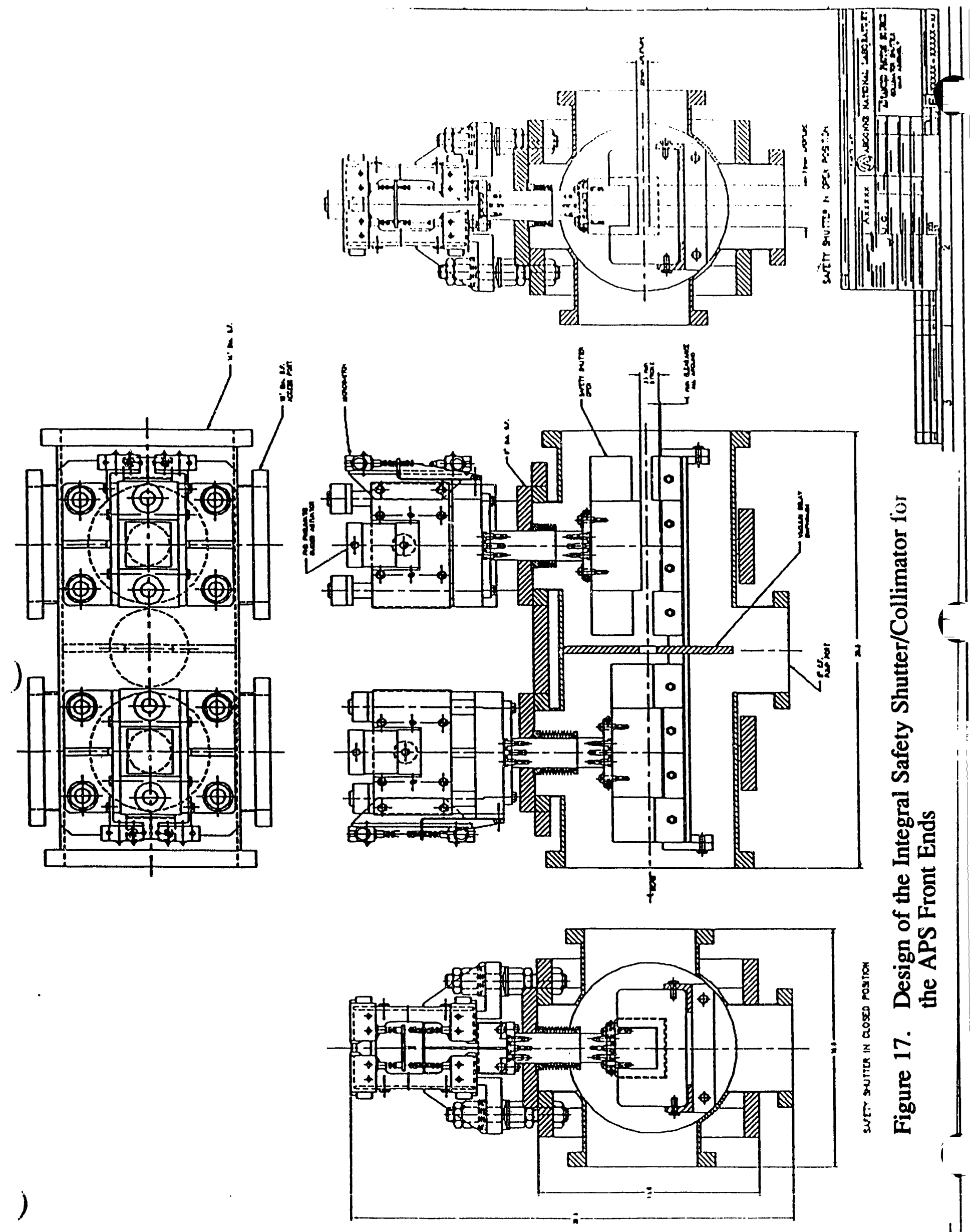




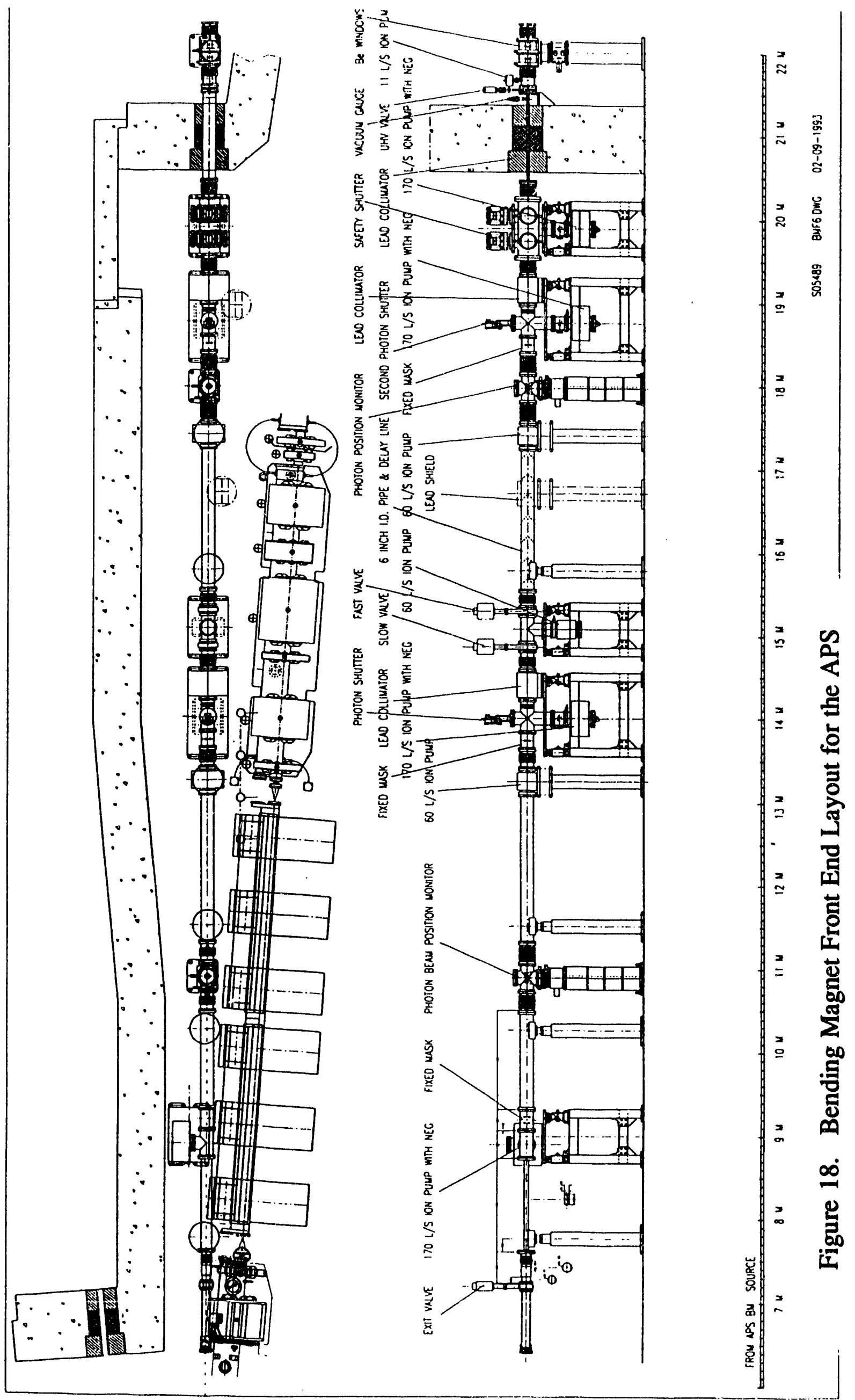




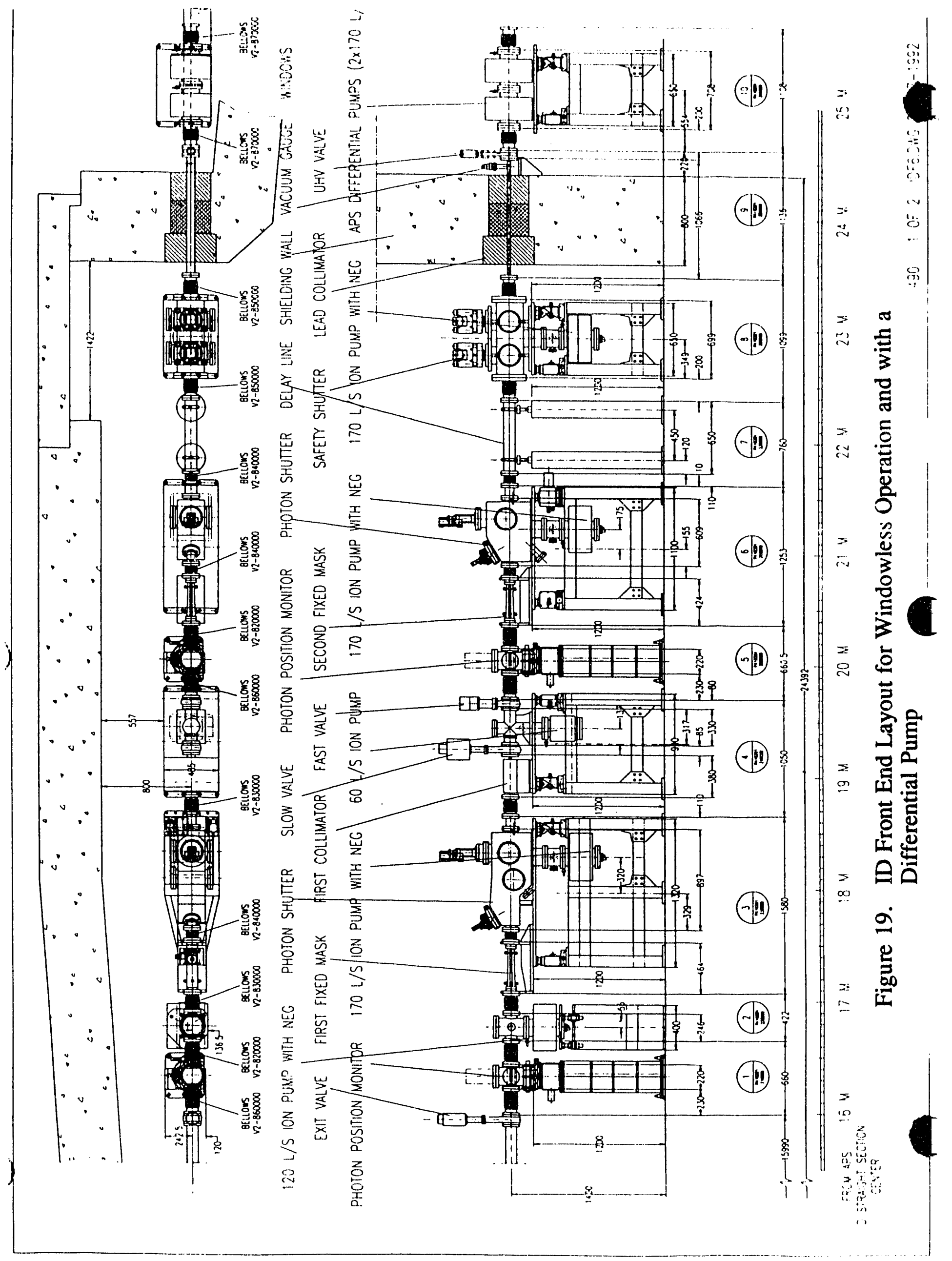



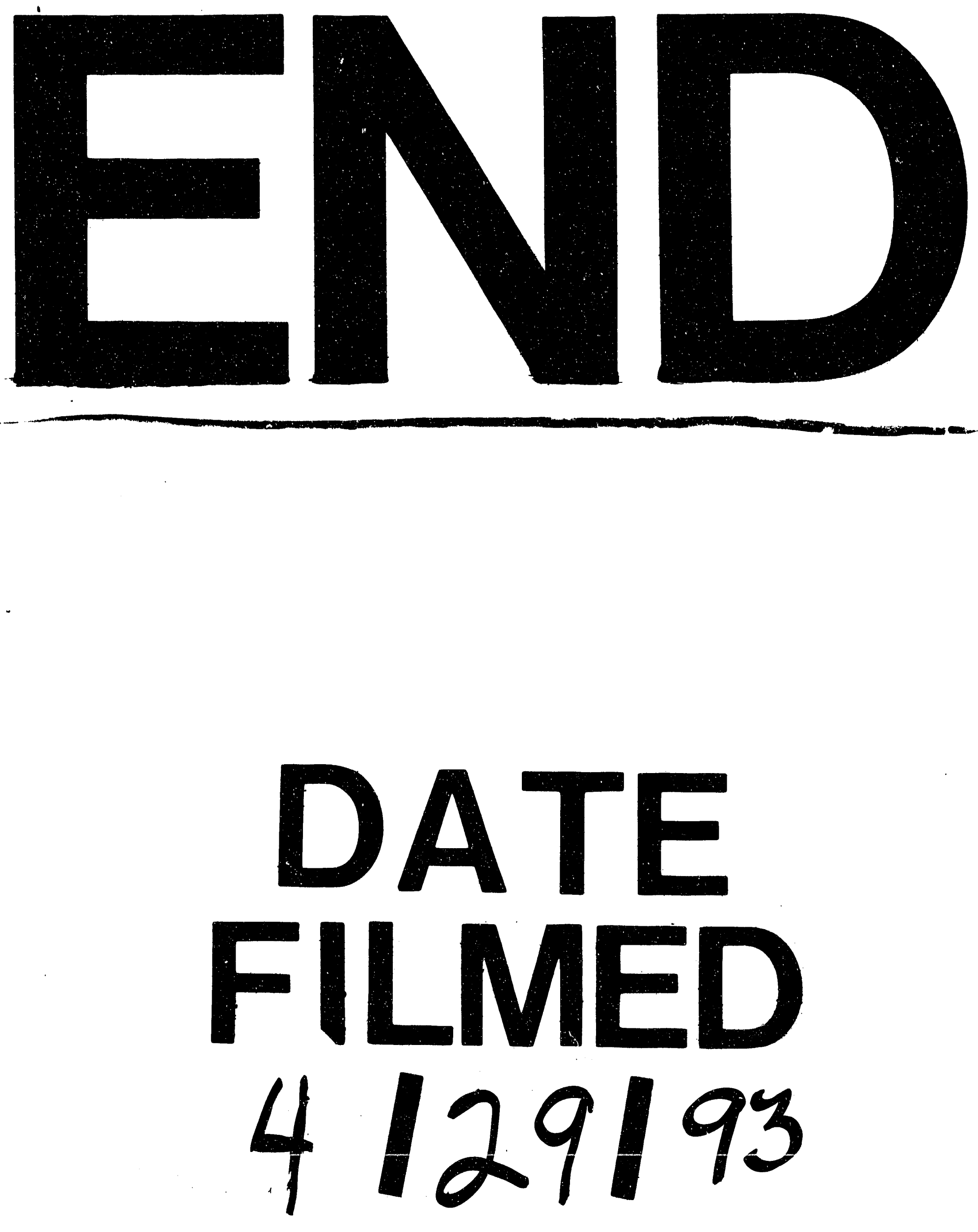


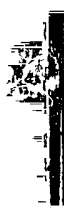

